Portland State University

PDXScholar

Summer 1-1-2012

\title{
Understanding the Experience of Air Force Single Parents: A Phenomenological Study
}

Samantha Everhart Blanchard

Portland State University

Follow this and additional works at: https://pdxscholar.library.pdx.edu/open_access_etds

Part of the Family, Life Course, and Society Commons, Military and Veterans Studies Commons, and the Work, Economy and Organizations Commons

Let us know how access to this document benefits you.

\section{Recommended Citation}

Blanchard, Samantha Everhart, "Understanding the Experience of Air Force Single Parents: A Phenomenological Study" (2012). Dissertations and Theses. Paper 621.

https://doi.org/10.15760/etd.621

This Dissertation is brought to you for free and open access. It has been accepted for inclusion in Dissertations and Theses by an authorized administrator of PDXScholar. Please contact us if we can make this document more accessible: pdxscholar@pdx.edu. 
Understanding the Experience of Air Force Single Parents:

A Phenomenological Study

by

Samantha Everhart Blanchard

A dissertation submitted in partial fulfillment of the requirements for the degree of

Doctor of Philosophy

in

Social Work and Social Research

Dissertation Committee:

Eileen Brennan, Chair

William Donlan

Katharine Cahn

Laura Nissen

Leslie Hammer

Portland State University

(C) 2012 


\begin{abstract}
Today, raising children under the best of circumstances represents a daunting endeavor as any parent and a growing body of research confirm. When a single parent is on active duty in one of the U.S. armed forces, there are additional challenges involved that may not exist among civilian counterparts. The phenomenon of single parents on active duty with its unique difficulties associated both with single parenting and with military service was the basis of this study. The purpose of the research was twofold: to describe the experiences of Air Force single parents as related to social support and worklife theory in the context of bureaucracy and to use that understanding to identify needed improvements in support services.

The specific aim of this study was to gain an understanding of single parents in the military through a phenomenological approach. Purposive sampling was utilized to identify the 13 participants. The central question for the study was the following: What are the experiences of single parents serving on active duty in the United States Air Force? The seven themes that were identified as part of the single parent experience were: (a) transition to single parent in the Air Force, (b) better life (c) parental responsibilities, (d) work responsibilities, (e) support provided by the work organizations, (f) informal social supports, and (g) work-life conflict.

Major findings include the importance of family-friendly supervisors that alleviated work-family conflict. Participants also noted the military family as being significant to their adjustment and acceptance of military life. Finally, participants were seeking a better life for themselves and their children by either joining as a single parent or deciding to stay as a single parent.
\end{abstract}


This study offers an opportunity to change policy and practice to enhance and encourage the retention of single parents. One application of study findings is the reexamination of the Family Care Plan to alleviate work-family conflict. Another area identified for practice enhancement is the education and training of family-friendly supervisors. 


\section{Dedication}

I am dedicating this dissertation to my family. My definition of family is broad. Having served over 25 years in the military, I cannot define family without including those members that I have served alongside. Even if we only were stationed together for a short time, each and every one of them has touched my life. A few of those that stand out include, Mollye Cash, Major Vicki Majors (retired), Major Polly Fulsaas, and Col. Terry Stotler. These four individuals guided me as well as encouraged me to fulfill my dreams of becoming a better Air Force social worker. I would also like to include Dr. Julius Harrington, one of my first professors during my BSW program. He truly ignited my fire to become a social worker and defined the true meaning of the profession to me.

My immediate family has always supported me during my military service. My mother Judy Fink who encouraged me join the Air Force those many years ago so I could "straighten out my life" was right. It was one of my better decisions. My brother, Alan (Tag) Everhart, who has been there for me through thick and thin, has helped me through some dark days. My dad, Alan Everhart, now deceased, would have been so proud. I once told him, "I can't write a thesis." What would he say if he knew I just wrote a dissertation? My children, Sydney and Morgan Blanchard, who have been traveling around the globe with me since they were born, hold a special place in my heart. They are the ones that know the true sacrifice of being raised by a single parent serving in the Armed Forces. I have to include my step children in this dedication, Chandler and Jack Dutton. Although, they do not know the sacrifice of being raised "military brats," they do understand the sacrifice of having a parent in a doctoral program. My former fatherin-law, Jeff Blanchard, who has been a part of my life for the past 20 plus years, he truly 
defines that family is not defined by blood. As I was concluding this dissertation, my niece, Kaley Dutton, became a permanent part of this family. I hope she is ready for the adventure of a lifetime!

I cannot leave out my loving, supportive, and understanding husband, Drew Dutton. I do not know how I could have done this without him. Even though we have only been married a short time, I cannot imagine my life without him. I cannot wait to see what the future holds for us as we move on to the next chapter of our lives. I love you. 


\section{Acknowledgements}

This dissertation would not be possible with the support from many people. My committee members were invaluable in guiding and supporting me. Ted Donlan spent time guiding me in qualitative methodology and discussing implications of my research. Katharine Cahn, one the original members of my comprehensive exam and proposal has been my biggest cheerleader for wanting to understand military culture. Laura Nissen, also an original member of my comprehensive exam and one time advisor, has been instrumental in my being successful through this process. Leslie Hammer, although not a social worker, has a true understanding of our profession. Her understanding of work-life concepts really made this paper come together. Last but certainly not least, Eileen Brennan. I refer to her as the Colonel, always directing, supporting, and offering a shoulder to sometimes cry on.... and of course, friendship. She went above and beyond the call of duty as she was especially supportive with the many hours and many years of telephone meetings to get me done.

The Air Force Institute of Technology provided funding the first two years of course work and one year toward preparing for the dissertation.

My participants were absolutely instrumental in making the project possible. They provided their insight and feelings surrounding their experiences in the Air Force. I cannot thank them enough.

Finally, I thank my family, friends, and co-workers who encouraged and supported me through this process. 


\section{TABLE OF CONTENTS}

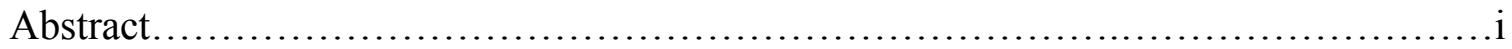

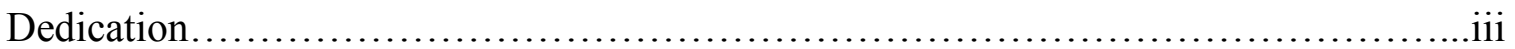

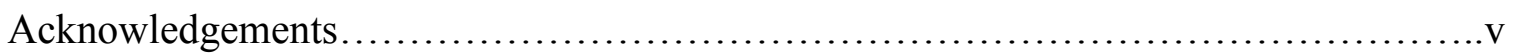

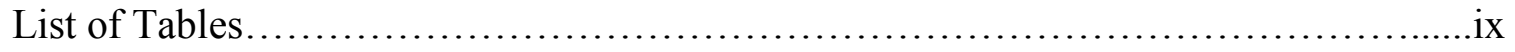

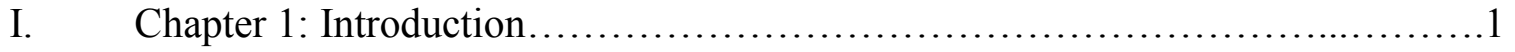

A. Statement of Problem..................................................

B. Formal Support for Military Personnel...................................4

C. Purpose of Study .................................................... 7

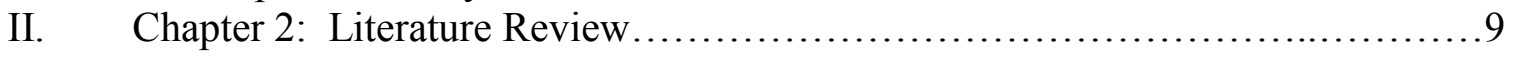

A. A Unique Combination-Bureaucracy and Support ...................... 9

1. Bureaucracy......................................................

2. Support..................................................... 10

B. Single Parents.................................................... 11

C. Single Parents in the Military..........................................14

D. Risk of Losing Highly Qualified Personnel from Military Service...........23

E. Relevance...........................................................24

III. Chapter 3: Theory and Research Questions................................26

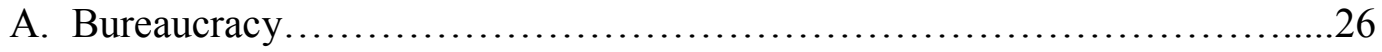

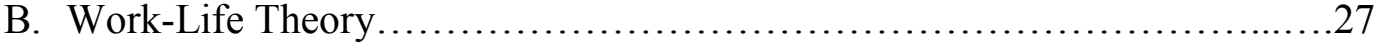

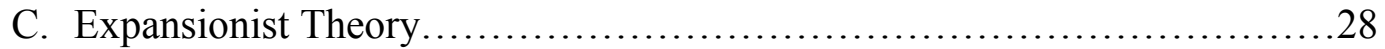

D. Spillover Theory ................................................29

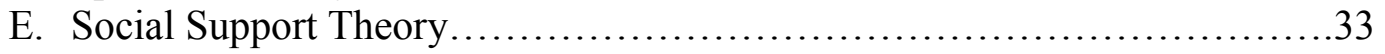

F. Family Specific Supervisor Social Support............................ 35

G. Support and Stress................................................. 38

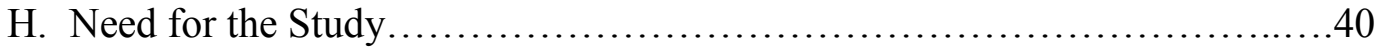

I. Purpose Statement.................................................4 41

J. The Research Questions............................................42

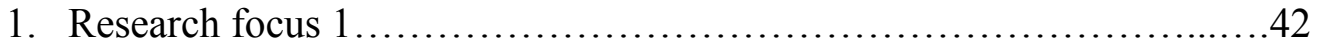

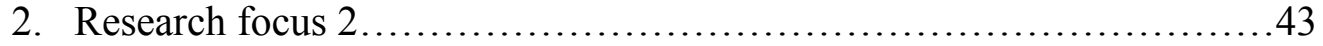

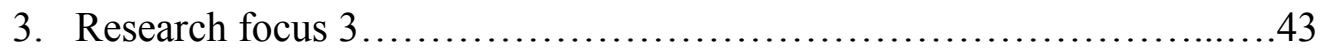

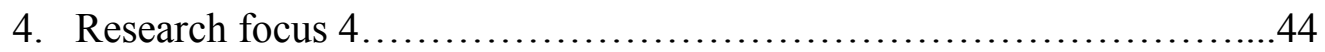

IV. Chapter 4: Methods..................................................46

A. Research Approach..................................................46

B. Criteria for Selecting Participants ...................................5 53

C. Participant Recruitment and Sampling Strategy.........................54

1. Purposive sampling............................................. 54

2. Recruitment Methods..........................................55

3. Recruitment through snowball sampling..........................55

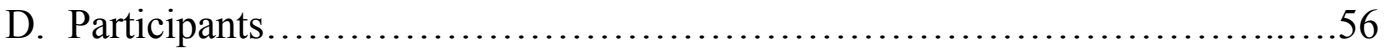

E. Procedures.....................................................59

F. Data Collection..................................................60

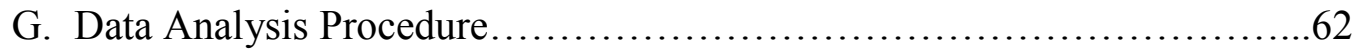

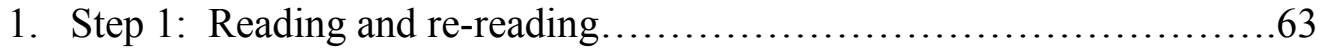


2. Step 2: Initial noting..............................................64

3. Step 3: Developing emerging themes.............................67

4. Step 4: Searching for connections across emerging themes.............72

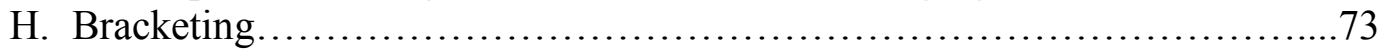

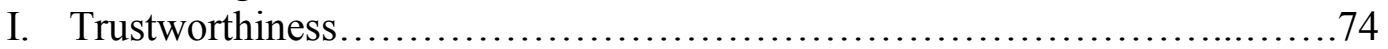

J. The Researcher as a Critical Tool......................................76

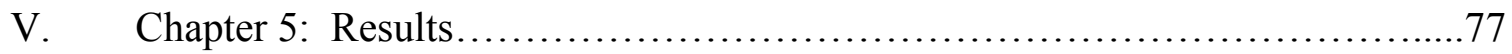

A. Air Force Single Parent Participants................................... 77

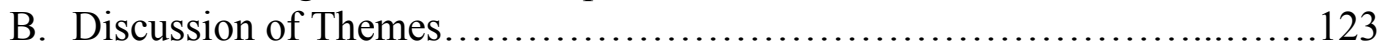

1. Transition to single parent in the Air Force.............................125

a. Pregnant young, without partner.............................125

b. Divorced/widowed......................................... 126

c. Gave up custody and then regained..........................126

d. Relationship issues............................................127

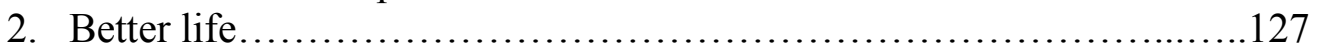

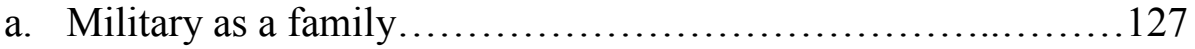

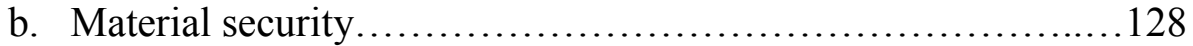

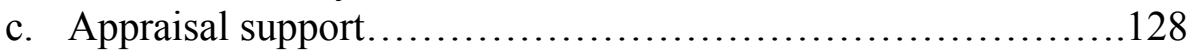

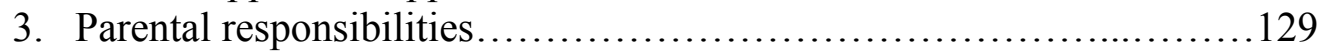

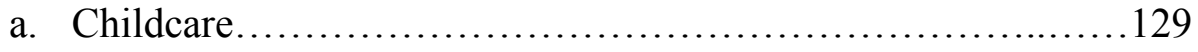

b. Education of children......................................... 130

c. Sole care of child............................................ 131

4. Work responsibilities........................................... 131

a. TDY (temporary duty at another location) ....................132

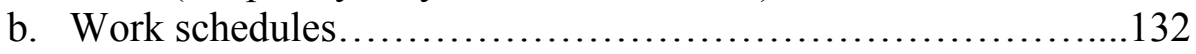

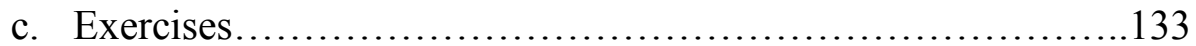

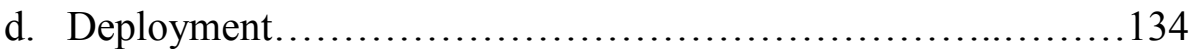

5. Supports provided by the work organization......................... 135

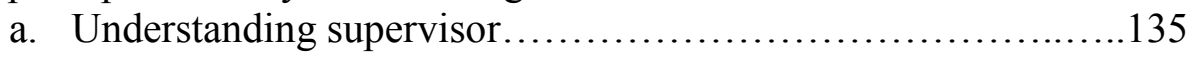

b. Support from peers...........................................

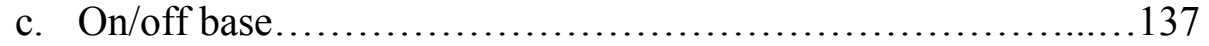

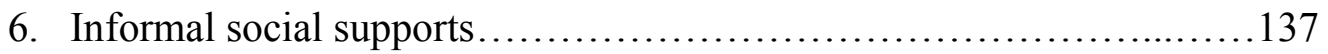

a. Extended family ......................................... 138

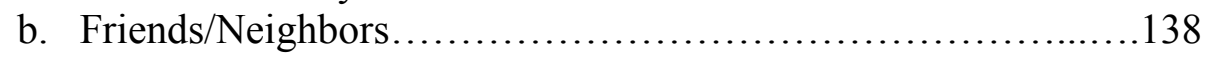

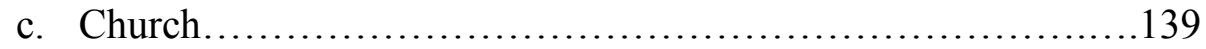

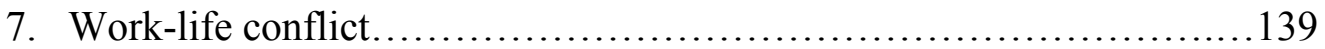

a. Child with special needs...................................139

b. Family care plan............................................ 140

VI. Chapter 6: Discussion................................................. 142

A. Major Study Findings................................................ 142

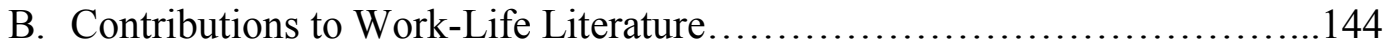

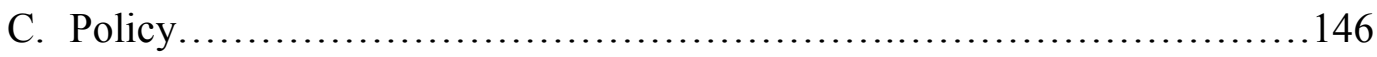

1. Family Care Plan............................................... 148

2. Policy Supports............................................... 148

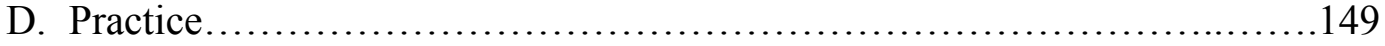




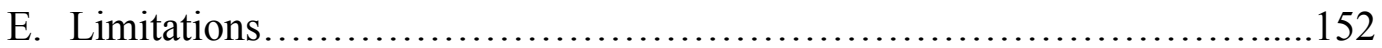

F. Future Research and Conclusion.......................................154

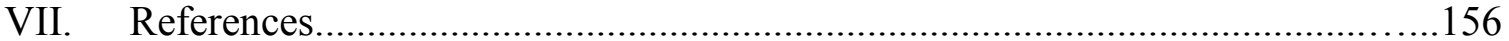

VIII. Appendices.......................................................... 169

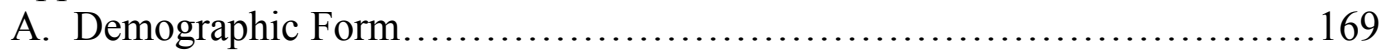

B. Protocol for Interview.............................................. 170

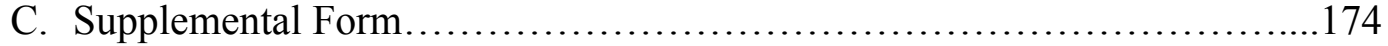

D. Informed Consent................................................... 176 


\section{LIST OF TABLES}

1. What Does an "Average” Single Parent Look Like? ..................................................13

2. Demographic Characteristics of Study Participants............................58

3. Air Force Single Parents at Study Location....................................59

4. Initial Comments...................................................... 64

5. Developing Emergent Themes............................................68

6. Abstraction Leading to the Development of a Super-ordinate Theme..................72

7. Master Table of Themes................................................. 124 


\section{Chapter 1: Introduction}

\section{Statement of the Problem}

An increasing number of women have found service in the armed forces to be an attractive alternative to the less secure civilian job market, as well as a chance for special training and an opportunity for professional mobility. Accordingly, women now comprise approximately $15 \%$ of all active military personnel in the U.S. armed forces (Taylor, Wall, Liebow, Sabatino, Timberlake, \& Farber, 2005).

The military career, though providing an opportunity for advancement in many ways, is also extraordinarily challenging, especially regarding the demands placed on the families of service members. In contrast to civilian occupations, for example, many active duty military personnel are expected to remain "mission ready" at all times. The full-time demands of active duty service are a particular point of interest today, when enlisted personnel frequently have more family responsibilities than did the young, unattached males around whom the expectations of military life were originally developed (Taylor et al., 2005, p. 84). Currently, the U.S. armed forces are the nation's largest employers of single parents (Buddin et al., 2001). Single parents cannot join the military as single parents. They can become single parents while serving and continue to serve as long as certain procedures are accomplished. When mission requirements (long hours, temporary assignments away from home, and the threat of rapid deployment) impinge on the military personnel's already above average number of responsibilities at home, they can create extraordinary stress on family life (Taylor et al, 2005, p. 84). 
According to Eastman, Archer, and Ball (1990), "There may be several unique sources of stress in military families. Frequent and prolonged separations, often associated with perilous duty under tense and potentially combative international relations, for example, represent one class of special challenges faced by military families" (p. 114). Military deployments embody particularly challenging periods of separation for single-parent families in the armed forces as defined by the following characteristics: (a) they originate from outside the family unit; (b) they directly affect all family members; and (c) they have a variable length of notification prior to onset, sometimes occurring with little or no prior warning. This inability to make reliable plans for the future is not unique to the armed forces, but it is particularly pronounced in active duty settings. Servicemen and women who leave a family behind when deployed, inevitably carry with them into stressful military scenarios, the additional stress of knowing the hardship being suffered by their families.

The Air Force manifests the predictable aspects of a bureaucracy, according to Weber (1978) and in particular those of a "greedy" bureaucracy according to Coser (1974), which has implications for recruitment and retention of qualified personnel to defend the country. These organizational expectations induce stress for all parties involved, and in particular for service members who are single parents. The social support theory predicts that providing attention to family members from within the organization might mitigate some of these stressors (House, 1981). The military has in place programs and policy steps to help increase social support, so that military personnel are available for the task of protecting the country. However, there are no support systems targeted specifically to single parents in the Air Force. In light of recent 
demographics indicating an increase in the number of single parents, the military should continue to build family support programs and policies, making note of the unique needs of growing populations such as military single parents, as a strategy to maintain a ready force.

The number of single parents serving in the Air Force on active duty is 8,800 , accounting for $2.7 \%$ of the total population. Although an overall small percentage, one must take a closer look at how this population is distributed. $4.5 \%$ of all female officers and $8.8 \%$ of all female enlisted are single parents. In other words, 1 out of every 11 women are single parents. (Air Force Personnel Center, 2012). The Air Force single parent is defined as an adult living with at least one child under the age of eighteen, with no other adult living in the household, was the focus of this study. The aim of the study was to add to the body of knowledge about single parents, and thus improve the quality of life for single parents serving in the Air Force.

Despite the growing body of research concerning the experiences and challenges associated with single-parent families, there remains a dearth of comparable research involving single parents serving in the military. This study is needed to add to our understanding of the single parent population in the Air Force.

Job-related separation of workers from their families is a part of many occupations; however, much of the existing body of knowledge of work-related separation comes from the literature on military-induced separation (Kelley, HerzogSimmer, \& Harris, 1994). The Air Force in particular provides many support services to military families when one parent is deployed and the remaining parent temporarily acts as a single parent (Air Force Instruction 36-3009, 2008). Although these services are 
available to active duty single parents, the support system is not designed for the unique needs of the population. This system is discussed below, outlining the support system in place for spouses that become single parents due to deployment.

\section{Formal Support for Military Personnel}

In order to assist families faced with this challenge, the Air Force has established the Airman and Family Readiness Center in which families can receive the support that they need in order to meet the demands created by the absence of the military parent (Air Force Instruction 36-3009, 2008). These services include the Air Force Aid Society, the Relocation Assistance Program, the Transition Assistance Program, Family Life Education, and the Family Readiness Program. More recently, Department of Defense initiatives, such as Our Military Kids and America Supports You, have been established to coordinate efforts by private citizens and corporations to address the needs of absentee reservist parents serving on active duty abroad. According to Secretary of Defense Robert M. Gates (2008),

Reaching across all 50 states, this organization has enabled nearly 3,000 children to participate in activities ranging from judo to ice hockey, from theater to dance, and from math class to driver's education. Its future goal is no less ambitious: To provide grants to the estimated 70,000 children of our Reserve and National Guard families. Organizations like Our Military Kids are making a tremendous difference in the lives of America's youngest heroes (p. 35).

Taken together, it is evident that the military has made progress in providing a wide range of support services available to military personnel and their dependents. Necessary for the success of these programs, however, is the value placed on, and use of, these resources by military families. It also shows a commitment by the nation's civilian and 
military leadership to address and provide needed services as the population changes. This support needs to be carried forward into the realm of active duty single parents.

Whitworth (1984) noted that military families are unique in at least eight ways: (a) mobility, (b) separation, (c) periodic absence of parents, (d) adjustment of children, (e) overseas living, (f) high-stress and high-risk jobs, (g) conflicts between the needs of the family and the needs of the military and (h) authoritarian management environment. These factors could potentially have a great impact on mental and emotional health and the military has developed health and social programs to address these unique needs.

Military and Air Force social workers in particular, are indispensable to the organization and its members. Social workers within the organization provide a wide range of services at both the micro and macro level. Micro-level services include counseling and referral in child neglect or substance abuse cases. Macro-level skills are developed as a result of military training in leadership, administration, and management (Garber \& McNelis, 1995). Air Force social workers are in an advantageous position to develop effective family support programs such as child care centers, and are in an opportune position to shape cogent policy (Daley, 1999). Programming and policyshaping are two different fundamental elements of developing comprehensive support for U.S. Air Force members and the single parents among them in particular, and both are addressed in concert by Air Force social workers.

Military social workers are also called upon to perform duties rarely seen in the civilian community. These include, but are not limited to: transition of political hostages from captivity to freedom; helping survivors of hijackings of commercial aircraft and ships; staffing crisis hot lines; briefing military members deploying to combat situations 
on such topics as preventative medicine and family separation; pre-deployment briefs to family members as to what services are available and what to expect while the family member is deployed; and social workers deploying with combat troops to offer support on the front lines (Hiratsuka, 1989, 1991, 1993).

Every facet of the armed forces, therefore, and not only departments directly related to recruitment processes, has a vested interest in retention of recruited members. From the perspective of military social workers, this means providing the frameworks to support families which become temporary single parent homes when one parent is called to duty, and even more so more permanent single parent homes. To the extent that military single parents can be provided with the support systems they need to maintain a viable career, like those developed and managed by Air Force social workers, costs for new recruits will be avoided, including the indirect costs of losing the tacit knowledge and valuable skills that the single parent has developed while on active duty.

According to Hammelman (1995), although lengthy separations of family members are a natural and expected consequence of military service, there have been some significant changes in recent years. For instance, Hammelman emphasized that during the Persian Gulf conflict, families were separated. Although this was typical for previous wars, more single parents were called to serve than in previous wars. In February 1991, there were approximately 16,300 single parents serving in the theater (Hammelman, 1995). Hammelman pointed out that the "Literature on stress and the military has emphasized two-parent families in which the man was called to duty; timely and relevant studies concerning the stress experienced by single-parent military families, though, remain virtually nonexistent" (p. 143). 


\section{Purpose of the Study}

This study was exploratory in nature. The study first examined the existing research, current policy, and relevant theories, as they applied to single parents in the U.S. Air Force. To this end, the study reviewed the literature on bureaucracy as defined by Weber (1978) and interpreted as Coser's (1974) “greedy" institution and House's (1981) social support theory, to attain a better understanding of the situation of single parents in the Air Force. Policies specifically surrounding family members as well as single parents were included in the scope of the literature review. An examination of how the Air Force responds to single parents in the context of family versus duty was explored as well. This study allows the reader to more fully understand the demands and issues facing single parents serving in the U. S. Air Force and how those demands and obligations affect their relationships with their families. In essence, this study explored the difficulties and strengths experienced by single parents serving in the Air Force as they fit their work and family responsibilities together. Another key component of this study was providing a forum for hearing what single parents say they need to successfully integrate their work and family life. This research will serve as the basis for subsequent studies that can help build a greater body of knowledge that can have a significant influence on policy and practice changes in support of the military single parent.

The phenomenological approach, as described by Creswell (2007), was the lens for this study. Creswell (2007) asserts that phenomenology is the most suitable qualitative research approach for what he calls "Essence questions: questions about what is at the essence that all persons experience about a phenomenon" (p. 239). In this case the investigation addressed the experience of individuals in the single parent 
serviceperson phenomenon. The process of conducting a phenomenological study is, in brief, to identify the phenomenon of interest, identifying and selecting individuals who experience the phenomenon and whose experiences will be reduced or synthesized into a common experience (Creswell, 2007). Although other approaches were considered for this study, such as grounded theory, ethnography, and case study, phenomenology was selected because of this population has very few studies, of which are twenty plus years old. Phenomenology allows a population to be studied in order to understand where future research could be focused.

This study opens with a review of the literature surrounding single parents in general as well as single parents serving in the military. The single parents are viewed through the lens of bureaucracy, work-life theory, and social support theory. 


\section{Chapter 2: Literature Review}

This section will review the critical points of current knowledge and methodological approaches to acquiring knowledge about single parents and parents in the military. The aim of this review is to bring the reader up-to-date with current literature in the field and to provide context for this study presented throughout the rest of the dissertation.

\section{A Unique Combination-Bureaucracy and Support}

The military presents as a bureaucracy, but has had to evolve to incorporate support services to retain highly trained personnel. This section is devoted to explaining this unique combination of bureaucracy and support.

\section{Bureaucracy}

As previously discussed in Blanchard (2012), the military, as an organization functions similarly to civilian institutions in communicating social expectations and values to its personnel and families. Concomitant with the social and family expectations exist military-related work expectations. As a workforce, the military requires a range of personal and family sacrifices in order to accommodate its mission, and these demands often dominate the lifestyles of military personnel and their families. Many unique and adaptive challenges are presented because the military's environmental context requires readiness and preparedness for missions crucial to national security (Bowen, 1985; Bowen, Orthner and Zimmerman, 1993; Jensen, Lewis and Xenakis, 1986; Walker, 1985). These demands of the armed forces dictate the acceptance by its members of a lifestyle that pervades almost every facet of a person's life. There are few civilian occupations that require such a high level of commitment and dedication from employees 
(Bowen \& Orthner, 1986). In this regard, Albano (1994) and Segal (1986) used Coser's (1974) notion of the "greedy institution" to describe the great demands that the military as an organization places on the time, energy, and commitments of service members and their families, demands that are unrivaled in the civilian workplace (Albano, 1994).

While all jobs involve some degree of organizational commitment, perhaps nowhere else in American society is this level of commitment so pronounced or wide ranging as in the armed forces. According to Coser (1974), "Members of greedy institutions must be so fully and totally committed to them that they become unavailable for alternative lines of action" (p. 8). Although circumstances have changed somewhat since the elimination of the draft and the introduction of an all-volunteer force in the 1970s, many enlisted personnel remain subject to the vagaries and capriciousness that go hand-in-hand with active duty service in the military. As Coser (1974) emphasized,

It is worth mentioning that in one American institution that is still a major holdout for archaic and traditional values, the military, diffuse and devouring expectations by high ranking military masters of enlisted men have by no means disappeared even though official regulations tend to disapprove of them (p. 13).

The military requires sacrifices by their personnel and their families to accommodate the requirements and objectives of the military (Bowen et al., 1993). The military compensates for this by providing economic and social support (Bowen, et al., 1993).

\section{Support}

Bowen and Orthner's (1986) classic study on single parents in the military revealed the importance of formal and informal family support networks to single parents. Formal support networks cited include child care arrangements, parent 
education, and single parent support groups; informal networks included parents and other relatives, who have an understanding of the stress endured by a single parent balancing work and family. Bowen and Orthner highlighted the potential for parent education programs and single parent organizations to reduce work-life conflict for single parents in the military. This study, however, cited the aforementioned potential only as indication of the need for developments in military policies concerning single parents and their achievement of a work-life balance. As will be presented in the literature review, this is still a prevalent and unresolved issue that requires more improvement and attention from policy-makers.

The importance of social support networks was further confirmed in a subsequent study by Bowen and Orthner (1993), seven years after their single parents in the military study. This quantitative study confirmed the authors' earlier findings that social support networks significantly influence the level of stress experienced by single parents in the military. Based on results from their 1993 study, the authors concluded that, "work stressors, family and community resources, and Army support resources" (p. 300) significantly contributed to family adaptation, particularly for single mothers.

\section{Single Parents}

Single parenthood is a growing phenomenon in contemporary society. It refers to the situation where a lone parent sustains the life of a child exclusive of instrumental support of the other biological parent. It can occur because of divorce, adoption or through naturally non-projected occurrences like death, child neglect, pregnant without partner (Armstrong, 2007). 
The 2009 U.S. Census Report reveals that there are about 13.7 million single parents. The following is some insight on how they balance their family as well as employment demands. Grall (2009) asserts that this group of parents is responsible for sustaining the wellbeing of over 21.8 million children in the country. Single parents have to work to raise children, as well as cater to their individual needs. This means tireless work for this population. Whether single through choice or any other means, these parents experience similar stressors. Appropriate balancing between the two domains requires adequate discussion by the employers and the parents in matters pertaining to their availability and their workload (Grall, 2009).

It is notable that mothers form the majority of single parents, $(82.6 \%)$ while fathers make up the rest $(17.4 \%)$. The employment of single parents in the public sector has amplified in the recent past. Full time positions have risen from $45 \%$ to $53 \%$ in the period from 1993 to 1999 . The proportion of the employed single fathers supersedes solo mothers. In 2007, approximately one quarter of solo parents had incomes beneath the poverty line (Grall, 2009). This is highlighted in Table 1 below: 
Table 1

What Does an "Average” Single Parent Look Like?

\begin{tabular}{lrr}
\hline Attributes & Female & Male \\
\hline & & \\
Custodial Parent & $84 \%$ & $16 \%$ \\
\hline & & \\
Divorced/separated & $44 \%$ & $57 \%$ \\
Never married & $33 \%$ & $24 \%$ \\
Married & $22 \%$ & $18 \%$ \\
Widow(er) & $1 \%$ & $1 \%$ \\
& & \\
& & $74 \%$ \\
Full time employment & $50 \%$ & $18 \%$ \\
Part time employment & $29 \%$ & $8 \%$ \\
Unemployed & $21 \%$ & $11 \%$ \\
Below the poverty line & $28 \%$ & \\
& & \\
\hline
\end{tabular}

Note. Grall, T. (2009). Custodial mothers and fathers and their child support: 2005, Current Population Reports, P60-237. Washington, DC: U.S. Census Bureau.

According to the U.S. Census of 2010, there were 116.7 million households in the United States with about 11.2 million (9.6\%) single parent households sustaining children below 18 years of age. Households headed by mothers accounted for $75 \%$ or 8.4 million of single parent households. On the other hand, there were 2.8 million single fathers raising children under 18 years of age (U.S. Census Bureau, 2012). Stacie (2010) indicates that there are realities that accompany single parents and work life. Stacie reports that single parents normally experience stigmatization at work. It is argued that single parents are not as productive since they need extra time to attend to their children. Because of this stigmatization, many single parents try to stay loyal to their job, thus 
possibly neglecting their family life (Stacie, 2010). Single mothers are $44 \%$ less likely to be productive in their work situations than their non-mother counterparts are, even if they possess similar qualifications. In addition, employers normally offer them low salaries compared to their counterparts. Women without children receive approximately $\$ 11,000$ more than single mothers for a similar job (Stacie, 2010).

Most single parents do not have adequate time to attend to their families. Long (2009) asserts that $50 \%$ of children from single families are poor because they come from single mother households that are under employed, or not in the labor force. He further asserts that these parents face dishonor and prejudice in work places (Long, 2009).

\section{Single Parents in the Military}

There are important differences between single parenting in the civilian world compared to single parenting in the armed forces. In sharp contrast to American society, the military places demands unrivaled in the civilian community. Frequent moves, deployment, long work hours, and at times, erratic work hours are some of the distinct differences single parents face in the military.

Importantly, military duty takes on many different forms. Some servicemen and women work for eight hours a day, five days a week, and enjoy a certain degree of stability in their schedules without the added concern of being deployed at a moment's notice. Other military occupational specialties involve long work days (in some cases 12 hours or more) and weekly schedules that frequently involve working or training on weekends and holidays. The latter category of military service may place inordinately high levels of stress on parents in general and single parents in particular as they struggle to balance their military responsibilities with their parenting. It is also important to take 
these issues into account when formulating support programs for single parents in the military because individual circumstances may differ greatly with military service being one of the only common denominators.

In this dynamic environment, identifying opportunities to improve the support services provided to servicemen and women is a timely and worthwhile enterprise because of the capacity of family support to contribute both to quality of life issues as well as the primary mission of the armed forces to remain combat ready. In this regard, Wingo (2002) reported that, "The military force must increasingly rely on women, thus, comprehensive family programs that recognize changes in military families...and improving policies regarding childcare are necessary to maintain combat readiness and to continue to recruit and retain highly skilled military personnel" (p. 18). However, one of the themes that quickly emerges from the review of the relevant literature is just how few studies have been devoted to how best to provide timely support services for those on active duty. Additionally, it has been indicated that there will likely be more single parents and more overseas deployment in the years to come rather than less (Wingo, 2002). As Wingo (2002) concluded when writing about military life,

Since it is not likely that there will be fewer global nomads among our population in the future, or around the world for that matter, there is room for even more research into the problems and advantages of this lifestyle. How to help those who need it, how we can fit positive aspects of nomadic growing up into our perception of an increasingly global world are still open questions (p. 31).

A qualitative study by Taylor and her associates (2005) looking at children with disabilities being raised by parents in the military, analyzed transcripts from interviews conducted with six military women. The in-depth interviews conducted took place during a 15-month period. While the issue of role balancing was not a specific topic 
involved in these interviews (Taylor et al., 2005) emphasized that this issue emerged spontaneously in all of the interviews with the mother-soldiers. The role balancing finding led to the conclusion that it was a subject that required further detailed study (Taylor et al., 2005).

Also relevant to this proposal, the women in the study by Taylor and her associates (2005) included single parents. Four of the six women in the study were single at the time of birth and three of the women were single at the time of the interviews. All the women in the study considered themselves to be single parents because the fathers of their children could not or would not play a role in raising their children with disabilities. Four of the women that did not have a partner, chose to separate from the military. The two women that chose to stay in the military had family support from partners (Taylor et al., 2005).

In what represents perhaps the most ambitious and timely study of the impact of military service on parenting in recent years, Pierce (1998) examined a stratified sample of 638 women obtained from a database tape provided by the Department of Defense Manpower Data Center that included data for all of the 88,415 women who either served in the Air Force on active duty, or were active members of the guard or reserve during the period of Operations Desert Shield/Desert Storm. This comprehensive study used a series of self-administered questionnaires designed by Pierce and provided some robust results concerning the impact of service in the U.S. Air Force on women.

The results of the Pierce (1998) study found that during the two year period following the end of the Desert Storm operation, almost one in five $(19 \%, n=97)$ of the participants ended their active duty service in the Air Force. The study also identified a 
significant difference among Air Force components among the 19\%, with $22 \%$ of those on active duty and $21 \%$ of reservists making the decision to terminate their active duty service compared to just $10 \%$ of guard members who had terminated their active duty service. Notably, Pierce added that,

There were no significant differences, by chi-square analyses, between leavers and stayers on the following demographic variables: rank, marital status, education, whether they were deployed to the theater, whether they were primary caretakers of children, family structure (alone, with a partner, partner and children, or with children only), or whether they were absent from their children during the war (p. 201).

The availability of alternative caregivers for children was shown to be one of the most important factors concerning whether the women in the Air Force made the decision to leave the service at the first available opportunity or not. Only $11 \%$ of the participants who were able to leave their child or children with their husbands or partners ended their active duty service following the Desert Storm operation, compared to $18 \%$ of the women whose child or children were cared for by members of their extended family. In fact, the highest attrition rate found by Pierce (1998) was among women in the Air Force who were forced to leave their child or children with ex-spouses, with $38.5 \%$ leaving the active duty following deployment and service in Desert Storm.

According to Pierce (1998),

Family demands appear to impact a woman's career decisions most dramatically at the birth of a child or if she is a single parent. It appears from the analysis that the time surrounding the birth of a child is a period of vulnerability during which a parent or parents may find it difficult to keep the same level of commitment to all the competing demands in their lives (p. 210).

In addition, the same levels of social support that civilian families may enjoy are not consistently available to military families, who may be separated geographically from 
extended family members who might be otherwise available to assist with the increasing demands of parenthood. In contrast to men in the military who were found to be more likely to have a nonworking spouse, women serving in the military were found to be almost entirely in dual-career relationships in which the respective careers of their husbands or partners must also be taken into account. In this regard, the study by Pierce found that there was a difference between those study participants who intended to leave the service and those who intended to remain on active duty relating to whether the woman had a significant other who was in the active duty military. According to Pierce,

Women with an active duty partner were nearly three times more likely to leave $(22 \%)$ than women with a spouse or partner in the reserve or guard $(8 \%)$, although one might think that a spouse in the service might have a greater understanding of the nature of military work, which includes long and unpredictable hours, unexpected travel or deployment, and exposure to dangerous work conditions (p. 210).

Because they may be called upon to deploy or train for extended periods of time away from the home, the availability of a surrogate caregiver is particularly important for single parents in the military. In another study of mothers serving in the U.S. Navy who had deployed for sea duty conducted by Kelley, Herzog-Simmer, and Harris (1994), single mothers were found to experience heightened levels of separation anxiety, diminished family cohesiveness, and less family organization compared to their married counterparts.

The study by Kelley et al. (1994) analyzed the effects of deployment based on the responses from 118 U.S. Navy mothers using the Parenting Stress Index, the Maternal Separation Anxiety Scale, the Parenting Dimensions Inventory, and on two subscales of the Family Environment Scale. This study found that the impact of deployment on the 
Navy mothers was related to the mothers' deployment cycle and marital status. According to these researchers, Navy mothers who were expecting to be deployed experienced substantially higher levels of parenting stress and more sensitivity to children than those who had just returned from a deployment; moreover, single mothers were found to experience heightened levels of separation anxiety, less family cohesiveness, and less family organization than their married counterparts (Kelley et al., 1994).

As Pierce (1998) emphasizes, though, the Kelley et al. (1994) study was limited in its scope and findings:

Unfortunately, it is not known what level or type of support was available to husbands, partners, or extended family members caring for the children of deployed women. It appears likely that spouses and partners in families who experienced significant disruption were less supportive of the women continuing in the military (p. 211).

As Pierce (1998) pointed out, the crux of the salient issues involved do not relate to whether there are dependent children or how many dependent children are involved in the decision to leave active duty at the first available opportunity, but rather to the timing of the birth of a child during periods in which work-related stressors and family demands are at their height. The study by Pierce found that active duty women who had a child during the period between the onset of the Desert Storm campaign and the point at which the survey was re-administered two years later were shown to be more than twice as likely to end their active duty commitment (31\%) compared to those women who did not have a child during that two year period (15\%). As Pierce emphasized, there is a gap in the literature in this area, and more systematic studies are required in order to better understand the work-related stressors and the support systems that are typically available 
to military women during their childbearing years to formulate informed opinions concerning what can be done to offset these trends.

Pierce suggested that longitudinal studies would provide the needed information required to gauge and monitor those variables that have the most impact on retention at different periods in a woman's military career as well as on her developmental life stages. In this regard, Pierce advised:

For example, as indicated, the impact of deployment is not a significant factor in retention but may be more stressful for women in the early childbearing years than for women later in their life and career cycles. Young families with multiple stressors, including financial hardship and demanding work patterns, require organizational support and policies to ease their burden so they can maintain military readiness and a stable family life (p. 211).

While the needs of service members of either gender may be different depending on the branch of service involved, there is a consistent theme that the provision of support services during these crucial periods in parents' lives plays a significant role in reversing the trend for the active duty single parents to leave the service at the first available opportunity. As Pierce emphasized,

Organizational attention to the needs of women in these two critical periods of their lives, particularly during the early childbearing years when competing demands are greatest, could significantly improve retention of career-oriented women as well as the mission readiness of the Air Force (p. 211).

This study focused on women and their intent to leave the service; it is unknown if the same reasons would be true for male single parents serving on active duty. Indeed, notwithstanding the numerous hardships and constraints involved in active duty service, many of the women in the Pierce study experienced sufficient personal value and reward in their service to keep them committed to their career even with the extraordinary challenges caused by deployment to theaters of war (Pierce, 1998). As a result, Pierce 
suggests that it is reasonable to conclude that to the extent that the child care needs of military women can be supported through the particularly stressful periods of the early childbearing years and the provision made for family support during deployments, will likely be the extent to which these women may willingly complete an active duty career. The level of commitment was also related to how much time the women in the Pierce study have invested in their Air Force careers at the time of the study:

Length of military service was longer (10.51 years vs. 7.82 years) among those who remained after the war, indicating, as others have shown (Price \& Kim, 1993), that the intention to stay is strongest among those who reach the midpoint of a 20-year career (p. 212).

Other issues identified in the Pierce (1998) study that contributed to a higher incidence of attrition among active duty mothers appear to be more related to the quality of leadership being provided. For example, the variables of balancing military commitments and family life, a perceived lack of promotion and recognition, dissatisfaction with work conditions and environment, and financial hardship were all shown to be salient in the decision-making process among those who decided to leave active duty following deployment during Desert Storm. According to Pierce, "Further studies regarding the multiple, interactive aspects of women's career patterns are essential to continuing to build a body of knowledge concerning gender-specific issues in today's changing military force" (p. 212).

Another issue that faces single parents serving in the Air Force is housing. Military housing offers a unique opportunity for single parents to obtain possible support from neighbors that understand the military environment. However, single parents serving on active duty are more likely to live in housing off base than their married 
counterparts, though they are much less likely to own their own homes than their civilian counterparts, preferring to rent, particularly if they expect to be reassigned or deployed in the near future. According to Buddin, Gresenz, Hosek, Elliott, and Hawes-Dawson (1999),

Single parents were nearly three times as likely as married couples without children and two-parent families to prefer civilian rental housing. Being a single parent increased the probability of renting compared to living on-base by 14 percentage points relative to married members with no children (p. 70).

In addition, single parents in the military have been shown to have an immediate need for housing in ways that differentiate them from their married counterparts. In this regard, Buddin et al. (1999) emphasized that the family situation greatly affected the motivation to wait for military housing, "being a single parent decreased the probability of waiting a year for high-quality military housing by $31 \% "($ p. 92).

Moreover, in sharp contrast to a married couple living off-base, single parents cannot rely on the expectation that a spouse would care for the home during their absence and would therefore not enjoy the equity benefits that accrue to home ownership (Buddin et al., 1999). Single parents choosing to live off-base may be missing valuable social support that comes with living in a military community. Drawing a conclusion from the literature, it may be that single parents are likely to take the first available housing in order to establish school, child care, and work commitments. Single parents may sacrifice a housing situation which might provide long-term support in order to quickly establish a routine, so as to interfere as little as possible with their work obligations.

A survey of literature on formal support systems or social networks for parents in the military showed that there are numerous available parent programs allowing parents 
to socially adjust with their families after returning from a highly stressful duty, such as assuming active duty in wars or international conflicts. The Return \& Reunion program contains sub-programs that aim to support military personnel in their re-adjustment to their social environment after a particularly stressful military assignment. These subprograms include stress debriefings, group presentations, and small group sessions enabling military personnel and their families to re-acquaint themselves with each other, and the sub-programs act as mediators through which understanding can be achieved between the two parties (Balsure \& Arnold-Mann, 1992). However, despite these constructive efforts, improvements are still needed in these military-mediated support programs, since they rarely meet recipients' (military personnel and their families) needs and expectations (Figley, 1993). Some of these programs, according to Figley (1993), failed to meet single parents' needs, wherein interventions and methods are responsive to the needs and nature and dynamics of the families involved. Clearly, from Figley's (1993) assessment, formal support systems provided for single parents in the military lack the equity critical to the success and satisfaction of single parents in a high stress institution such as the military. In this case, equity meaning the system is available to single parents but not designed for single parents.

\section{Risk of Losing Highly Qualified Personnel from Military Service}

A study of women serving in the U.S. Air Force during the First Persian Gulf War deployment conducted by Pierce (1998) revealed a number of work-family conflicts that contributed to the resignation of these service personnel once their enlistments were completed. Such conflicts were identified by $25 \%$ of those leaving military service and rated as critically important by $11 \%$. Many respondents commented that there was simply 
insufficient time to meet all the demands placed on them. Although some parents had successfully managed their work lives, the anticipation of having children had caused a reappraisal of their commitment to the military. As one respondent stated: "I want to have children, and it would not be practical with a military career. I feel that either the children or my career would suffer if I tried to do both."(Pierce, 1998, p. 195).

Other respondents also commented on the difficulty of managing both career and family such as one parent's observation that: "Social functions or family functions almost always seem to be on the UTA [unit training assembly] weekends;" and another respondent stated, "[I experience]... disagreement between what I view my family role to be and what the Air Force views it to be. In my Air Force job, fluctuating shifts and hours and being sent away is unacceptable"; and yet another interviewed parent said, "I'm a single parent and I just don't have enough time with my child" (Pierce, 1998, p. 195).

Other respondents commented on the incompatibility of military life and family life, with statements such as "I could no longer put my Air Force responsibilities first" (Pierce, 1998 p. 196). A number of active duty parents in this study expressed a desire to provide for the safety, security, and stability of their families but found that the demands of a military career made this goal unattainable (Pierce, 1998, Taylor et al., 2005).

\section{Relevance}

Today, single parents are certainly not rare and indeed have become increasingly commonplace in recent years. According to Horn and Bush (1997),

Families are the primary institutions through which we protect and nurture our children, and upon which free societies depend for establishing social order and promoting individual liberty and fulfillment. However, over the past several decades the United States has been experiencing a dramatic decline in the institution of marriage and family (p. 39). 
Custodial Mothers and Fathers and Their Child Support: 2005, a report released by the U.S. Census Bureau in August 2008, revealed that there are approximately 13.6 million single parents in the U. S. Those parents are responsible for raising 21.2 million children (approximately $26 \%$ of children under 21 in the U.S.). Table 1 denotes the percentages of single parents in varying demographic groups. The Air Force single parents also enjoy a 100\% employment rate unlike the civilian community. This study captures both male and female aspects of serving as single parent on active duty. 


\section{Chapter 3: Theory and Research Questions}

Determining the needs of single parents in the military, and the policy gaps in meeting those needs, requires an understanding of their different contexts and dimensions. This objective would also entail identifying and applying the appropriate theories to the issue - that is, theories that are relevant to the experiences of single parents in the military. This review of related literature is thus divided into two sections: first, a discussion of bureaucracy, work-life, and social support theories, and second, research questions as they apply to the theories discussed.

\section{Bureaucracy}

The military is a unique institution not found anywhere else in America. Weber (1978) identified a basic premise about organizations functioning as a bureaucracy: tasks are put before people. Albano (1994) and Segal (1996) utilized Coser's (1974) “greedy institution" to further describe the military. Coser explains the "greedy institution" in the following manner:

[T]hey seek exclusive and undivided loyalty and they attempt to reduce the claims of competing roles and status positions on those they wish to encompass within their boundaries. Their demands on the person are omnivorous...they tend to rely on voluntary compliance and to evolve means of activating loyalty and commitment...they exercise pressures on component individuals to weaken their ties, or not to form any ties, with other institutions or persons that might make claims that conflict with their own demands...Members of greedy institutions must be so fully and totally committed to them that they become unavailable for alternative lines of action. (Coser, 1974, p. 4)

Understanding the military's basic premise, as explained above, facilitates an understanding of the difficulties of incorporating social support for its members. It would appear that the two are incompatible. In fact, Taylor (1947) who led the "scientific management" movement whose main preoccupation was the programming of the 
contents of operating work, wanted to remove "all possible brain work" from the shop floor. By doing so, he also removed all possible initiative from the people who worked there. Thus his "machine" had no will of its own. Treating people as "means" which were "categories of status and function rather than as individuals" had the "consequence of destroying the meaning of work itself" (pg. 302). Organizations have paid for these attitudes in various forms of worker resistance - absenteeism, high turnover rates, sloppy workmanship, strikes, even outright sabotage (Mintzberg, 1983).

However, the military has successfully incorporated many support programs to entice military members as well as their families to remain in the military. Work-life theories are examined with the "greedy" institution as the back drop. Understanding the demands of the military bureaucracy will aid in the understanding of how work-life responsibilities fit or do not fit depending on the variables being studied.

\section{Work-Life Theory}

The area of research recognized as "work-family" began with Kanter's 1977 book in which she dismissed the "myth of separate worlds." The theoretical model of segmentation, claiming that work and family were entirely separate, to explain the relationship between work and family, was no longer relevant. Since Kanter's (1977) seminal work initiated a new perspective on work and family, a variety of theoretical models have developed to explain the relationship between work and family, one of which is spillover and the other is conflict (Young \& Kleiner, 1992). Spillover will be discussed at length later in this chapter. Much research has concentrated on role conflict in that working family members find their roles as parents or spouses conflicting with their roles as employees in terms of time, energy, and character traits that each arena 
requires (Bailyn, 1993; Burke \& Bradshaw, 1981; Howard, 1992). However, Barnett, Marshall, and Singer (1992) and Barnett and Hyde (2001), disputed this position and demonstrated that multiple roles enhance well-being. Role quality, not the number of roles, is the crucial factor in determining working parents' welfare.

Several researchers have documented interrelationships that exist between the family and work lives of individuals (Bianchi, Casper, and King, 2005; Boles, 2001; Chow \& Berheide, 1988; Felstehausen, Glosson \& Couch, 1986). Early research initiated by Hill (1949), there has been ongoing study of the interrelationships of family stress and military work life (Adams, Jex, \& Cunningham, 2005; Boss, 1987; Britt, 2006; Burr, 1973; Drummet, 2003; Faber, 2008; Finkel, 2003; Hammer, Cullen, Marchand, \& Dezsofi, 2005; McCubbin, Joy, Cauble, Comeau, Patterson, \& Needle, 1980; Pincus, 2001; Rothrauff, 2004).

According to Lewis, Rapoport, and Gambles (2003), "work-life integration" is the degree to which individuals are able to successfully combine work outside the home and their personal life. When employees have work-life supports, they are more able to meet responsibilities as a parent and be successful at work (Voydanoff, 2004).

\section{Expansionist Theory}

Utilizing this work-life perspective, the work of Barnett and Hyde (2001) is most important. Barnett and Hyde argued that work-life theory has not evolved with the changing family and economic systems. This theory attempts to bring a modern understanding of families into the work-life literature.

Based on prior research, Barnett and Hyde (2001) asserted that multiple roles are beneficial to both men and women. They note that when men and women have a strong 
commitment to one role, it does not exclude a strong commitment to another role. The effects of multiple roles include increased social support and added income. Certain conditions must exist for the multiple roles to be beneficial, such as the number of roles and the time requirements for each role. These multiple roles do provide opportunities for success as well as opportunities for irritation or stress overload. Incidences of multiple role frustration were highest for low wage earners, and those who experienced work discrimination, or sexual harassment at work (Barnett, et al., 2001). Lastly, this theory states that the nature of men and women does not force them into genderdifferentiated roles of family and work.

Multiple roles for single parents can be beneficial. However when compared to their married counterparts it could be argued that cumulative demands of multiple roles may increase a single parent's role strain (Goode, 1960). According to Shinn, Wong, Simko, and Ortiz-Torres (1989), stressors, schedule flexibility, and the ability to cope were slightly more important for single rather than married parents. Their research findings were inconclusive as to whether role overload, job strain, work-family conflict, and psychological well-being differ according to marital status (Shinn et al., 1989). Shinn et al. (1989) noted that flexibility was more important for single parents than their married counterparts. This flexibility in the military is even more important because service members frequently relocate thereby reducing the continuity of informal instrumental social support (Taylor et al., 2005).

\section{Spillover Theory}

There have been early studies indicating that work stress is occurring in the lives of personnel regardless of their family situations. Shirom (2003) emphasized work stress 
as a concern for all organizations, because work stress can be chronic. Shirom's study revealed that employees with burnout had higher rates of absenteeism and turnover and less attachment to the organization. In another study Swanberg, (2006) documented numerous deleterious outcomes associated with work-non-work role stress such as poorer job attitudes and increased levels of psychological strain, stress-related physical health concerns, depression, alcohol abuse, and burnout.

However, spillover theory focuses on the impact that satisfaction and affect from one domain has on the other domain. Positive spillover refers to situations in which the satisfaction, energy, and sense of accomplishment derived from one domain transfers to another. On the contrary, negative spillover is the derived problems being carried over from one domain to another. For example, increased satisfaction (dissatisfaction) in the work domain leads to increased satisfaction (dissatisfaction) with other parts of life (Bakker, Demerouti, \& Burke, 2009).

Spillover theory is also offered as a guiding framework for understanding the home lives and work lives of single military parents. There is scant research on military single parents; therefore this review will consider the possible spillover effects on military single parents and examine the results of research on civilian single parents.

Spillover theory as defined by Edward and Rothbard (2000) can to help understand work and family relationships in military single parents. The military organization has job requirements that are not typical of civilian work centers as discussed earlier in this dissertation. Because of the heightened demands, the potential for negative work to family spillover may be increased. Spillover is not unidirectional, and can involve spillover from work to family life and family to work. As noted earlier 
in this proposal, the military offers benefits such as stable employment, medical benefits, and a multitude of family programs. These programs may help in reducing the stress of military service and result in positive spillover from military life to family life.

Hanson, Hammer, and Colton (2006) have defined work-family positive spillover as the transfer of positive affect, skills, behaviors, and values from the originating domain to the receiving domain. Therefore beneficial effects from the original domain would be transferred to the receiving domain. This study developed and assessed a multidimensional measure to capture different facets of spillover based on (a) work-tofamily affective positive spillover, (b) work-to-family behavior based instrumental spillover, (c) work-to-family value-based instrumental positive spillover, (d) family-towork affective positive spillover, (e) family-to-work behavior based instrumental spillover; and (f) family-to-work value-based instrumental positive spillover (Hanson et al., 2006). The scale developed was further validated in a 2007 study published by van Steenbergen, Ellemers, and Mooijaart (2007). This study confirmed the Hanson et al. (2006) study findings and also supported the distinction between energy-based, timebased, behavioral and psychological work-family facilitation (van Steenbergen et al. 2007).

Another framework that has been used to define this phenomenon was introduced by Greenhaus and Powell (2006) and defined as enrichment. Enrichment is said to occur when resources are generated in one role domain, such as the family, that improve the quality of life in another role domain, such as work. Greenhaus and Powell define resources widely to include personal resources, as well as social capital and material assets. 
Bowen (1987) studied 87 single fathers in the US Air Force regarding their personal and family characteristics, job demands and satisfaction, life satisfaction and major problems, children, dating arrangements, relationship with former spouse, fatherchild relationships, relationships with friends and work associates, child-care arrangements, and single-parent support groups. Findings suggest that most fathers (mean age 40 years) experienced satisfying parent-child relationships, adjusted well to the exigencies of Air Force life, reported high job satisfaction, and considered themselves to be highly self-reliant. Perhaps these are indications of positive spillover from one domain to another, meaning that those fathers were generating resources from one role that impacted positively the quality of life in another role.

Negative and positive spillovers result from the absence or presence and high or low levels of the following factors, considered relevant to work-family spillover: general life satisfaction, work satisfaction, work-related variables (e.g. job role in the organization), extra-workplace contexts (i.e., the kind of organizational structure the individual belongs to), and (positive or negative) physiological condition (Pryor, Harlow, \& Howles, 1982). Among these factors, Pryor et al. (1982) consider life satisfaction, work satisfaction, and health condition of the individual as most critical in determining whether the individual would experience a negative or positive work-family spillover. The life satisfaction factor includes family life, community life, and individual life. These factors are noted in the discussion of the social support theory that addresses the systems that single parents in the military critically need. Grzywacz and Marks (2000) produced a study that looked at negative spillover, with one research question focusing on marital status; the researchers did not report information on parenting status. One finding was 
although being unmarried is associated with less negative spillover from work to family, being unmarried was also robustly associated with less positive spillover from family to work (Grzywacz \& Marks, 2000).

\section{Social Support Theory}

The presence of both negative and positive work-life spillovers among individuals, particularly in the work setting, necessitates the introduction of another theory: social support theory. Social support has been technically defined in different contexts, but most relevant for the purpose of this study is under the context of social exchange among networks: "social support may be defined as support accessible to an individual through social ties to other individuals, groups, and the larger community," (House, 1981). Like spillover theory discussed above, social support theory has both negative and positive dimensions. In other words, social support attempts may either positively or negatively affect the person supported; it is a complex, multi-faceted framework in which both desirable and undesirable outcomes must be considered. The presence of these dimensions in social support theory brings into the forefront the issue

that not all support systems available and accessed by an individual will result in positive outcomes.

The issue of single parenting also puts forth the question of equity versus equality, allowing single parents to have access to support systems and resources that would allow them to create the work-life balance they need (Young, 1999). Equality is equal access to support resources, while equity is applicable support for the various individuals accessing the support system. Ultimately, Young contends that equity and equality influence individuals' perception of the social support given, whether this support is negative or 
positive for them. Perceptions of work-life spillover and social support (positive or negative) also determine individual perceptions of "organizational justice," the extent to which individuals think the system has failed them in providing support for their family and work lives as a single parents (Young, 1999).

Although the literature contains thousands of related articles, there appears to be a lack of consensus on the definition of social support (Williams, Barclay, and Schmeid, 2004). For the purpose of this dissertation, I have chosen to incorporate the work of J. S. House (1981) because his work most closely aligns with the military work culture.

Barnes (1954) was the first theorist to describe patterns of social relationships that were not explained by families or work groups. House (1981) went on to discuss how social support theory is associated with the networking that helps people cope with stressful events. Social support theory distinguishes among four types of support as described by House (1981):

Emotional support is associated with sharing life experiences. It involves the provision of empathy, love, trust and caring. Instrumental support involves the provision of tangible aid and services that directly assist a person in need. It is provided by close friends, colleagues and neighbors. Informational support involves the provision of advice, suggestions, and information that a person can use to address problems. Appraisal support involves the provision of information that is useful for self-evaluation purposes: constructive feedback, affirmation and social comparison (p. 46-47).

Although the Air Force is structured as a bureaucracy, the organization provides all four types of social support to its personnel. Emotional support is provided by other members of the organization that are experiencing the same stressors. Instrumental and informational support is provided through the numerous agencies created by the organization to decrease stressors associated with serving in the armed forces. Appraisal 
support is provided indirectly by the organization by providing a way of life that cannot be compared to any other organization, such as taking pride in serving in an organization that is so unique.

Emotional support is associated with the general perception that one is being cared for, that one's feelings are being considered, and that individuals feel comfortable communicating with the source of support when required. According to Hammer et al (2007), supervisor emotional support includes consulting employees and understanding their family and personal life commitments. In addition, it includes the extent to which supervisors make employees comfortable discussing family related issues, express concern for the way that work responsibilities affect family, and demonstrate respect, understanding, sympathy, and sensitivity with regard to family responsibilities (Kossek \& Lambert, 2005).

Instrumental support is reactive and relates to supervision as managers and supervisors respond to individual employee's work and family needs in the form of day to day resources or services to help employees in their efforts to successfully manage their responsibilities in work and family roles. These involve responding to requests for schedule flexibility, needs to interpret policies and practices, and managing routine work schedules to ensure that employees' job tasks get done.

\section{Family Specific Supervisor Social Support}

Hammer, Kossek, Zimmermann, and Daniels (2007) depict supervisor support as a source of social support from work. Family supportive supervisors empathize with employees' desires to seek a fit between work and family responsibilities. In addition, informal supervisor support for work and family may be more important to employees' 
overall well-being than the provision of formal workplace policies and supports for family such as alternative work schedules, family-friendly interpretation of policies and dependent care supports.

Hammer et al. (2007) discussed the conceptual model of family supportive supervisor behavior, and identified four dimensions of emotional support, role modeling behaviors, instrumental support, and creative work family management. Hammer, Kossek, Yragui, Bodner, and Ginger (2009) identify social support from supervisors as a necessary resource that can assist in reducing negative effects of work and family stressors. Supervisor support as a source of social support is related to reduced levels of the employee's work-family conflict. Support from supervisors can benefit employees as a resource and according to Thomson and Prottas (1995) has been related to higher levels of positive work-family spillover. Furthermore, supervisor support has enhanced job attitudes such as job satisfaction and is negatively associated with turnover intentions (Thomson et al., 2005).

Informational support is evidenced by supervisors demonstrating how to integrate work and family through role modeling behaviors on the job. In terms of family supportive supervision, role modeling behavior refers to the extent to which supervisors offer examples of strategies and behaviors that workers believe will lead to desirable work-life outcomes. The social learning perspective postulates that the majority of human learning occurs through observation of others rather than direct experience (Bandura, 1977). Hammer et al. (2009) further suggest that cultural change will happen only when supervisors and organizational leaders reinforce work life values through what they say and $d o$. 
Indirectly related to appraisal support is the concept of creative work-family management. Work-family management involves actions that are managerially initiated to restructure work to facilitate employee effectiveness on and off the job. These behaviors include changes in time, place, and way that work is done that simultaneously balances sensitivity to employees' work family responsibilities and company, customer, and coworker needs. Some examples of work-family management include being able to think about work-family demands in terms of the total work group in order to provide structural group interventions such as cross-training within and between work departments. Hammer et al. (2007) define creative work-family management as the willingness and ability to challenge organizational assumptions that then result in the redesign of work to enhance organizational outcomes, while also facilitating employees' efforts to integrate work and family responsibilities.

Antoniou, Cooper, Chrousos, Speilberger, and Eysenck (2009) postulate that work-life training for a supervisor achieves results. Accordingly, work-life training encourages managers to be supportive of supervisors and the employees directly reporting to them. They contend that better knowledge of work-life matters can be an easy and effective way to improve the health and job satisfaction of all employees. Supervisors and employees yearn for such assistance from managers; however, with organizations streamlining or reducing their training budgets, this means that a supervisor may lack basic management skills required to support employees through work-life challenges. It is widespread in civilian work centers to provide supervisors with incentives for increasing revenue, human costs notwithstanding. Such a policy is shortsighted in terms of retention especially when it trickles down to workers with low 
level wages; many of these people struggle with their family and personal requirements (Antoniou et al., 2009).

Kossek and Hammer (2008) put emphasis on managers being taught to support the people they are supervising. According to these authors, addressing work-life issues can be a simple and effective route to enhance employee health and satisfaction. In their multi-year study of frontline workers and supervisors in American supermarkets, supervisors were found to be eager to be supportive of daily struggles. Supervisors get rewarded by organizations for success in the critical supportive role they contribute in running the organization.

Not only are support systems important, how individuals and families respond to the demands of military life are also important. Coping mechanisms learned through military experience and life experience aid in the ability to navigate a system not designed to accommodate single parents serving on active duty.

\section{Support and Stress}

The manner in which individuals and families in the military interpret and respond to demands is directly linked to their previous life experiences, intensity of military and other life stressors, availability of social supports, socio-economic status, family attributions about stressful experiences, and family/individual characteristics and coping capacities. These factors remain in a fluid, rather than static state, changing significantly over time (Bowen, 1985). Thus, coping mechanisms exhibited by individuals and families reflect a response to the critical role of the interrelationship of organizational and community expectations in the management of stress (McCubbin, 1979). Longer serving members provide newer members with coping mechanisms they 
have learned over time. Experienced personnel direct the newer members to services designed to help with serving in the armed forces and help them to "navigate the system." Cohen and McKay (1984) noted that there are a number of social support variables found in military communities and they may promote psychosocial adjustment. These variables include: neighbors that provide emotional and practical support (Goldberg, Greenberger, Hamill, \& O’Neil, 1992), strong informal support networks (Simons, Beaman, Conger, \& Chao, 1993), and supportive community services and leadership (Bowen et al., 1993). Barrera, Li, and Chassin (1993) noted that social support affects the stress of individuals and that satisfaction with social supports is associated with more responsive, sensitive parenting behavior.

The Air Force behaves as the definition of bureaucracy would predict and especially as Coser (1974) would predict a "greedy institution" would behave. As the military has evolved over the decades, social support theory provides insight as to how this institution has mitigated the more harmful aspects of bureaucracy. The Air Force has retained and recruited highly qualified and mission-ready personnel to the degree it attends to the development of rich social supports.

This literature review on the theories guiding this study offers to help better understand the scant research on the subject of military single parents. Utilizing the little research there is available on single parents in general this author hopes to bridge the gap in understanding work-life, social support, and bureaucracy as it is applied to Air Force single parents. 


\section{Need for the Study}

As stated previously in this dissertation, this population is understudied in the literature. The single parent culture in the military is virtually unknown. We do not understand how single parents manage their careers or their family obligations. Not understanding this population could lead to missed opportunities to increase their support systems, to provide classes to help them more fully integrate their work and family lives, and to educate their supervisors on how to better manage this sub-set of the military population. The current situation for single parents serving in the Air Force includes not having specific policies or practices in place to address the specific needs of this population. The Air Force does provide policy and practice guidelines for many other sub-populations serving in the military. As mentioned in previous chapters, education is provided to spouses that are waiting for the return of their active duty partners from deployment. Utilizing a phenomenological approach to this study is of particular importance because it could heighten awareness of the needs of this vulnerable population.

The central research question of this study is "what are the experiences of single parents serving on active duty in the United States Air Force as related to social support and work-life theory in the context of bureaucracy?" Addressing this central question, four specific questions were utilized to begin to understand this population, to include decisions surrounding housing situations, how their supervisors manage them, how they learned to manage work-life and the bureaucracy of the military, and challenges they have experienced. These questions were established to begin to gain insight into the experiences of this group. Much more research on this population will be needed to fully 
understand the needs and challenges currently being faced by single parents in the military.

As seen in previous chapters of this study; the research base is scant (see Eastman et al., 1990, Hammelman, 1995). The only published study done exclusively on Air Force single parents was done in 1986 by Bowen and Orthner. This study focused on formal and informal networks of single parents. This study was conducted over 25 years ago. The military has changed significantly over that time. The actual number of persons serving on active duty has decreased to less than half of the 1986 numbers. The nation is no longer fighting a "cold war" but multiple frontline battlefields. This has increased the number of deployments significantly over the past 10 years. The military is the largest employer of single parents in America (Buddin et al., 2001). Single parents make up 2.7\% of the Air Force population (Air Force Personnel Center, 2012). As noted earlier, $8 \%$ of the single parents are women. Not understanding this population could have impacts on retention as well as quality of life for the military member as well as the children being raised by active duty single parents.

\section{Purpose Statement}

The purpose of research is twofold: to describe the experiences of Air Force single parents as related to social support and work-life theory in the context of bureaucracy at an Air Force base in the western U.S, and to use that understanding to identify needed improvements in support services. In that vein, this study addressed what is known about the Air Force single parent phenomenon and how that knowledge was synthesized, as a starting point for expanding that area of research. 


\section{The Research Questions}

The questions for this study were derived out of the existing literature on single parents. The questions had been asked before in previous studies on single parents. The need is to update the answers and to connect them to single parents in the Air Force. The central question for the study is the following: What are the experiences of single parents serving on active duty in the United States Air Force as related to social support and work-life theory in the context of bureaucracy? I proposed four research focus areas that will aid in answering the central research question.

\section{Research focus 1}

1) How do single parents in the Air Force describe the circumstances under which they became single parents?

Single parents are "created" from a multitude of different scenarios. This focus allowed the researcher to understand the single parents as they have been affected by the circumstance that led to becoming a single parent. Becoming a single parent could have been a voluntary or an involuntary decision and might be earlier or later in their military career. This played a role in understanding the participants and how they accommodated their lives as single parents. This research question was addressed using the following interview questions:

Could you describe the circumstances that led you to become a single parent?

Probe: When did you start being a single parent?

Probe: What were the circumstances? Divorce, death, etc? 


\section{Research focus 2}

2) How do single parents describe the work-life challenges they experience in the Air Force?

In the preceding chapters, challenges and issues were discussed that face single parents in the civilian community as well as some literature on military single parents. There is a dearth of research on this population. Asking this population about their challenges and issues will highlight the stressors not indicated in the literature to date. The researcher asked a broad question at the beginning of the interview to allow for an all encompassing view of how the participants' life was challenged as a single parent. The following question was asked:

After becoming a single parent, what work or family challenges or issues did you experience that you had not encountered before you were a single parent?

Probe: Were some family (work) challenges easier or harder for you?

Probe: Which were easier or harder?

Probe: How did you resolve these challenges?

Probe: How did the Family Care Plan help or hinder you?

Probe: Please describe your most recent PCS as a single parent.

\section{Research focus 3}

3) How do Air Force single parents describe their experience with navigating the system?

Single parents in the civilian world as well as the military must learn to understand the world with this changed role. Challenges such as child care issues, financial issues, social support, housing, leadership/supervisor support, and a myriad of 
other issues must be dealt with upon entering this world of being a single parent. How these parents learned to negotiate this world is what this researcher finds the most exciting. Certainly some single parents are quite successful and some single parents find this more challenging. Getting an understanding of how single parents in the military accomplish negotiating the system, or not, will open new opportunities to help single parents. The following are the questions posed to the participants to answer this research question:

Of the issues you noted in the previous question, how did you resolve these challenges?

Probe: Who or what helped you?

Probe: Who helped with child care?

Probe: Did your supervisor allow for any "flex" time?

Probe: Did your co-workers give you the support that you needed?

Probe: Did your extended family help?

Probe: Did any formal military programs help you?

Probe: What is your housing situation?

Probe: Why did you choose your particular housing situation?

\section{Research focus 4}

4) What do Air Force single parents say the Air Force could do to better support them in their work-life sphere?

The Air Force has a history of providing social support to its members. Multiple agencies as well as policies supporting not just active duty members but their families are commonplace in the Air Force. The sub-population of single parents certainly benefit from these already established programs, however these programs were not designed to 
target single parents. The answer to this research question may guide the Air Force in initiating policy and program changes to benefit the single parent population. The following question and probes were utilized to reach an answer to the primary research question:

Describe a time that you felt supported as a single parent in the Air Force.

Describe a time that you felt unsupported as a single parent in the Air Force.

Probe: In what ways do you feel comfortable or uncomfortable?

Probe: What military programs have you used for support?

Probe: What things would have to change in order for you to feel comfortable with serving in the Air Force?

Probe: How do you think the Air Force could better support you as a single parent?

And, finally, is there anything you would like to add or emphasize to our discussion that I may have missed?

During the course of the interview the questions and/or the probes were changed in order to keep the interview free flowing or to capture the information needed to answer the research questions noted above. The following chapter will discuss how the data were collected and analyzed following the interviews. 


\section{Chapter 4: Methods}

There is a pressing need to start looking at and listening to the experiences of Air Force single parents. A better understanding of this population could possibly lead to improvements in policy and practice. This pressing need to understand this population is not fully addressed by this study. This researcher wants to start the dialogue to make real policy and practice changes to support this population. How can the Air Force know to make changes in policy and practice if no one asks the basic questions about the situation of single parents in their organization? The first step is to ask "What are the experiences of single parents in the Air Force as they relate to social support and work-life theory in the context of bureaucracy?" This central question was used to guide a study resulting in the identification of the thematic patterns that comprise the essential structure of single parents' lives in the Air Force as captured by their interviews. This question was most effectively addressed through a phenomenological approach (Creswell, 2007).

\section{Research Approach}

Phenomenology is a philosophy as well as a research method through which the investigator seeks to gain a deeper understanding of the lived experiences of the subjects of their study (Grbich, 2007). It is a type of qualitative research method that is focused mainly on describing, reflecting, interpreting, and engaging the subjects of the study. Phenomenology therefore entails a process of reading, reflecting, and writing which enables the researcher to "transform the lived experience into a textual expression of its essence" (Morse \& Field, 1995, p. 151). A phenomenologist tries to express a lived experience exactly as it is, without having to give causal explanations. Investigators interested in phenomenology research make the assumption that human existence is 
significant and relevant only because human beings are always conscious of something (Partis, 2003). "Existence in this world" is a phenomenological phrase which acknowledges the fact that people are embodied in their own worlds and therefore we can only understand them if we understand their world. A number of research methods can be used to conduct a phenomenological study including: in-depth interviews, participant observation, and analysis of texts (Stern, 2006). Other qualitative approaches were considered for this study, such as case study, ethnography, and grounded theory. The following is a discussion that briefly explains each approach and why it was not selected for this study.

A case study refers to the presentation of information about a participant or small group, frequently including the accounts of subjects themselves. A type of qualitative research, the case study investigates an individual or small group, drawing conclusions only about that participant or group and only in that specified context. The emphasis is placed on exploration and description (Stake, 2005). On first blush, this approach seems appropriate to use for the questions I used. However, Yin (2003) indicates six types of information to collect in order to conduct a case study. These six types are documents, archival records, interviews, direct observations, participant-observations, and physical artifacts. Direct observations and participant-observations could not be done in this study because of the environment in which the participants are working. The participants were working in a top secret work center and therefore barring entry to the researcher.

Ethnography is based almost entirely on fieldwork. The ethnographer lives among the people who are the subject of study. The researcher participates in everyday life while trying to maintain a degree of objective detachment. The researcher usually 
cultivates close relationships with participants who can provide specific information on aspects of cultural life. While detailed written notes are the mainstay of fieldwork, ethnographers may also use tape recorders, cameras, or video recorders (Creswell, 2007). Critical ethnography is most closely aligned to the population in this study. The military has marginalized this population and this researcher is attempting to advocate for this group (Thomas, 1993; Carspecken, \& Apple, 1992). The limitation associated with this approach is aligned to the previous approach: access. Entering the work centers of participants would have proved very difficult.

Grounded theory is a qualitative research approach that was originally developed by Glaser and Strauss in the 1960s. The purpose of grounded theory is to develop theory about phenomena of interest. The theory needs to be grounded or rooted in observation. This same hurdle could not be overcome because of the observation criterion as noted in the first two approaches.

Other phenomenological methods besides semi-structured interviewing were considered but determined not to address the purpose of this study. The following is a brief explanation of the decision to not employ these alternate phenomenological methods.

Focus groups are used to learn through discussion about conscious, semiconscious, and unconscious psychological and socio-cultural characteristics and processes among various groups (Basch, 1987; Lengua, Roosa, Schupak-Neuberg, Michaeles, Berg, \& Weschler, 1992). Focus group interviews are either guided or unguided discussions addressing a particular topic of interest or relevance to the group and the researcher (Edmunds, 1999). Focus groups were not utilized because of the 
distinct possibility of not being able to obtain enough participants to participate at the same time. The military population of single parents may prefer to keep their private lives as private as possible. There is also a rank issue, with lower rank individuals not wanting to express real feelings due to a fear of retribution.

Participant observation refers to the researcher being "immersed in the day-to-day lives of the people and observes and interviews the group participants." (Creswell, 2007, p. 68). Participant observation however goes a step further by allowing the researcher to be a part and parcel of the subjects' lives under investigation. The researcher lives with them and takes part in their daily routines. When using observation to collect data, the researcher must aim at providing a cautious account of the activities without overly exerting influence on the setting in which the phenomenon is being observed. The data are usually collected via a combination of field notes and audio or visual recorders. Field notes are particularly important in collecting non-verbal communication which may be difficult to capture using audio recorders. Audio and video recordings facilitate the analysis of the data collected later and allow external researchers to analyze data. However in phenomenological research, the use of external researchers in a data analysis is limited. This is because "the main objective of phenomenological research is to describe a lived experience" (Mackey \& Gass, 2005, p. 139). As such, researchers who did not take part in the actual data collection may not be in a position to explain phenomenon under investigation exactly as it is. The meanings of the phenomenon can only be understood by the researcher having a deep interaction with the subjects.

Participant observation was not selected because the logistics of observing military personnel accomplishing their missions would prove difficult. Not all single 
parents work in the same work center or even work the same hours. Observation may create the problem of "observer's paradox." This is a situation in which those being observed may fail to behave normally once they recognize the presence of the observer. On the same note, it may create the Hawthorne effect in which the persons under investigation behave differently than they normally do, due to the presence of the observer (Ary et al., 2009).

Document analysis is a research method that uses written documents or other artifacts to gain insight into the phenomenon under investigation. Documents may include written, physical and visual materials. They may also be personal such as diaries, letters, and autobiographies, or official such as memos, reports, and films among others. Besides the written documents, other types of documents can also be used including photographs, audiotapes, and videotapes. A researcher can use documents that already exist or alternatively may ask the participants to create the documents themselves. In phenomenological research, personal documents are best used to achieve the objective of the research: that is, to gain a deeper understanding of the participants of the investigation. Participants can be asked to create journals or diaries, write letters, or make videos which capture their experiences about a particular issue. A primary document is one that is written or prepared by a person who had a firsthand encounter with the problem under investigation. A secondary document is prepared by a person who may have heard about the issue under investigation (Bernard, 2006).

Documents are susceptible to bias and distortion especially if they are secondary documents. Documents may not have originally been created for research purposes and therefore they may have incomplete or unrepresentative information. It is therefore 
imperative for the researcher to determine the originality of the documents used in the research process (Bernard, 2006). Utilizing official memos from the Air Force concerning single parents did not seem appropriate for this study. The purpose of this study is to capture how the single parent experiences serving on active duty. Official memos would only recount the official stance of the Air Force, thereby not capturing the essence of this population.

Although there are many methods that can be used in a phenomenological approach, semi-structured interviews were the chosen vehicle. A semi-structured interview is flexible, allowing new questions to be brought up during the interview, as the interview can take on new dimensions depending on the interviewee. The specific topic or topics that the interviewer wants to explore during the interview are developed well in advance based on a thorough literature search on the topic being researched. An interview guide is prepared, which is an informal grouping of topics and questions that the interviewer can ask in different ways for different participants. Interview guides help researchers to focus an interview on the topics at hand without constraining them to a particular format. This freedom can help interviewers to tailor their questions to the interview context/situation, and to the people they are interviewing (Lindlof \& Taylor, 2002).

An interview is a personal conversation between the researcher and the respondent. In-depth interviews are used in gathering data about participants' opinions, feelings, ideas, and beliefs about the problem under investigation. They are used to aid the understanding of the experiences of people as well as the meanings they attach to the experiences instead of testing hypotheses. This means that a researcher using an in-depth 
interview is in a better position to gain a deeper understanding of the context of a participant's behavior. In-depth phenomenological interviews can either be semistructured or unstructured but not structured (Moustakas, 1994).

A semi-structured interview is one in which the researcher determines the area of interest and formulates questions which will aid data collection (Grbich, 2007). However, the interviewer has the flexibility of adjusting the questions or format based on the direction which the interview is taking. An unstructured interview on the other hand is unplanned. The researcher neither premeditates nor prepares any questions. Thus the questions asked depend on the setting and the responses given by the participants. All in all, in-depth interviews use open-ended questions which provide the respondents with the opportunity to give detailed responses. Open-ended questions also enable the researcher to probe further or clarify vague responses (Ary, Jacobs, Razavieh, \& Sorensen, 2009). In phenomenological research studies, the use of in-depth interviews enables the researcher to gain a deeper understanding of the phenomenon under investigation as well as the worldview of the participants.

In-depth interviews enable the researcher to collect huge volumes of data in a short time span. In-depth interviews also provide the researcher with deeper insight into the respondents' perspectives, the meanings they attach to their social world, information about the setting, and information about unexpected issues (Reimen, 1986). In-depth interviews also enable the researcher to follow up on the respondents immediately and to clarify any vague responses, an element which is lacking in other research methods such as mailed questionnaires (Moustakas, 1994). 


\section{Criteria for Selecting Participants}

Interviewing participants is a common and accepted method of data gathering method in qualitative research. For optimal interviews, participants were selected according to general criteria including (a) having had a personal experience of the topic of research; (b) sufficient communication skills to describe the relevant experience in detail; (c) openness and lack of defensiveness; and (d) an interest in participating (Terre Blanche, Durrheim, \& Painter, 2006; Sobh \& Perry, 2005). In this study in order to select participants with the relevant experience Air Force single parents who were interviewed met the following criteria: (a) on active duty, (b) have at least one child under the age of eighteen living in the home, (c) no other adult living in the home, (d) participant can be male or female, (e) enlisted or officer, and (f) must have been a single parent for at least two years.

These criteria have been adapted from official Air Force single parent criteria which states that active duty personnel who are unmarried with minor children listed on their orders will be considered single parents and will accomplish a Family Care Plan (Air Force Personnel Center, 2010). Interviewing only active duty single parents was crucial to this study. Active duty personnel experience military life much differently from their Guard or Reserve counterparts. Active duty personnel serve full-time in the military. Their Guard or Reserve counterparts typically serve only one weekend a month and two weeks during the summer. Active duty single parents will typically live farther away from extended family, and so may have less help with their family obligations. Guard and Reserve personnel typically serve in their hometowns or nearby. This allows them access to their extended family for family support. 
Participants with adult children were excluded because they could legally offer support for younger children or take care of themselves in the extended absences of their parent. If another person, such as the military member's mother, sibling, or a partner were available, this would not provide for the understanding of what it is like to be the sole decision maker in the household, as all parents with another adult in the home were excluded.

Interviews with male and female single parents were important because of the different views of being a single parent held by men and women. Enlisted and officer single parents offered a different perspective as well because of their differing economic and social status. Officers typically make more money than enlisted personnel and enjoy a privileged social status.

Ensuring that participants had the experience of being a single parent for at least two years was also important. This allowed the participants to be fully engaged in navigating the military system as a single parent. The time requirement may have also allowed the single parents to have experienced some issues or challenges with their single parent status.

\section{Participant Recruitment and Sampling Strategy}

Participants were recruited first through criterion then convenience sampling and finally through snowballing. The stratified purposive sample recruited illustrated subgroups and facilitates comparisons.

\section{Purposive sampling}

All participants met a list of criteria in order to insure that the diversity of the population is represented and to gain a broad understanding of the phenomenon of single 
parents serving in the Air Force. Participants were screened to insure that they were: currently serving on active duty, had at least one child under the age of eighteen living in their home, had been a single parent for at least two years, and had no other adult living in the home.

\section{Recruitment Method}

The outpatient clinics (pediatrics and family medicine) at a federal hospital at an Air Force Base in the Western United States that this researcher had access to were utilized as the primary organizations for purposive sampling. There are approximately 44,800 empanelled patients at this hospital with over 310,000 outpatient visits last year. Of the total patients, over 8,500 are pediatric patients with over 25,000 pediatric outpatient visits last year. It is unknown how many of these pediatric patients have single parents. Recruitment flyers were distributed to potential participants during their children's appointments. These same flyers were also distributed through informal networks such as the single parents' group, Chaplain's office, base child care facilities, first sergeant's group, and youth programs. When potential participants contacted the researcher, they were screened to ensure they met sample inclusion and demographic profiles. An interview was then arranged at a place designated by the participant.

\section{Recruitment through snowball sampling}

The snowball sample method was also utilized for recruitment. Participants recruited through the previous method were asked to nominate other single parents in the Air Force that met the sampling criteria and who might like to participate. The participants were asked to give permission to use their names as part of the recruitment process, and some did; others took recruitment flyers to give to other single parents. 


\section{Participants}

Data were collected through in-depth interviews with thirteen participants. Participants were since they met the general criteria for the study as determined by the the screening questions included in Appendix A. According to Terre Blanche et al., 2006 and Sobh and Perry, 2005) the participants should also have the following characteristics: (a) having had a personal experience of the topic of research; (b) having sufficient communication skills to describe the relevant experience in detail; (c) openness and lack of defensiveness; and (d) an interest in participating Only active duty single parents meeting study criteria were used as participants; five males (38.4\%) and eight females (61.6\%) participated. Eight participants (61.6\%) declared White as their racial/ethnic group; three (23\%) declared Hispanic as their ethnic group and $2(15.4 \%)$ declared Black as their racial/ethnic group.

The mean age of the participants was 36 years old; the oldest was 45 years old while the youngest participant was only 26 years old. In terms of the number of years being a single parent, younger participants indicated that they were single for 2 to 6 years while older participants reported being single for 9 to 17 years. Table 2 presents a detailed demographic profile of the participants.

As a comparison to the study participants, Table 3 gives an approximation of single parents serving at the study location. The Air Force distinguishes "single parents" as anyone who has dependents under the age of eighteen and is not married. The projected numbers at the study location were calculated by finding the total number of single parents as identified by the Air Force in each subgroup and applying the percentage to the base at which this study took place. The Air Force has approximately 
8,800 single parents, accounting for $2.7 \%$ of the population. The study location has approximately 7,000 personnel assigned. This indicates the possibility of 189 single parents serving at this location. The Air Force does not break down single parents in terms of ethnicity, the number of children, or how long they have been a single parent. It does provide a breakdown by gender and rank (officer versus enlisted). Of the Air Force personnel in the national sample, single parents comprised $8.8 \%$ of enlisted females, $4.5 \%$ of officer females, $1.6 \%$ of enlisted males, and $0.78 \%$ of officer males (Air Force Personnel Center, 2012). These numbers are comparable to those recently reported in a statistical portrait of households in the United States; $7.2 \%$ of all households are headed by single women while $2.4 \%$ are headed by single men (U.S. Census Bureau, 2012).

The percentages of study participants in the current research sample based on rank and gender were: $38.5 \%$ enlisted females, $23.1 \%$ officer females, $15.3 \%$ enlisted males, and $23.1 \%$ officer males. 
Table 2

Demographic Characteristics of Study Participants

\begin{tabular}{|c|c|c|c|c|c|c|c|}
\hline $\begin{array}{l}\text { Participant } \\
\text { Code }\end{array}$ & Rank & Gender & Ethnicity & $\begin{array}{l}\text { Participant } \\
\text { Age } \\
\text { Range }\end{array}$ & $\begin{array}{l}\text { No. Of } \\
\text { Children }\end{array}$ & $\begin{array}{l}\text { Age of } \\
\text { Children }\end{array}$ & $\begin{array}{l}\text { Years } \\
\text { Being } \\
\text { Single }\end{array}$ \\
\hline 1 & Enlisted & Female & Hispanic & $18-29$ & 1 & 6 & $0-5$ \\
\hline 2 & Officer & Female & White & $40-49$ & 1 & 17 & $11-17$ \\
\hline 3 & Enlisted & Female & Black & $30-39$ & 1 & 12 & $11-17$ \\
\hline 4 & Enlisted & Male & White & $30-39$ & 3 & $11-14$ & $6-10$ \\
\hline 5 & Enlisted & Female & Hispanic & $18-29$ & 1 & 3 & $0-5$ \\
\hline 6 & Officer & Female & White & $40-49$ & 4 & $3-14$ & $6-10$ \\
\hline 7 & Officer & Male & White & $30-39$ & 1 & 11 & $0-5$ \\
\hline 8 & Officer & Female & White & $30-39$ & 2 & $5-7$ & $0-5$ \\
\hline 9 & Officer & Male & Hispanic & $40-49$ & 2 & $15-17$ & $0-5$ \\
\hline 10 & Officer & Male & White & $40-49$ & 1 & 10 & $11-17$ \\
\hline 11 & Enlisted & Male & White & $30-39$ & 1 & 3 & $0-5$ \\
\hline 12 & Enlisted & Female & White & $30-39$ & 2 & $8-11$ & $0-5$ \\
\hline 13 & Enlisted & Female & Black & $30-39$ & 1 & 10 & $11-17$ \\
\hline
\end{tabular}


Table 3

Projected Air Force Single Parents at Study Location

\begin{tabular}{llc}
\hline Rank & Gender & $\begin{array}{r}\text { Calculated number } \\
\text { of single parents }\end{array}$ \\
\hline Officer & Male & 8.6 \\
& Female & 11.5 \\
Enlisted & Male & 73.9 \\
& Female & 95.0 \\
Total & & 189 \\
\hline Note. Numbers based on percentages from current statistics at Air Force levels for each
\end{tabular}

Note. Numbers based on percentages from current statistics at Air Force levels for each subgroup (Air Force Personnel Center, 2012)

Procedure

Each participant completed a face to face interview that lasted from 45-90 minutes. The researcher asked participants where they would like to be interviewed: the researcher's office, the participant's home, or the participant's work center. All participants chose to be interviewed at the researcher's office. The researcher first read the informed consent form aloud and asked the participant to sign prior to beginning the interview. Two consent forms were signed, one kept by the participant and one kept by the researcher (See Appendix D for the informed consent form). The participants were informed about mandatory reporting procedures in the consent form, prior to the interview. After securing informed consent, the interview proceeded. At the conclusion of the interview, a written list of resources that could have been utilized to cope with any uncomfortable feelings invoked during the process was given to all participants. The 
resources included numbers for military One Source, the Life Skills Support Clinic, and the Airman and Family Readiness Center. All of these agencies provide a variety of support services that are offered to all military members. The interview was concluded with an expression of the author's appreciation for their participation, and interviewees were given the contact sheet with resources. Participants were asked if they would be willing to be contacted in the future to participate in member checking, and several members agreed. Member checking was utilized to ensure the researcher captured what the participants were conveying during the interview. All participants were asked to grant their permission to contact them if the researcher had more questions. A \$20 gift card incentive was given to the participant at the conclusion of the interview. Finally they were asked whether they knew anyone meeting the criteria who would like to participate in the study.

\section{Data Collection}

Individual face to face interviews provided the data for this study. At the beginning of each interview, demographic items were asked of each participant, such as age, gender, ethnic background, number of years as a single parent, job type, number of children, rank, time in military, deployment status, ever moved as a single parent, what support programs they have utilized, and whether they live at on-base or off-base housing. (See Appendix B for the interview instrument and Appendix C for supplemental questions).

In-depth, semi-structured interviews were the only source of data for this qualitative study. In order for the participants to be comfortable, the following items were accomplished: the interviewee was invited to choose the time and place (options 
included, the researcher's work center, their work center, or their home) of the interview and they were told before the interview approximately how long the interview would last. If the interview took place in the participant's home, another adult accompanied the researcher to provide child care for the child(ren) if requested by the participant.

The interview schedule guided the process. Field notes, analytic memos as well as "my own lens" notes were taken during the interview. Field notes were taken to document any non-verbal and contextual information not captured by the transcripts. Field notes enabled the researcher to collect her own intuitions, impressions, and emerging questions (Grbich, 2007). Field notes are particularly important in collecting non-verbal communication which may be difficult to capture using audio recorders.

Analytic memos were utilized to make note of any emerging themes that might have been identified during the interview process. "My own lens" notes journaled my thoughts and feelings that occurred during the interview. Attempts were made to not pressure the participants to stay on topic and they were encouraged to share any experiences they brought to the interview. If a participant appeared to not understand the question, the question was re-worded for the participant.

All interviews were audio-taped and transcribed by a paid transcriber, who also signed a confidentiality form. The researcher read over the transcripts and then listened along with reading the transcripts to take notes, and made any needed corrections in the transcripts. This allowed the researcher to "go back to" the interview to capture the essence of the interview, and permitted the researcher to put herself back into the interview to listen for and detect verbal cues to the emotions being displayed. The 
consent forms, tapes, transcripts and notes were kept in a locked filing cabinet at the researcher's office.

Analysis began after obtaining four transcribed interviews. A peer consultant also began his coding checks at this time. After this analysis and feedback from the second coder, any adjustments to questions or probes were made and documented in the analytical memo being utilized during this process. This occurred after every three interviews.

A peer consultant was needed to ensure we were hearing the same themes. The consultant is a PhD student in sociology at the University of Nevada Las Vegas. He is trained in phenomenology and qualitative research methods. The consultant does not have any in-depth knowledge of military life. He was utilized to code raw data and to find any "conversations" that are not clear to a non-military person.

\section{Data Analysis Procedure}

The purpose of this study was twofold: (1) to describe the experiences of Air Force single parents as related to social support and work-life theory in the context of bureaucracy at an Air Force base in the western U.S., and (2) to use that understanding to identify needed improvements in support services. The aim was to gain a better understanding of how single parents experience life in the military from their own perspective. The overarching research question that was addressed is: What are the experiences of single parents serving on active duty in the United States Air Force as related to social support and work-life theory in the context of bureaucracy?

Five sub questions were examined to further explore the experiences of single parents serving in the United States Air Force: (1) How do single parents in the Air Force 
describe the circumstances under which they became single parents? (2) How do single parents describe the work-life challenges they experience in the Air Force? (3) How do Air Force single parents describe their experiences with navigating the system? (4) What do Air Force single parents say the Air Force could do to better support them in their work-life sphere? and (5) How could the Air Force better serve single parents in balancing work and parenting?

These questions were examined using interpretive phenomenological analysis (IPA) as outlined by Smith, Flowers, and Larkin (2009). The essence of IPA lies in its analytic focus, which is directed toward the participants' attempts to make sense of their experience. The shared aspect of all phenomenological approaches to research is that it seeks to understand empirical matters from the perspective of those being studied (Creswell, 2007; Moustakas, 1994; Reimen, 1986).

In order to show how this analysis was utilized, four steps are outlined below in the response to one question answered by all the participants; "Can you describe the circumstances that led you to become a single parent?"

\section{Step 1: Reading and re-reading}

After collecting all the interviews and having each transcribed, the transcripts were re-read while listening to the audio tape of the interview. This first step is to ensure the participant is the focus of the data. This allowed for immersion in the original data. This facilitated ensuring the transcripts were correct and allows for the overall interview structure to develop. The overall interview structure helps the researcher understand how narratives can bind sections together. For example, within chronological narratives there may be shifting between a generic explanation to specific life event. 


\section{Step 2: Initial noting}

This level of analysis is time consuming and more detailed. Language is evaluated on the most exploratory level. This allows for more familiarity with the transcript. Note taking directly on the transcript took place during this step of analysis. Some areas of the interview were richer than others, thereby more comments were made.

Table 4 shows an example of this process from the initial question of the interview, addressing how they became a single parent in the military. This shows how exploratory commenting was conducted. This initial noting was done through the lens of bureaucracy as it pertains to becoming a single parent in the Air Force.

Table 4

Initial Comments

\begin{tabular}{|l|l|l|}
\hline P & Original Transcript & Exploratory Comments \\
\hline 1 & $\begin{array}{l}\text { I was seventeen when I got pregnant, and I was } \\
\text { eighteen when she was born, and when we } \\
\text { decided to try to fix it, the relationship with the } \\
\text { father try to work it out (me and her Dad), we just } \\
\text { couldn't. He wanted to buy his nice things so I... } \\
\text { moved in [with] my Aunt and Uncle, [who] were } \\
\text { in the military so they are the ones who gave me } \\
\text { the idea to get in and finish high school and get a } \\
\text { degree and then have a career for me and then } \\
\text { give her a chance to do it too. }\end{array}$ & $\begin{array}{l}\text { Gave up custody due to } \\
\text { military policy } \\
\text { Wanted more in life }\end{array}$ \\
\hline 2 & $\begin{array}{l}\text { I was actually engaged when I got pregnant and } \\
\text { then he deployed and decided that he didn't really } \\
\text { want to get married after all. Because I was } \\
\text { already in the reserves so that was waivered since } \\
\text { I was already in the military, I didn't have to give } \\
\text { up custody or anything to continue in the Air } \\
\text { Force...so that was a nice thing. }\end{array}$ & $\begin{array}{l}\text { Was engaged however, never } \\
\text { married to partner } \\
\text { Reservist, no need to give up } \\
\text { custody }\end{array}$ \\
\hline 3 & $\begin{array}{l}\text { My boyfriend at the time was living...in } \\
\text { Pennsylvania... so we were together... I found } \\
\text { out I was pregnant. I didn't want to get married } \\
\text { because I knew I was going to get out of school, } \\
\text { graduate early and I wanted to try school out with }\end{array}$ & $\begin{array}{l}\text { Young } \\
\text { relationship } \\
\text { Pregnant during high school } \\
\text { Tried college }\end{array}$ \\
\hline
\end{tabular}




\begin{tabular}{|c|c|c|}
\hline & $\begin{array}{l}\text { working and see how that goes like maybe a year. } \\
\text { Then at the last minute I decided to go with the } \\
\text { Air Force; because the recruiter, he was very } \\
\text { patient he went through exactly all the process as } \\
\text { a single parent ... not being married, so that } \\
\text { seemed like the best option for me.... so what I did } \\
\text { was give my mom temporary custody because we } \\
\text { weren't married and he wasn't living in the same } \\
\text { state I was. They told me that my mom would } \\
\text { have to have full custody of her and she would } \\
\text { have to keep her my whole enlistment or I would } \\
\text { have to get out on administrative discharge, so } \\
\text { during my first enlistment I ended up having to go } \\
\text { back home to give my mom full custody of my } \\
\text { daughter. }\end{array}$ & Custody issues \\
\hline 4 & $\begin{array}{l}\text { I married young, almost immediately joining the } \\
\text { military... She was left alone, abandoned with a } \\
\text { child, so I came in and sort of did the super hero } \\
\text { thing, rescued her, married her, adopted our } \\
\text { daughter. Shortly thereafter we had two other kids } \\
\text { and then about three years into our marriage she } \\
\text { said she needed a divorce. }\end{array}$ & $\begin{array}{l}\text { Young } \\
\text { Wanted more out of life } \\
\text { Divorce }\end{array}$ \\
\hline 5 & $\begin{array}{l}\text { I think the stress of that deploying and the } \\
\text { multiple TDY's you know him having to do the } \\
\text { single parenting, the stress of me having to do the } \\
\text { single parenting when he had been deployed or } \\
\text { TDY'd, just caused our marriage to dissolve. We } \\
\text { did child custody in a different state. Because of } \\
\text { our divorce decree we ended up doing it a } \\
\text { different state and it was challenging because we } \\
\text { had split custody, I guess you call it shared } \\
\text { parenting. Just a lot of stress just having to be the } \\
\text { person that takes care of the kids, hold down a full } \\
\text { time job, and try to go to school the same time, } \\
\text { horribly stressful. Yes, kind of raised our kids and } \\
\text { did the reserves and had the civilian job and went } \\
\text { to school and then came back on active duty, and } \\
\text { the first three years of my active duty we had a } \\
\text { deployment. }\end{array}$ & $\begin{array}{l}\text { Military stressors; effect on } \\
\text { the marriage } \\
\text { Reserve to active duty } \\
\text { Deployments } \\
\text { Divorce }\end{array}$ \\
\hline 6 & $\begin{array}{l}\text { I broke up with my son's dad. We weren't married } \\
\text { we were just living together. This was my second } \\
\text { marriage and I had been on active duty. I married } \\
\text { the first time young but that was a mistake. I had } \\
\text { the twins and my son with him. I was hoping this } \\
\text { second relationship would last, he was pretty }\end{array}$ & $\begin{array}{l}\text { Young } \\
\text { Didn't marry partner } \\
\text { Already on active duty when } \\
\text { became single parent }\end{array}$ \\
\hline
\end{tabular}




\begin{tabular}{|c|c|c|}
\hline & helpful with all the kids, but now I'm on my own. & \\
\hline 7 & $\begin{array}{l}\text { It was a divorce. Problems leading up to that... } \\
\text { prior assignment. Got here, no real reconciliation } \\
\text { possible. So within a couple months of being here } \\
\text { we started a separation process. We decided it was } \\
\text { better for our daughter to stay with me. Even } \\
\text { though we had been here four months or so, she } \\
\text { was in a good school, good friends, good } \\
\text { programs and also the uncertainty of where my ex } \\
\text { was going to be going, what she'd be doing. We } \\
\text { felt like it was the best place for my daughter at } \\
\text { least initially was here. After that she was already } \\
\text { rooted at that point, as far as you could be rooted, } \\
\text { as far as being a military child, but just to keep the } \\
\text { consistency. }\end{array}$ & $\begin{array}{l}\text { Divorce } \\
\text { Marital stressors } \\
\text { One child } \\
\text { Stayed with dad on active } \\
\text { duty }\end{array}$ \\
\hline 8 & $\begin{array}{l}\text { My boss reviewed my child's medical record } \\
\text { without my permission, and led to me getting sent } \\
\text { to that base anyways. I think that led what would } \\
\text { have been normal marital dysfunction problems to } \\
\text { become explosive because it was deemed that I } \\
\text { wasn't fighting for our family, I wasn't standing } \\
\text { up for our family, the injustice, blah, blah, blah, } \\
\text { blah, blah. It exploded with an abuse situation that } \\
\text { led to family action. I was divorced with two } \\
\text { children, one special needs and I had to move to } \\
\text { another base. }\end{array}$ & $\begin{array}{l}\text { Child with special needs } \\
\text { Moved to another base } \\
\text { capable of taking care of } \\
\text { medical needs } \\
\text { Domestic violence } \\
\text { Divorce }\end{array}$ \\
\hline 9 & $\begin{array}{l}\text { My ex-wife, she got into financial problems, she } \\
\text { has four kids. So she was separated from her } \\
\text { husband, which it can really cause some hardship. } \\
\text { So she told me I could take my daughters, (she } \\
\text { has four), my two daughters, if I could. So before } \\
\text { I even came over here I already knew that was } \\
\text { happening, that they were coming to live with me } \\
\text { in at my current base. So this whole time I wasn't } \\
\text { with them, but I knew coming to live at my } \\
\text { current location that they was coming to live with } \\
\text { me...one was starting junior high school and the } \\
\text { other high school. }\end{array}$ & $\begin{array}{l}\text { Civilian mom had custody } \\
\text { but could not afford to raise } \\
\text { children } \\
\text { Was married to mom prior }\end{array}$ \\
\hline 10 & $\begin{array}{l}\text { My wife passed away five years ago from breast } \\
\text { cancer. I could not be there for my daughter, I was } \\
\text { blinded by grief. It all seemed so overwhelming. I } \\
\text { didn't think about my career as a pilot, my } \\
\text { daughter, just me... it seems so selfish now. }\end{array}$ & $\begin{array}{l}\text { Widower } \\
\text { One child } \\
\text { Pilot }\end{array}$ \\
\hline
\end{tabular}




\begin{tabular}{|l|l|l|}
\hline 11 & $\begin{array}{l}\text { My girlfriend got pregnant right after we started } \\
\text { dating, we didn't get married and her job deployed } \\
\text { a lot. She didn't want to be a mom. I just took } \\
\text { over childcare and now I do it full time. }\end{array}$ & $\begin{array}{l}\text { Young } \\
\text { Never married } \\
\text { Mom wasn't ready to be a } \\
\text { mom } \\
\text { Single dad } \\
\text { Already in military }\end{array}$ \\
\hline 12 & $\begin{array}{l}\text { I divorced before I even joined the Air Force. My } \\
\text { kids were like 4 and 7, I think. I wanted a better } \\
\text { life for my kids. I kept getting laid off or let go } \\
\text { because of the economy. I needed health benefits } \\
\text { and a steady paycheck. The Air Force offered all } \\
\text { that. I signed over custody of my kids to my mom } \\
\text { while I went to basic and tech school. I regained } \\
\text { custody when I arrived here. I did wait until I had } \\
\text { a base house to move into. }\end{array}$ & $\begin{array}{l}\text { Wanted more for kids } \\
\text { jave up custody of kids to } \\
\text { join }\end{array}$ \\
\hline 13 & $\begin{array}{l}\text { I got pregnant with my then boyfriend. It never } \\
\text { really worked out for us, and we were way too } \\
\text { young. I tried to make it on my own but it was } \\
\text { really difficult. I decided to join the Air Force so } \\
\text { I could better take care of my son. }\end{array}$ & $\begin{array}{l}\text { Never married } \\
\text { Young } \\
\text { Better life } \\
\text { Harder as a civilian } \\
\text { Custody issues? }\end{array}$ \\
\hline
\end{tabular}

\section{Step 3: Developing emerging themes}

As the analysis progresses through the exploratory comments in developing emerging themes, the data set grows substantially. The emphasis shifts to working with the exploratory comments from the transcripts. The transcripts remain extremely important but moving to the exploratory comments helped the process of identifying and thereby developing the emerging themes. Table 5 gives an example utilizing the aforementioned transcripts. 
Table 5

Developing Emergent Themes

\begin{tabular}{|c|c|c|c|}
\hline Emergent Themes & $\mathbf{P}$ & Original Transcript & $\begin{array}{l}\text { Exploratory } \\
\text { comments }\end{array}$ \\
\hline $\begin{array}{l}\text { Pregnant at early age } \\
\text { Gave up custody due } \\
\text { to bureaucracy } \\
\text { Wanted a better life }\end{array}$ & 1 & $\begin{array}{l}\text { I was seventeen when I got } \\
\text { pregnant, and I was eighteen } \\
\text { when she was born, and when we } \\
\text { decided to try to fix it, the } \\
\text { relationship with the father try to } \\
\text { work it out (me and her Dad), we } \\
\text { just couldn't. He wanted to buy } \\
\text { his nice things so I... moved in } \\
\text { [with] my Aunt and Uncle, [who] } \\
\text { were in the military so they are } \\
\text { the ones who gave me the idea to } \\
\text { get in and finish high school and } \\
\text { get a degree and then have a } \\
\text { career for me and then give her a } \\
\text { chance to do it too. }\end{array}$ & $\begin{array}{l}\text { Young } \\
\text { Gave up custody } \\
\text { Wanted more in life }\end{array}$ \\
\hline Pregnant at early age & 2 & $\begin{array}{l}\text { I was actually engaged when I got } \\
\text { pregnant and then he deployed } \\
\text { and decided that he didn't really } \\
\text { want to get married after all. } \\
\text { Because I was already in the } \\
\text { reserves, so that was waivered } \\
\text { since I was already in the } \\
\text { military, I didn't have to give up } \\
\text { custody or anything to continue in } \\
\text { the Air Force... so that was a nice } \\
\text { thing. }\end{array}$ & $\begin{array}{l}\text { Never married to } \\
\text { partner } \\
\text { Father also active } \\
\text { duty } \\
\text { Reservist, no need to } \\
\text { give up custody }\end{array}$ \\
\hline $\begin{array}{l}\text { Pregnant at early age } \\
\text { Seeking for job } \\
\text { opportunity } \\
\text { Gave up custody due } \\
\text { to bureaucracy } \\
\text { Wanted a better life }\end{array}$ & 3 & $\begin{array}{l}\text { My boyfriend at the time was } \\
\text { living...in Pennsylvania... so we } \\
\text { were together... I found out I was } \\
\text { pregnant. I didn't want to get } \\
\text { married because I knew I was } \\
\text { going to get out of school, } \\
\text { graduate early and I wanted to try } \\
\text { school out with working and see } \\
\text { how that goes like maybe a year. } \\
\text { Then at the last minute I decided } \\
\text { to go with the Air Force; because } \\
\text { the recruiter, he was very patient } \\
\text { he went through exactly all the }\end{array}$ & $\begin{array}{l}\text { Young } \\
\text { Indecision about to } \\
\text { commit to } \\
\text { relationship } \\
\text { Pregnant during high } \\
\text { school } \\
\text { Tried college }\end{array}$ \\
\hline
\end{tabular}




\begin{tabular}{|c|c|c|c|}
\hline & & $\begin{array}{l}\text { process as a single parent ... not } \\
\text { being married, so that seemed like } \\
\text { the best option for me.... so what I } \\
\text { did was give my mom temporary } \\
\text { custody because we weren't } \\
\text { married and he wasn't living in } \\
\text { the same state I was. They told } \\
\text { me that my mom would have to } \\
\text { have full custody of her and she } \\
\text { would have to keep her my whole } \\
\text { enlistment or I would have to get } \\
\text { out on administrative discharge, } \\
\text { so during my first enlistment I } \\
\text { ended up having to go back home } \\
\text { to give my mom full custody of } \\
\text { my daughter. }\end{array}$ & \\
\hline $\begin{array}{l}\text { Married at an early } \\
\text { age } \\
\text { Better life } \\
\text { Divorce }\end{array}$ & 4 & $\begin{array}{l}\text { I married young, almost } \\
\text { immediately joining the } \\
\text { military... She was left alone, } \\
\text { abandoned with a child, so I came } \\
\text { in and sort of did the super hero } \\
\text { thing, rescued her, married her, } \\
\text { adopted our daughter. Shortly } \\
\text { thereafter we had two other kids } \\
\text { and then about three years into } \\
\text { our marriage she said she needed } \\
\text { a divorce. }\end{array}$ & $\begin{array}{l}\text { Young } \\
\text { Wanted more out of } \\
\text { life } \\
\text { Divorce }\end{array}$ \\
\hline Individual career & 5 & $\begin{array}{l}\text { I think the stress of that deploying } \\
\text { and the multiple TDY's, you } \\
\text { know him having to do the single } \\
\text { parenting, the stress of me having } \\
\text { to do the single parenting when } \\
\text { he had been deployed or TDY'd, } \\
\text { just caused our marriage to } \\
\text { dissolve. We did child custody in } \\
\text { a different state. Because of our } \\
\text { divorce decree we ended up doing } \\
\text { it a different state and it was } \\
\text { challenging because we had split } \\
\text { custody, I guess you call it shared } \\
\text { parenting. Just a lot of stress, just } \\
\text { having to be the person that takes } \\
\text { care of the kids, hold down a full } \\
\text { time job, and try to go to school } \\
\text { the same time, horribly stressful. }\end{array}$ & $\begin{array}{l}\text { Military stressors } \\
\text { effect on the marriage } \\
\text { Reserve to active } \\
\text { duty } \\
\text { Deployments } \\
\text { Divorce }\end{array}$ \\
\hline
\end{tabular}




\begin{tabular}{|c|c|c|c|}
\hline & & $\begin{array}{l}\text { Yes, kind of raised our kids and } \\
\text { did the reserves and had the } \\
\text { civilian job and went to school } \\
\text { and then came back on active } \\
\text { duty, and the first three years of } \\
\text { my active duty we had a } \\
\text { deployment. }\end{array}$ & \\
\hline Pregnant at early age & 6 & $\begin{array}{l}\text { I broke up with my son's dad. We } \\
\text { weren't married we were just } \\
\text { living together. This was my } \\
\text { second marriage and I had been } \\
\text { on active duty. I married the first } \\
\text { time young, but that was a } \\
\text { mistake. I had the twins and my } \\
\text { son with him. I was hoping this } \\
\text { second relationship would last, he } \\
\text { was pretty helpful with all the } \\
\text { kids, but now I'm on my own. }\end{array}$ & $\begin{array}{l}\text { Young } \\
\text { Didn't marry partner } \\
\text { Already on active } \\
\text { duty }\end{array}$ \\
\hline $\begin{array}{l}\text { Prioritize career that } \\
\text { led to marital } \\
\text { dysfunction }\end{array}$ & 7 & $\begin{array}{l}\text { It was a divorce. Problems } \\
\text { leading up to that prior } \\
\text { assignment. Got here, no real } \\
\text { reconciliation possible. So within } \\
\text { a couple months of being here we } \\
\text { started a separation process. We } \\
\text { decided it was better for our } \\
\text { daughter to stay with me. Even } \\
\text { though we had been here four } \\
\text { months or so, she was in a good } \\
\text { school, good friends, good } \\
\text { programs and also the uncertainty } \\
\text { of where my ex was going to be } \\
\text { going, what she'd be doing. We } \\
\text { felt like it was the best place for } \\
\text { my daughter at least initially was } \\
\text { here. After that she was already } \\
\text { rooted at that point, as far as you } \\
\text { could be rooted, as far as being a } \\
\text { military child, but just to keep the } \\
\text { consistency. }\end{array}$ & $\begin{array}{l}\text { Divorce } \\
\text { Marital stressors } \\
\text { One child } \\
\text { Stayed with dad on } \\
\text { active duty }\end{array}$ \\
\hline $\begin{array}{l}\text { Prioritize career that } \\
\text { led to marital } \\
\text { dysfunction }\end{array}$ & 8 & $\begin{array}{l}\text { My boss reviewed my child's } \\
\text { medical record without my } \\
\text { permission, and led to me getting } \\
\text { sent to that base anyways. I think } \\
\text { that led what would have been } \\
\text { normal marital dysfunction }\end{array}$ & $\begin{array}{l}\text { Child with special } \\
\text { needs } \\
\text { Moved to another } \\
\text { base capable of } \\
\text { taking care of } \\
\text { medical needs } \\
\end{array}$ \\
\hline
\end{tabular}




\begin{tabular}{|c|c|c|c|}
\hline & & $\begin{array}{l}\text { problems to become explosive } \\
\text { because it was deemed that I } \\
\text { wasn't fighting for our family, I } \\
\text { wasn't standing up for our family, } \\
\text { the injustice, blah, blah, blah, } \\
\text { blah, blah. It exploded with an } \\
\text { abuse situation that led to family } \\
\text { action. I was divorced with two } \\
\text { children, one special needs and I } \\
\text { had to move to another base. }\end{array}$ & Domestic violence \\
\hline Financial problems & 9 & $\begin{array}{l}\text { My ex-wife, she got into financial } \\
\text { problems, she has four kids. So } \\
\text { she was separated from her } \\
\text { husband, which it can really cause } \\
\text { some hardship. So, she told me I } \\
\text { could take my daughters, (she has } \\
\text { four), my two daughters, if I } \\
\text { could. So before I even came } \\
\text { over here I already knew that was } \\
\text { happening, that they were coming } \\
\text { to live with me in at my current } \\
\text { base. So this whole time I wasn't } \\
\text { with them, but I knew coming to } \\
\text { live at my current location that } \\
\text { they was coming to live with } \\
\text { me...one was starting junior high } \\
\text { school and the other high school. }\end{array}$ & $\begin{array}{l}\text { Civilian mom had } \\
\text { custody but could not } \\
\text { afford to raise } \\
\text { children } \\
\text { Was married to mom } \\
\text { prior }\end{array}$ \\
\hline Death of spouse & 10 & $\begin{array}{l}\text { My wife passed away five years } \\
\text { ago from breast cancer. I could } \\
\text { not be there for my daughter, I } \\
\text { was blinded by grief. It all } \\
\text { seemed so overwhelming. I } \\
\text { didn't think about my career as a } \\
\text { pilot, my daughter, just me...it } \\
\text { seems so selfish now. }\end{array}$ & $\begin{array}{l}\text { Widower } \\
\text { One child } \\
\text { Pilot }\end{array}$ \\
\hline Pregnant at early age & 11 & $\begin{array}{l}\text { My girlfriend got pregnant right } \\
\text { after we started dating, we didn't } \\
\text { get married and her job deployed } \\
\text { a lot. She didn't want to be a } \\
\text { mom. I just took over childcare } \\
\text { and now I do it full time. }\end{array}$ & $\begin{array}{l}\text { Young } \\
\text { Never married } \\
\text { Mom was ready to be } \\
\text { a mom } \\
\text { Single dad }\end{array}$ \\
\hline $\begin{array}{l}\text { Individual career } \\
\text { Gave up custody due } \\
\text { to bureaucracy }\end{array}$ & 12 & $\begin{array}{l}\text { I divorced before I even joined } \\
\text { the Air Force. My kids were like } \\
4 \text { and } 7 \text {, I think. I wanted a better }\end{array}$ & $\begin{array}{l}\text { Divorced } \\
\text { Wanted more for kids } \\
\text { Gave up custody of }\end{array}$ \\
\hline
\end{tabular}




\begin{tabular}{|l|l|l|l|}
\hline Wanted a better life & & $\begin{array}{l}\text { life for my kids. I kept getting } \\
\text { laid off or let go because of the } \\
\text { economy. I needed health } \\
\text { benefits and a steady paycheck. } \\
\text { The Air Force offered all that. I } \\
\text { signed over custody of my kids to } \\
\text { my mom while I went to basic } \\
\text { and tech school. I regained } \\
\text { custody when I arrived here. I } \\
\text { did wait until I had a base house } \\
\text { to move into. }\end{array}$ & kids to join \\
\hline $\begin{array}{l}\text { Pregnant at early age } \\
\text { Gave up custody due } \\
\text { to bureaucracy } \\
\text { Wanted a better life }\end{array}$ & 13 & $\begin{array}{l}\text { I got pregnant with my then } \\
\text { boyfriend. It never really worked } \\
\text { out for us, and we were way too } \\
\text { young. I tried to make it on my } \\
\text { own but it was really difficult. I } \\
\text { decided to join the Air Force so I } \\
\text { could better take care of my son. }\end{array}$ & $\begin{array}{l}\text { Young } \\
\text { Better life }\end{array}$ \\
\hline
\end{tabular}

\section{Step 4: Searching for connections across emergent themes}

This level of the analysis is looking for connections to draw together the emergent themes and to produce a structure to identify the most interesting or important themes. In the previous steps, only the first interview question of the study was "walked" through the analysis process. The following will utilize the same question and pull the like emergent themes to form a super-ordinate theme. This is illustrated in Table 6 below.

Table 6

Abstraction Leading to the Development of a Super-ordinate Theme

Transition to Single Parent in Air Force

Pregnant young, no partner

Divorced/widowed

Gave up custody, then regained it

Relationship issues 
This super-ordinate theme presented itself in two ways. The participants were either already on active duty when they became a single parent by pregnancy outside of a partnership, divorce, or spousal death, or alternatively they became a single parent, gave up custody, then joined the Air Force and regained custody, resuming their life as a single parent. The participants that were already serving elected to stay in the Air Force despite having to complete a Family Care Plan and renegotiating their work and personal lives. The participants that joined the Air Force to provide for their children had to give up custody to meet the bureaucratic rule that prohibits those with dependents under 18 years old from enlisting. After joining the Air Force, all regained custody after initially giving up their custody to other family members or to their estranged partners.

The preceding steps showed how a theme was developed from one question from the study. In the next chapter, all themes will be identified in a master table of superordinate themes and discussed in detail.

In order to understand the place this researcher comes from in developing these themes and the lens she sees through, bracketing was utilized. The following explains the lens the researcher utilized.

\section{Bracketing}

This researcher was a single parent for seven years while serving on active duty in the Air Force. During this timeframe, she was experiencing many aspects of integrating the social supports offered by the Air Force and the work-life aspects of functioning as an Air Force social worker and a mother of two daughters. The seven years included being separated from my children for as little as two days to as much as 60 days. It also meant moving four times, including a move overseas to Japan. The Air Force has much to offer 
but the particular programs made available to me did not adequately address my specific needs. In my experience, most of my supervisors were supportive of my single parent status but there were at least two who were not. I relied heavily on my co-workers and my neighbors to help with my children. I was also more financially stable which allowed for access to quality childcare and structured activities for my daughters. The time spent as a single parent was difficult and I do believe that it has impacted my career as a social worker in the Air Force. I was unable to volunteer for assignments that would put me on a path for promotion. I was forced to only take positions that did not require extensive travel or time away from home. On the occasion that I could move beyond my restrictions as a single parent (my daughters spending the summer with their father) I was given recommendations for career advancements that I could not follow through because my daughters would be returning in a few weeks. As I am an insider of this community, I may not have been fully able to completely remove my own experiences from the analysis; however every attempt was made to keep the focus on the participants' experiences as they revealed them in their interviews, and to attain trustworthiness.

\section{Trustworthiness}

According to Lincoln and Guba (1985) four general criteria must be met to establish rigor without sacrificing the relevance of the qualitative study. The four criteria are the following: (a) truth value as evidenced by journaling, (b) applicability as evidenced by utilizing a comparison sample to the demographic data, (c) consistency as evidenced by a second coder; and (d) neutrality as evidenced by journaling. Each of these strategies have been utilized in this study. The researcher kept field notes, analytic memos and "my own lens" notes during the interviews as well as when coding the 
transcripts. A nominated sample was utilized as the participants were nominating themselves for the study. From the initial sample, a snowball technique was utilized which has the first participants nominating others that may fit the criteria. The final sample of participants was compared to the demographic profile of the entire community. The use of a peer consultant added to the consistency and dependability of the study by having a "second set of eyes" on the data. Giving a full and robust description of the research methods also adds to the consistency and dependability of the data. Key elements in ensuring the researcher's trustworthiness to the participants are the following: researcher's credibility, promise of anonymity and confidentiality, and skill of the interviewer in establishing rapport with the participant.

A researcher's credibility does not only come from the researcher's demeanor during the interview. Most critical to the attendance of the participant and accomplishment of the interview is the researcher's use of the proper channels to acquire the permission of the participants to conduct the interview. In addition to the formal introduction and request for permission to be interviewed, participants were also assured that any information they shared during the interview remained confidential. Moreover, the participant's identity will not be revealed and results have not been reported as coming from an identified respondent. All insights, especially verbatim statements that are quoted in the report did not fully reveal the participant's identity. Lastly, the researcher's skill in interviewing has ultimately determined the participant's perception of her as a trustworthy individual. Maintaining trustworthiness happens only if the participant decides that the researcher is indeed credible and worthy of his/her trust as the interview progresses. 
Member checking as well as bracketing were utilized for this study. Two participants were asked if they would consider reading over the results to ensure the trustworthiness of my interpretations. Their comments were that the analysis was accurate. Bracketing will used to identify my personal experiences as a single parent serving in the Air Force, thereby attempting to take a fresh perspective from the participants (Creswell, 2007).

\section{The Researcher as a Critical Tool}

In qualitative studies, the researcher is the most important and critical tool at every stage of the research process. This is attributed to the nature of the research design itself: qualitative studies are analyzed and interpreted subjectively, and the key to a successful analysis and insightful qualitative research report is its researcher. From research conceptualization to report writing, the direction and angle from which the topic or phenomenon will be discussed and reported will be dependent on the researcher's point of view, in addition to, of course, the theories the researcher will apply in the study. This judgment call—to include or not include relationships that will be determined and explored through analysis - gives credence to the qualitative researcher's ability to recognize patterns and possible insights for the study, having learned all relevant information about the study during the conceptualization stage, and having experienced the collection of new information about the topics covered in the research. 


\section{Chapter 5: Results}

In this study single parents serving in the Air Force shared their experiences through a semi structured interview. The interview was the only source of data collection. What emerged from the data were six super-ordinate themes capturing their experience as told through the interviews. One theme was discussed in the previous chapter to illustrate the steps that were taken to develop the theme: Transition to Single Parent in the Air Force. This theme as well as the remaining six themes include: (a) better life (b) parental responsibilities, (c) work responsibilities, (d) work support, (e) social support and (f) work-family conflict; all seven themes will be discussed at length in this chapter.

\section{Air Force Single Parent Participants}

Before discussing the themes that emerged from the analysis, a biographical sketch was created for each participant to give context to that single parent's experiences.

\section{Participant 1}

This young, enlisted Latina got pregnant, and felt that the father of her child was immature. She stated, "We were both young, and we were trying to work it out for the first year, and then, guys just mature late, so he was still immature." Participant 1 continued,

I was seventeen when I got pregnant, and I was eighteen when she was born, and when we decided to try to fix it, the relationship with the father try to work it out me and her Dad, we just couldn't.

Participant 1 had difficulty securing childcare for her child while in the Air Force. When asked what she found particularly difficult, she responded, "Just trying to find someone to watch her, it was just really difficult." She experienced difficulty finding 
someone to watch her daughter because of the 12 hour shifts that she worked. She also noted that working weekends makes it difficult to find childcare as well. She stated, “...now it's harder because we work weekends too, so, it's harder." She found another single parent, and they help each other by providing childcare for one another. She said, "She's a single parent, she works 12 hour shifts. When she's off she watches my daughter, when I'm off I watch her son. I was really happy with that."

She said that the Family Care Plan is a nearly useless element of bureaucracy. In response to a question regarding the effectiveness of the Family Care Plan, she stated,

I don't think it does anything. You can have people, on there, and the next minute they PCS [permanent change of station] or they deploy. Civilians, they can just up and move, so they can get fired. I mean, it doesn't, I don't think it does anything. It's just a piece of paper that you have to have names on it.

A permanent change of station (PCS) is a military term indicating a move to another military installation.

She felt that her supervisors and co-workers were not very considerate of her situation as a single parent. She said, "It's bad because one of the supervisors is a single parent himself, but he doesn't have to do the same shifts we do, so he doesn't really have to worry about it." She continued,

So I think he kind of forgets how single parents are and I'm the only single parent in the entire work [ group]...he does eight hours and leaves at four, so I don't think he really understands or remembers how it is, so I don't really get a leeway at all.

However, she said that she was treated differently in some of her other positions. With regard to previous jobs in the Air Force, she said,

They worked with you. If we stayed over longer. Sometimes we had to stay over to $4: 30$ because of the doctors. They would assign somebody else to cover you if they knew you were a single parent. They'd find time to let you go. 
In particular, she said that her co-workers were the most accommodating of all those in her workplace. She said, "Very [helpful], they volunteered to help." She felt that her coworkers did not resent her for the sometimes special treatment she would receive. When asked if it seemed that co-workers felt that she got the "better end of the deal," she replied, "Never, not at all. I never felt like that."

She said that her immediate family was very helpful with taking care of her child. She stated, "Yes, a lot. When I was deployed they watched her for the entire six months." She continued to explain that she is very lucky with regard to her parents and siblings being so helpful. She stated, "My parents will send anything. My sisters, they'll always be there. That's one thing I'm really lucky with." The only Air Force resource that was particularly useful to her with regard to taking care of her daughter was the childcare center. She stated, “...really only the childcare." She mentioned that she never had used the housing program, but noted that if she works nights she will probably have to use it, since the childcare center is closed at night. She stated, "No. I'm sure when I go to nights I'll have to see if they can do that. The childcare's not open."

The Air Force has a program to enhance the child development center hours of operation; it is formally known as Family Child Care. This program is licensed, sanctioned child care provided by military spouses in military housing. The military spouses providing child care in their homes can operate outside of "normal duty hours." This allows shift workers an option to have their children in a child care setting on the installation. In the course of the interviews, many participants did call the program by its official name, Family Child Care. 
She described being a single parent in the Air Force as "always a struggle." She discussed a time when she was forced to work one weekend when no other employees were available and had to leave her daughter with someone she barely knew. She said,

I couldn't switch with anybody and it was really, really hard, and I had to find some random person that I talked to a couple times. She had kids too and I was desperate. I couldn't get out of work; I couldn't just call in, so I had to just ask her.

She said that she felt like there was no support from the Air Force for her in this situation. She stated,

But I felt like there was just nothing. I know it's not their responsibility it is my responsibility, but it was just no help at all. It was like 'oh it's your problem.' That was the worst.

She suggested extending the hours of the childcare center, when asked what the

Air Force could do to help her feel more comfortable as a single parent. She stated,

The hours at the childcare center [were very limited]...I was just surprised that they didn't have childcares that are open for people who work 12 hour shifts. The hospital's open $24 / 7$ so I was just really surprised they didn't have childcares on the weekends or that are open [until] 7:00 or 7:30 at night.

She continued, "That's the main thing that I would change because it would help so many people, especially single parents.”

She also said that single parents should have more options. She said,

Have more options for single parents, not necessarily let them choose their schedule, but give them a little leeway...make sure they have somebody lined up, make sure the childcares are open on the weekends if you're going to work weekends, on holidays, and family days.

She also said that more information about their options would help single parents.

She stated, 
Just little helps like they give you the little brochures on childcare centers off base, schools off base. Things like that, information just to help them out...That would be a really big help because we don't really know where to look.

She said she plans to remain in the military despite her struggles. She stated, "It's really difficult, I think it's just a struggle and I just have to stay with it." She continued and explained that she has to do whatever she can to provide for her daughter. She said, "But then in order to keep this life, a stable life, it's worth it just for her not to struggle." She compared both civilian and military life, and said that being in the Air Force was better than caring for a child as a single parent civilian. She stated, "Civilian life is really, really bad. I would choose the Air Force. If I have to deploy, I have to deploy, but it's a stable life and [my daughter's] worth it."

\section{Participant 2}

A middle aged, White officer, this participant was engaged to a service member at the time she got pregnant. She said, "I was actually engaged when I got pregnant and then he deployed and decided that he didn't really want to get married after all." She was an enlisted reservist when she got pregnant, then finished school, became commissioned, and then was active duty. She was able to serve even though she was a single parent at the time of her active duty. She explained,

I was already in the reserves so that [requirement on custody] was waivered since I was already in the military, I didn't have to give up custody or anything to continue in the Air Force... so that was a nice thing.

As noted earlier in this dissertation, there are policies surrounding single parents joining the Air Force. One has to give custody to another non-military person before joining. In Participant's 2's case, she was already serving in a reserve role. This policy 
does not affect someone already serving as a reservist, as a National Guard member, or transferring from another branch of service.

Participant 2 said that her parents were very supportive and helpful with raising her child. She said, "Fortunately I had my parents that were very supportive so I lived with them. At first they took care of all of us, I didn't have to worry about that." She continued,

I was fortunate to have my parents to take care of him at first when I was going to college, then there was the fun, I went to OTS (Officer Training School; this is the first training received by officers upon joining the Air Force). So I had my four months away from him, they took care of him then.

Her son was in childcare; while she was in tech school (technical school is completed by all Air Force personnel in a vocation that was chosen by the member at the enlistment or commissioning stage). She stated, "I got to stay off base and put him in childcare, so he just stayed in childcare while I went to school every day and then got home." She felt that the family childcare program was very beneficial. She simply stated, "The family childcare is a wonderful thing."

She cited a time of lengthy deployment as a time that was particularly troublesome for her as a single parent. She said, "I guess the only thing where there has been trouble is when I've been deployed for the longer periods of time." During these periods, she said her son began to show anger and anxiety issues. She said that visiting with her son helped to alleviate these issues. She stated, “...he had the opportunity to visit me...so that helped but again we started noticing some more anger issues and anxiety issues, and things like that." 
She made use of both the regular childcare and the family childcare programs. She said, "During the regular week he would go to the regular childcare, then outside of those hours, when I was working Saturday and Sunday, family childcare." She cited her son's independence as a factor that made being a single parent easier. She stated, "Then he got old enough to be left at home, that was wonderful...He's always been incredibly self-reliant."

She said that the Family Care Plan is tedious and does not guarantee anything. She said, "I think it's a pain in the butt. It's a lot of work to put together, just to update for someone else to have." She continued to explain that her problem with the Family Care Plan is that you are supposed to use local caregivers, but often times, hers were far away. She explained,

The problem's always been that they want all these local people and most of my plan has always been, to send him to live with family members that are not local. Typically there's not been local people that I would want to [have him stay with].

She mentioned that it is difficult to find local people to take care of her child. She stated, "How do you find a local person within a week... 'Hi, here I am. I've lived here for a week, would you take care of my child?'”

This experienced officer said that she has had good interactions with sponsors and with supervisors. All Air Force personnel are assigned a sponsor once PCS orders are received. PCS orders are the official notification that an Air Force member is moving to another installation. Sponsors at the receiving installation aid in the transition of these members. They help in a variety of ways, including acclimation to the new installation. She stated, "The sponsors have been great. We've had good sponsors and have had, I've 
been assigned sponsors and they've all been really good...I've had really good sponsors over time." She explained her supervisors, "I've had pretty flexible supervisors that understood that childcare closes on the dot and it's per me after that...I've had really fabulous supervisors that have understood." She stated that people have always treated her well and that she's been lucky in that regard. She said, "but I've been extraordinarily lucky I think with having people, co-workers, bosses and sponsors." She continued, "I've had great bosses, I've had family, I had some co-workers [who were supportive]." She did not believe that her co-workers felt that she got special treatment due to her situation as a single parent. She stated, "I don't think any [of them felt I got special treatment], certainly not that I've noticed. But I've always, as I said, made sure to kind of make up for it." She contributed to her work group "By staying late when I could and helping out my co-workers if they had something going on."

She said she would improve the way the Air Force handles single parents by eliminating the Family Care Plan. She stated, “[it would be better] if we didn't have to do the stupid family plans." Other than the elimination of the Family Care Plans, she could not cite any other improvements to the current system, but later mentioned education. She discussed more education about programs available as a possible way to improve the system. She said, "Maybe education for people all the way around." She said that she would prefer it if the programs that are in place would remain in place (other than the Family Care Plan). She said that it is up to the individual single parents to actually have a plan, rather than rely on the Family Care Plan. She stated, "It's up to the single parent to plan, to have not just paper plans, but just to know themselves what can you do." 


\section{Participant 3}

This young Black mother of a pre-teen child explained that she got pregnant while in high school and her daughter's father initially wanted to become married, but she eventually changed her mind about getting married to the father of her child. She chose the Air Force as a career rather than other service branches because the recruiter explained the process and assured her that she would be accepted as a single parent. She revealed,

I went through seeing the recruiters to decide which one I wanted to [join]. Then at the last minute I decided to go with the Air Force; because the recruiter, he was very patient he went through exactly all the process as a single parent and stuff like that, not being married, so that seemed like the best option for me.

In order to join the Air Force, she gave partial custody of her child to her mother, but later she learned that she must give full custody to her mother in order to serve. She explained,

I would have to either get with my daughter's father to see if he would get custody of her while I was in training and then I would be able to get my daughter back...so what I did was give my mom temporary custody because we weren't married and he wasn't living in the same state I was.

She then learned that her child had to be in permanent custody of somebody else,

so she decided to give her mother full custody. She stated,

They told me that my mom would have to have full custody of her and she would have to keep her my whole enlistment or I would have to get out on administrative discharge, so during my first enlistment I ended up having to go back home to give my mom full custody of my daughter.

She said that her family and friends were supportive of her and her daughter until she decided to join the military, then those same people started backing away. She stated, "With everybody being available for me...they were excited, they'd help me out and stuff 
like that, but when I made my decision to come into the Air Force, they weren't okay with that." Participant 3 continued,

So it seemed like everyone kind of backed away. They felt like I was leaving my daughter behind. They were saying that everybody thought that because you're a single parent, you're not supposed to leave them...That was my major challenge.

Participant 3 said that moving from one military base to another was difficult when her daughter was young. She stated, "The transition was kind of difficult at first because she was just in kindergarten." She was happy that her daughter would be in full day kindergarten, since she would not have to arrange for additional childcare. She said, "I was excited because of the fact that they had just started full time kindergarten at school." She also mentioned that her daughter's school was far from where she worked, however, and that it was sometimes challenging to coordinate her daily activities with picking up her daughter. She stated, "So it would take me literally 20 minutes to go there and get her and then come back, so it was a challenge."

She cited her supervisor as being helpful, particularly by being flexible with her schedule. She explained that her supervisors are usually understanding. She said, I let my supervisors know what's going on most of the time, any issues that come up, so I haven't really had too many problems with that. I'm so glad that they came up with the whole FCC (Family Child Care) thing.

The family childcare program was useful for her and her daughter, but she expressed concerns for those with children who are too young to communicate. She said, "I'm glad my daughter was old enough where she could talk at the time because I know they were saying they were having issues before I got here about doing in home childcare. People didn't feel comfortable." She continued, "Because certain situations were going on in base housing, [I was warned] to be careful about it...I'm glad my 
daughter is old enough. I think I would have been concerned if I'd had a brand new baby." Family Child Care is regulated by the Air Force. This participant was not comfortable because there was only one adult providing care, as opposed to having multiple caregivers in a center. She was also concerned that there were no cameras in Family Child Care homes. She wanted the extra layer of safety for her child.

She expressed that the Family Care Plan can sometimes be confusing and a somewhat unhelpful bureaucratic program. She stated, "It helped out, it's just...it's been conflicting about the access cards, they change it. It's never the same process." All of the Family Child Care homes are located on a military installation. Without a base access card, the adults designated in the Family Care Plan cannot enter the base. There are guards at every entry point. On base child care utilized by single parents while they are deployed will have to choose someone that has access to the installation. "I got deployed and the process was totally different from when I first got here." She explained that the rules are confusing with regard to who is allowed to care for your child and who is permitted on base to pick up or care for the child and who is not. Military bases change access standards based on national security measures. When national security dictates, the base becomes more secure, not allowing routine access until the security risk passes. She summarized,

But it's conflicting, it's not really helping. I know they want to protect the base, but at the same time I'm a single parent and if I'm getting somebody to come out of their comfort zone, out of their state, or out of their home to come stay with me, to help me with my child for four or six months, [to have access] would better help them.

When her daughter was younger, she intended to use the Air Force childcare services, but the amount of paperwork required prevented her from doing so. She said, 
"The childcare situation, that was kind of frustrating for me...I was trying to make sure I had everything set up...I faxed them my paperwork...called to make sure I had everything, they said everything was fine." She continued, "When I got here...they were telling me they couldn't find my paperwork.” Because her daughter was about to turn six, she technically had to go through the youth center. There are different levels of child care on the installation. The child development center cares for children six weeks through 5 years. The youth center cares for children age 6 through age 12. The teen center offers activities for teens aged 13-17. The Family Child Care providers can care for any age child. No one informed her of age restrictions until it was too late, so she enrolled her daughter in a private childcare off base. She explained, "The reason they couldn't find my paperwork is because they got rid of it because my daughter was about to turn six, and when the kids turn six...you have to switch them over to the youth center. That ended up being a month process because no one called me to notify me or let me know." She explained how she resolved the situation,

So I ended up enrolling my daughter in [a private childcare facility]. It was more expensive there, but the times worked out (It was 6:00AM to 6:00PM) and I could get people to pick my daughter up, so it kind of worked out for me.

She said that communicating with supervisors is important for Air Force single parents. She offered the following advice,

You have to be able to communicate. You have to put your family first, I know you're like you have to put the Air Force first, but I'm like, 'No my daughter comes first.' I have to make sure my daughter's taken care of so I can be able to focus and do my job every day.

She explained that she lets her supervisor know about any issues that arise due to her being a single parent. She said, 
So if I'm having any issues at home I let my supervisor know, but if I feel like my supervisor is not helping me I go up my chain. I've always done that, so if I feel like I have a supervisor that's not helping me, then I'll go [the] next step up.

She said that family and friends have been helpful in caring for her daughter. She said,

It's been mostly my military family or my FCC providers or my friends that I've made in church or my hairdresser that I've had for the six plus years since I've been here. So basically, family and friends either from home or where I've been deployed [have helped].

She mentioned that supervisors have also been helpful and flexible with regard to work hours, even allowing her to bring her daughter to work when necessary. She said,

Our work hours are 7:00 to 4:00, and when we have different shifts, if we have exercises, that's when I use my FCC provider or I'll arrange for somebody to come pick her up, or I'll bring her into work with me.

She explained that she felt that some co-workers seemed to have a problem with her and might perceive that she gets special accommodations due to her status as a single parent, but that it mostly depends on the person. She stated,

I've started to notice it's been an issue, when I first got here it used to be. I felt like there was some kind of separation with people who have kids versus people who didn't have kids, like how they were treated.

She continued, “...it just causes conflict in the office with certain people." She was clear to note that she feels she gets her share of work done despite her status as a single parent. She said,

I would stay late if I have to; if there is some way I have to be with my daughter, stuff like that. If I can't bring her there with me I try to leave early, but if I have to I'll stay late. Just make sure it gets done.

She mentioned that sometimes missing work is unavoidable, however, due to unforeseen circumstances that a single parent might face. She said, "You can't predict 
getting sick [or] if your kid's going to be sick. This has to be done or this has to be done."

Her daughter had been living with her mother for three years, and her daughter's transition to living with her on the Air Force base was hard. She said that the Airmen and Family Readiness Program was helpful in understanding and monitoring her daughter's transition. The Airmen and Family Readiness Program is designed to help military families. Many programs include psycho-educational information surrounding military life and military families as well as other programs noted earlier in this dissertation. She stated, "The Airmen and Family Readiness Program, any programs that they offered there I volunteer, help out, and try to get involved with so I can keep in the know to help my daughter's transition." She felt that she had the support of those in the Air Force community. When asked about times she felt supported as a single parent in the Air Force, She said, "From the military community, from the Airmen and Family Readiness Center and my FCC providers." She also praised the youth center for now offering tutoring. She said, "But now they are starting to offer tutoring after school. I'm like okay, yeah, after six years, it took six years to get it done, but, it's happening."

She felt unsupported when she had supervisors that did not have regard for her situation as a single parent in the Air Force. She responded, "There's different things, when you have supervisors that aren't concerned, don't care about you, what you have going on, your kids and stuff like that, you have to go over their head." She continued, ...I think there's challenges every day as a single parent. But I try to overlook the negativity because if you sit there and worry about that, it's going to wear you out; it's going to wear you down. And you already have enough stuff to worry about being a single parent. 
She said the Air Force could advertise or reach out more in an effort to better support single parents. She essentially wants to get the word out on single parents. She responded, "Trying to advocate, they are getting better about trying to advocate different programs and different stuff to get people involved, people that are outside of the military family so that they can understand." She also felt that supervisors should get some sort of training to help them understand the situation many single parents are in. She stated, I don't know if the supervisors have to get training. People who don't have kids in the military and people who are not in the military, there should be mandatory training for them to have to take and classes and stuff [to understand what you're going through].

\section{Participant 4}

This middle-aged White father of three children was married shortly after he joined the military. This enlisted man married a woman who had a child and they had two more, but three years into the marriage, they divorced. He said, "I married young, almost immediately joining the military... She was left alone, abandoned with a child, so I came in and sort of did the super hero thing, rescued her, married her, adopted our daughter." He continued, "Shortly thereafter we had two other kids and then about three years into our marriage she said she needed a divorce." He retained custody of all three children but currently only has full time custody of his two biological children. He has visitation rights in the summer for the adopted child.

He mentioned that how to handle child care was a challenge that he had not encountered until he was a single parent. He stated,

Child care, it was a rude awakening. She [his ex-wife] was a stay at home mom, so immediately having to find someone to take care of my kids that I trusted, working with the $\mathrm{CDC}$, (child development center) working through home childcare. 
He concluded, "That was the biggest adjustment." He was fortunate enough to find a trustworthy family childcare provider. He stated, "Even the exercises weren't bad because my very first day care provider was just phenomenal...it was easy she just worked with me on everything so I got lucky in that aspect." The Air Force practices its wartime mission through training events known as exercises. These are usually scheduled, but sometimes not. The exercises are structured in such a way to not provide notice because Air Force leadership wants to test the capabilities of its personnel to respond in a no notice situation. The Family Care Plan is the vehicle that is used to see if this expectation can be met. The exercises tend to run through weekends with most participants working twelve hour shifts.

When asked about the Family Care Plan, he said it was a hindrance. He stated, "[The Family Care Plan] hinders me a lot.” He explained,

Tracking down signatures is difficult because they want an actual ink signature. You can't have a faxed copy. Asking people, 'Can you do this?' and you have to explain to them what it is and what they're signing, because no one is going to willingly sign anything.

He uses his extended family as his long term care provider for his children, but noted that the short term provider might not always be who the plan says it is. He said,

$[\mathrm{M}] \mathrm{y}$ father being the long term care provider, my parents. They're military and I trust them in the fullest with my kids, but the truth of the matter is, it's a fake form because if something happens, my short term care provider is not going to be who it says on the paper...it's going to be whoever's off, whoever I can call, 'Hey can you stay with the kids?'

He concluded, "It's really more of a fake form than anything." 
He mentioned that finding a place to stay immediately was challenging. When he first moved to his present base, he was told "you have to go find a hotel," and he mentioned that he didn't care for that. He also said that finding child care was difficult. He stated, "Finding child care right off the bat, I found one that was $24 / 7$, but it was horrendous." He said that his flight chief helped him through his challenges. He stated, "When I got here I talked to my flight chief at the time in the ER, explained my situation." Flight chiefs are the enlisted supervisors of a given section. The flight chief was able to switch his shift so that he could be more accommodating to his children. $\mathrm{He}$ said,

The thing that helped me the most was my flight chief in [my unit] just making that move getting me out of shift work, getting on to a Monday through Friday [standard shift] so that I could be there for the kids in the evening. That was a big help.

His supervisors also were flexible with regard to work hours. He said, "They allowed me to come in at 7:30 to be the late technician, so there was that flexibility and then there were always the times where kid's sick, you go to go home.” Typically duty day hours are 0700 to 1600 . Some work centers stagger their hours to accommodate patients or maintenance schedules. "They didn't make me take leave, and things like that. I try not to abuse that one because I do know that people get stressed who don't have kids and they don't get that off time."

He said that some of his co-workers were unsupportive, while others were supportive. He explained,

The people who have kids, some of them do [support], but it's funny because there's people that have kids, they're married and their life is perfect and they don't understand that there is nobody to call. I'm the only one that can go pick them up. 
He said that the after school program was beneficial for his kids. He said,

It was the after school program that really perked my interest...I think they have such a great after school program for the kids. The summer program is just phenomenal. Four times a week they're doing something.

He felt that the Airmen Family Readiness program had good intentions, but was mostly useless. He stated, I think the Airmen Family Readiness Center, they have a lot of good intentions, but I think it's just a completely wasted program. The Air Force puts a lot of money into the Airmen and Family Readiness Program, and it's not that they don't try; it's just that the programs are virtually dead.

He said he felt especially supported during one Thanksgiving holiday, when his flight chief came to his house and giving him a care package. He stated, "My supervisor, the flight chief of [my unit], showed up at my house with a box, a Thanksgiving care package, so I just looked at him and I started crying." He cited an air show when many employees had to work as a time when he felt unsupported. He stated,

My folks that work for me they kind of felt resentful because they all had to work. They were either on shift in [my work unit] or work a shift out at the air show and I didn't. I feel justified in what I did because I work 10 hours a day doing all their additional duties...so they don't have to come in on their days off.

He continued, “...just the look of resentment on that aspect. They really didn't see what all I was going through.”

Participant 4 suggested that the Air Force be more lenient with expectations. He stated,

I think the military can be a little bit more understanding with expectations...They should just understand that sometimes some of the tasks that they give you are a little bit monotonous and don't necessarily need to happen... That's also not just for the single parent, but for everybody that has a family. 
He continued, "What the Air Force can do is understand that putting those time constraints and restrictions and all those things on people is not good for people's home lives; it really isn't."

\section{Participant 5}

This Hispanic, enlisted female stated that she broke up with her son's dad, “we weren't married we were just living together.” After becoming a single parent, she said that "Nothing changed except for I just had to [do] everything on my own." When asked about challenges that were easier or harder in her work areas, she mentioned that "Within work, no because at the time I was at [another base], they were pretty family friendly and oriented." Participant 5 was working in [one work unit] explained that it was "...a little bit harder as far as Family Care Plan and if I did have to come in before hours, [my] childcare doesn't open until six thirty so I'd have to have a[n] [alternative] plan.”

In resolving these challenges with [her work unit], she mentioned, "I had to just kind of hope I wasn't going to have anything like that come up, like a recall or anything, if we did have to change our times that we worked." She added,

But also being new here I didn't know anybody that would be able to take my son if the childcare was not open at the time. So I kind of had to start getting that ball rolling like who I know who can I trust, and kind of ask them if this did happen, would you be willing to or whatever...

She stated that Family Care Plan would help her. "Before, I think not knowing anybody I just kind of had to put anybody, they have to be civilian in certain parts of the Family Care Plan." To be the short term caregiver on a Family Care Plan, the designated caregiver cannot be military. They have to be a civilian because the military member could also be deployed. This makes it difficult to find someone to be the short term care 
giver because you do not have an opportunity to meet many civilians at your work center.

She added, “And if you don't know anybody you're just kind of making it up, which mine was not correct." When asked about the issues that came up with her with the PCS part, she said:

I think the only one I was really worried about is whether or not I was going to get into a childcare right away. Before having to start work, you don't want to give an impression of 'Oh she's going to have an issue with kids' or whatever but it ended up working out good.

She further said that her mom had helped her with childcare. She said,

She came out there [picked up my son] and flew back [to her home] with my son. And I drove all my stuff, took leave and went down and got him at my mother's house and came back once I was settled.

She also mentioned that her supervisor allowed for any flextime when she needed to go to an appointment with her son. She cited that either off duty time or take leave, “there are certain things you can't predict. Luckily my son is not a sickly kid or a baby so he was never really a problem as far as childcare." She added that, "Because they have their rules if the temp goes over whatever but, luckily that never happened. If it did, which I think it did a few times it was hard, just explaining."

She further noted,

...I think with single parents you can tell the difference between one that uses it as an excuse all the time for different things or ones that really [need work adjustments]...it's not a frequent thing, it doesn't always happen, you can kind of tell that. If I was going to ask for some time it's because I really need it, not because I'm making up an excuse.

She also cited that her mom and her sister have helped while her son's father, stationed in another state does not really help her at all. She said, "every two to three 
months, he'll take my son for four to five days at a time. Sometimes it doesn't happen for like four months."

She added that the childcare on base would help her during weekend.

I tried to use the Give Parents A Break Program because they offer childcare for half a day on Saturday, but I haven't used it, I would, I think. I was on leave or something and I didn't need it then.

She noted that her housing situation was off base because she wanted "to get away I'm here most of the time. Just to get away from base."

She stated that while serving in the Air Force, "I feel like if anything at all was to come up, I would be $100 \%$ supported. I'm at ease I know that if something happened, I would be okay." When asked about the time where she felt very unsupported as a single parent, she said,

Not so much, when I first PCS'd, because I was in ALS (Airmen Leadership School). It was probably beginning of 2009, I deployed June 2009 so that was different. I guess a year and a half into my last duty section.

She added, "ALS is very stressful. At that time I was not in the CDC (child development center) yet I had a FCC (Family Child Care) provider and she gave me a very hard time and I had to pay more." According to Participant 5, "Because at ALS the hours are way longer than a duty day here. So it was really stressful. Four and a half weeks." Airmen Leadership School is a formal military professional education course. It is the basic supervisory course everyone is mandated to complete prior to making Staff Sergeant, approximately at the four year mark.

During her deployment she said that her son stayed with her mother and said that it was hard for him to come back home from staying with Mom. When asked about things that the Air Force could change to make her feel better as a single parent, she 
stated, "I think that they offer enough, but I don't think you're ever going to change

people, management or anything." She added,

I guess teach people especially if you have somebody that is not a parent or doesn't have kids can't relate that would be hard. Maybe if they taught people or made them aware of what really happens--that it's not a disability to be a single parent.

When asked about her perception about what might help in understanding single parents, she stated she had no particular suggestions, “...besides that fact that it is harder than if you had the second person there with you. Just because of all the responsibilities." According to this participant:

You know you have leadership courses and PME (professional military education) that you have to go to, some out of state, TDY (.Temporary Duty). If I was on shift work I don't know what I would be doing right now. They're going on TDY's all year, but I think that's part of why you signed up. I understand it, if it happens, it happens. But I won't volunteer.

Many activities within the military system are not volunteer. There are

opportunities to volunteer for educational, deployment, or training opportunities;

however many times personnel are told to participate.

\section{Participant 6}

This experienced white, officer stated that she was married to her husband for thirteen years while they were both active duty. She stated that her military commitment caused her to deploy and "the stress of trying to make that work and have kids" have led her to become a single parent. She mentioned that they were married while they were both enlisted and did the reserve time. She said,

...I think the stress of that deploying and the multiple TDY's (Temporary Duty is when a service member goes to a training that is not located at their home station), you know him having to do the single parenting, the stress of me having to do the 
single parenting when he had been deployed or TDY'd, just caused our marriage to dissolve.

She stated that "being responsible for everything" and being "the bread winner" were the family challenges she experienced after she became a single parent. She mentioned, "We did child custody in a different state. Because of our divorce decree we ended up doing it a different state and it was challenging because we had split custody, I guess you call it shared parenting." She added, "Just a lot of stress just having to be the person that takes care of the kids, hold down a full time job, and try to go to school the same time, horribly stressful."

When asked about certain things that were easier or harder that she remembers about first becoming a single parent, she mentioned that it was easier because she could make the decisions "without having somebody criticize or critique" what she was making a decision about. She explained that the most challenging thing was

...just trying to juggle work, school work, making sure you're on time for work, making sure the kids had to be dressed and ready, meeting all the time constraints with having a job running pretty much around the same time as childcare starting.

However, she stated that there were some constraints on the care plan. She said, “even though I had a care plan, [the] care plan didn’t really work." She stated, "There are a lot of constraints with the care plan in my opinion. ... it's supposed to work a certain way but it doesn't always work out that way." She added,

There's a lot of constraint because a lot of people don't realize with the way it reads. A lot of people panic when they see that you're totally responsible for " $x$ " amount of days that could turn into weeks, not really understanding that. 
When asked about her most recent PCS, she said that "I was in the middle of a custody battle and it's very stressful because when I found out I was PCS'ing it opened up a can of worms..." She added,

I tried to get it into our decree saying that it is in fact a condition of our employment, that we have to deploy and we have to transfer job stations. So I did try to get that into my decree but somehow there was some fine line with where it happened.

Moreover she "ended up not PCS'ing until after my maternity leave was over. I had just gone back to work for a couple of weeks but in the interim my ex-husband was able to take me back to court." She also mentioned that

After being married to somebody for thirteen years and both of us be military we had already PCS'd several times, that's our life... I had to go through a huge custody battle that cost me a lot of money and was very stressful.

She cited, "I ended up having to leave the children, even though I had proven to the court that [military provides family housing], they don't understand that for some reason." She added, "So he was given custody for the first six months. So then I had to go back three more times in order to get my kids' custody. It's very stressful."

Participant 6 stated she was able to find a house within the first six months and was situated. She said she had a very good supervisor and was able to go and take care of her business. She added, "I had a pretty good support system on this end I can't say that for my last base but this end, it was good." When asked if anyone has helped her with child care when she arrived, she answered, “I didn't have any child care issues when I got here. I didn't have any child care issues because I didn't have the kids when I first got here.... But they did offer the "Give Parents a Break", I think I might have used it one or two times." Give Parents a Break is a program that offers eight hours of free child care 
per month, usually the first Friday of the month in the evening hours for four hours and the second Saturday of the month in the afternoon. This program is offered to all newcomers to a base to help ease the transition of moving. This program can also be extended to families that are going through an unusually stressful temporary situation.

When asked about the time when she felt supported as a single parent in the Air

Force, she stated that,

The deployment [support] was fantastic. Red Cross offers all kinds of great programs for the kids. They have a lot of scholarship programs. So when I deployed, [I found out about] things that I wasn't aware of as a single parent before.

However, she stated that there was once or twice when she felt unsupported at her work site. She said,

So I had an experience a couple of times where we at the last minute were told that we were going to have to stay late. Which I didn't have a problem, but you can't tell me ten minutes before we're going to have to stay late and then not be able to make arrangements.

When asked about her perception about what to change to be comfortable as a single parent in the Air Force, she stated,

...I had a really good experience as being a single parent. I haven't really had any issues. I just haven't. Everybody seems very (supportive)... especially when we had PTO's (Parent Teacher Organization meetings) or something like that. I let people know, sometimes realistically I know that were in a military environment and that the tempo is high.

She added, "I've had a really good [experience]...everybody has been very understanding, I just let them know I am a single parent...” When asked about whether Air Force can do better by single parents, she said,

The only thing I would say is looking at, I know everybody has to do their time as a deployer, I have no issue with that at all. But I do think that people, who 
haven't been tasked, want to go and then they don't get picked, I do not understand the rationale for that.

She added, "They have people and they really want to go, why they are not letting people that want to volunteer step up, because that's happened too."

She further mentioned, "The Air Force does a pretty good job of kind of looking at people's home situations. I think they are very good, it's come a long way, let's put it that way, very cognizant of people's home life." She stated that "(with) all the support programs with the Military One Source and all the options that people have, it is good." She added that they family counseling that was helpful to be able to pick from what they were offering. She said, "It seemed like the people at Military One Source was very familiar with families, military families." Military One Source is a program that is utilized by all branches of the military. It is similar to an employee assistance program but provides even more extensive information and services. For example Military One Source offers services to help members find someone to fix their roof or locate child care, while it also offers counseling.

\section{Participant 7}

This participant is a White officer and became a single parent through divorce. He said, "Problems leading up to that, prior assignment. Got here, no real reconciliation possible. So within a couple months of being here we started a separation process." He was married for ten years to a civilian. When asked whether it was a mutual agreement for his daughter to stay with him, he said, "Yes, even though we had been here four months or so, she was in a good school, good friends, good programs and also the uncertainty of where my ex was going to be going what she'd be doing." He stated, 
We felt like it was the best place for my daughter at least initially was here. After that she was already rooted at that point, as far as you could be rooted as far as being a military child but just to keep the consistency.

After becoming a single parent, he mentioned some family challenges he

experienced. According to him,

[T] he time management, some of the inconsistency. 'I got to stay late for work tonight'... Professionally it's not great but, so that was different because I was used to stability and being able to depend upon someone else if I couldn't be available for her.

He added,

Then home time management, just the workload sharing, and it seems weird to say share the workload with an eleven year old, but for better or worse I started having more expectations of her to pick up her room. That probably would have came anyway.

He also mentioned, "I don't know if easier is the right word but my relationship

with my daughter actually improved. Like I said I was forced to be more communicative with her." He noted that

Mom was always a very communicative person with my daughter, not that I wasn't. I had to step it up; I had to make sure she understood what was going on and where I was coming from with everything from discipline to work to the changes that did come about like 'Now you have to go to Safekey where before you could come home'.

SafeKey is a local program hosted by elementary schools to host a safe place for children that did not have a parent home in the afternoon. He added, "So in a way the communication in the relationship came a bit easier because it was something that I just had to do. If it's something you have to do, I just do it."

When asked about Family Care Plan, he said,

It was good, because I had this in my mind anyway. But it really forced your hand at what's your support system, what's the plan you PCS'd or if you deploy, or get pulled out for a week long TDY or all those things. 
He added, "So I valued it, like I said, for me structure and stability, so that made me create some sort of structure around the uncertainty of TDY's, deployments, even exercises depending on what was going on."

Participant 7 mentioned that he did not PCS as a single parent because when he arrived he was still married. In resolving these issues, he noted,

[T]he Airmen Family Readiness Center had the MFLC (Military Family Life Consultant). We tried that as a couple, still and it didn't really pan out. But from there we went into full on marriage family counseling out on the civilian side.

The MFLC is a contracted program that positions a master's level therapist at every military installation. They are there to help with any transition issues that affect the family. According to Participant 7:

...it was a big help, because we realized early it was pretty much irreconcilable. It was too far gone. So what that turned into was a lot of planning for what would be the least disruptive to our daughter, what's best for her...

He also utilized off base programs through a local church. He said, it was "like a spiritual healing program" and child care was associated with it.

He noted that "professionally there was enough support there to make sure that if I needed to be somewhere I could get there." He also mentioned,

[T] he indifference of my commander, like I said he would say, 'yeah whatever. We'll do whatever we need." He added, "Didn't always [help]...he was helpful at the very first but after that, I don't know if he just had his own [issues]... because he PCS'd and I don't know if he got wrapped up in that. I wouldn't necessarily say... he was overwhelmingly supportive.

When asked about whether he experienced any problem with co-workers in getting preferential treatment, he said, “No, I don't. If it was there I never sensed it. The people I was around for the most part, some of them had been through the same thing so they were very understanding of what it entailed." When asked about help from extended 
family, grandparent, or siblings, he said, "Nobody was here, but [I got] as much [help] as you can over the phone." He also said he was deployed. He noted, “...I had a couple of deployments come up and then fall through. Then I got notified, like eight days, after I thought I was in the clear they were like you need to be there by the eighteenth.” According to him,

I called my ex and I was like...because the plan had been, if I get pulled for deployment she'll just go to [his ex-wife's home in another state] so her second half of the school year will be in [in another state]. Where she'd stay sucked.

He said,

Because I knew I wouldn't probably get her back for her sake. But my ex said, 'Well you know, what about your Mom? Talk to her.' She's a nurse, but on a contract so she wasn't really tied down. So it was she that recommended that, so I called my Mom and my Mom said 'of course.' She came out in like a week.

He also mentioned that it helped because of what he earns during deployment, "financially good except (that I had to make up for) what my mom was losing."

According to him,

So I didn't make out like a bandit like most people on deployments because it went to my Mom and what she was missing out on, but I'm so grateful. Again it speaks a lot to my ex-wife's real commitment to what's best for our daughter because it was she who brought the idea up.

When asked about the child care, he said, “...Because we live in about 25 miles

from base, so to come to the CDC on base wasn't ideal. She had Safekey from school. So that gave until six on most nights and then...I'm trying to think." He added,

You know on the weekends...like I said our relationship improved so we spent a lot of time together. Daddy daughter days and just going out and doing stuff. Friends that I did have that had kids, they pulled us in. 
He also said he lived off base; he said "We wanted to. Officer housing wasn't up to speed yet. Everybody had kind of talked about ...and my ex because we were moving we kind of wanted a pool." According to Participant 7, his wife stated to him ,

'So if you're going to take me where it's a hundred and twenty degrees, at least give me a pool to jump in'. So we moved out there, found something that was really nice, again schools being what they are here, we found one of the few public schools that is decent, got my daughter in there.

When asked about the time he felt very supported as a single parent in the military, he noted,

...I was in a very different professional position. Someone else probably could have been more strict like: 'No you are supposed to be here during these times doing this stuff engaged in these sections of the hospital' and you know they didn't [specify] when I would have to be somewhere.

He cited, "Not specifically work related stuff. Not the military structure but the military family structure was very important. If I had been in a different place with a different supervisor it could have been a lot worse." The military likes to build on the concept of military family. The personnel in the military are often far from home and family. The military wants to create a family atmosphere within work centers so that personnel feel comfortable and connected on a level of family.

When asked about being unsupported, he said, "The deployment only because it was such short notice. Like I said 'yeah, your name is in the bucket, yeah' but having eight days' notice that hurt. That sucked." He added,

You know I'll tell you because I was thinking earlier on in the parenthood process. After I got back and I was finishing up the residency, they didn't know. I had come out here with the hopes that I could stay on here.

He cited, 
...there was some serious discussion about moving me and I protested at the time and a couple of other folks from here went to bat for me with AFPC (Air Force Personnel Center) said that he's a single dad, his kid's in school.

Participant 7 noted, “So very much, even though AFPC don't see the underlying circumstances, after a couple of discussions from some of the key people here [they decided to let me stay here]."

Moreover, when asked about program recommendations for single parents, he answered that it would be the structure with the deployment bands. He added, "Trying to eliminate some of the short notice but I understand that happens. I think their attempts at that are a good faith effort to try to build some sort of consistency." According to this Participant, "Planning for family purposes if you want to have kids or work around that it's a good way to go. [I think it was] the execution piece that sort of fell through on my end." He also added,

...I understand the exercises and all that and that's why the Family Care Plan makes sense to have in place. So you know there's some sort of structure to know what you're going to do last minute if you have to go somewhere.

\section{Participant 8}

This White officer, mother of two, became a single parent because of a divorce while already serving on active duty. She was a victim of domestic violence and had a child with special needs to care for during this time.

She explained, “In the PCS process I felt like I didn’t love him, but I religiously felt like I was committed to marriage, that marriage wasn't always blue skies, green grass.” According to her, “There's tough times. I saw my parents fight sometimes but they were in it together and they are happy and now still to this day best friends forty five years later." She added, “ I felt I did not love him at that time, I really didn't even like 
him at that time (laughing) but, hoped hopefully one day, we'd figure things out." When asked about her kids, she noted,

...They luckily never heard or saw any of that. I think they could sense some tension at the end when we lived in [another city], but we just continued to grow further and further apart during that time and interacted less.

Participant 8 said that, "There was stress over a PCS that was initially denied, the move was denied." The Air Force attempts to move personnel to locations that can care for special needs within the family. If a spouse or child has a chronic medical condition, every effort is made to ensure the place the military person is going to will have the services necessary to treat the family member. She has a daughter with special needs. The base this participant was initially sent to did not have the facilities to care for her child. According to her,

.... a boss reviewed my child's medical record without my permission, and led to me getting sent to that base anyways. I think that led what would have been normal marital dysfunction problems to become explosive because it was deemed that I wasn't fighting for our family...

She said, "I wasn't standing up for our family, the injustice... It exploded with an abuse situation that led to family action."

She also said that she was notified when she was being assigned to her previous base, "and so the assignments process had been explained to residents several times before because, the year ahead of us there were several people who got unfavorable locations." She said, “...I was nowhere on that list, with people of higher rank. Like I was not anywhere near, there were so many people in my residency class alone that would have been in the boat for those locations." The Air Force attempts to give their personnel 
locations of their choosing however the needs of the Air Force can always trump these desirable locations.

She further noted that she started the assignments process keeping in mind her daughter's disability and need for services. According to her,

I never filled out the initial EFMP (Exceptional Family Member Program) paperwork for my daughter because I honestly felt like, I'll be assigned somewhere in the U.S., [where] they'll have all the services I need...we weren't requesting to go anywhere overseas.

EFMP is a program that helps determine the availability of specialty medical services for family members that are moving to a new location. She never imagined that there were places in the United States that could not care for her child. She viewed the initial paperwork as unnecessary at the beginning of the process.

She further stated,

Then it came down that we were going to this remote location installation. I filled out the EFMP paperwork, and it got sent there and we got denied because they didn't have a speech therapist. Not in the schools, not in the local area, because they can't get people there. It got denied, and then my boss. The person, the provider who had been seeing my daughter retired so he was following all of her paperwork.

The participant describes that the continuity of care for her daughter was lost in the bureaucratic system and she was allowed to move to an installation without the specialized care for her child.

When asked about choosing to live off base or live on base, she said "I was always told as a medical provider, you should never live on base." One would always have neighbors asking about health care issues. The military healthcare system is not based on a fee for service business plan. All military beneficiaries have access to all care. Medical providers that live on military installations typically have neighbors that will 
seek medical advice without going through the traditional "make an appointment" system.

She further mentioned that all her experiences with family issues and lack of family support were her reasons for deciding to leave the military. When asked about what would have to change for her to be comfortable in the military, she said, "I wish there was some understanding for my life. I wish there was flexibility...flexibility of how we get that accomplished in average over a week."

She also stated

The service I provide generates them revenue or saves them money, whatever, a lot. But yet I'm not given any leeway compared to my enlisted technician, who, oh gosh, one of our technicians in the fall, she got to be let off, showed up in the morning and let off because she moved during the middle of the week and she wanted to go meet the cable person.

She further remarked, “... it’s a lot more of take care of your people. And I don't know how, in other parts of the medical group, there is no support system amongst this section. When finally someone saw I was drowning" She said,

...I've never in my wildest imagination, thought to go up to somebody who doesn't know my kids very well and say, 'Will you take my kids tonight, because I need to come in and work on my charts?' I've never thought, much less... what I would think someone would do is say 'Hey, can I help you, you look like you're struggling?'

Further, she said, "I think it would definitely be harder because, and I've thought about that. They have health care I have health care, medications." According to her, "Using the CDC is no cheaper than any other childcare for me. I pay top money but for an enlisted it would be cheaper." She further mentioned,

The thing that was so great about the $\mathrm{CDC}$ at the last base, is that they were right across the street from me and I knew them so intimately because number one I 
was the CDC medical director and they knew me so much that they were so nice and flexible that I wonder at a big base if I would feel the same way.

The Child Development Center supports itself on a sliding fee scale and is subsidized by federal money.

She mentioned that

At my last base in my office I had a refrigerator where I kept snacks for my daughters, coloring books and crayons activities because I don't know how many days we would be there. They would have to practically eat dinner out of my little refrigerator in my office.

She also cited,

It was a totally different support effort, although that place definitely had its challenges too I mean. But there are PT days, group PT's you were told that parents who need to drop their kids off at the CDC start PT at six thirty where everybody else started at six.

PT is Physical Training, it is mandated that every Air Force member work out at least

three times per week. Many units will do this in a group. This participant noted that the

child development center at her previous base made allowance for this as did her unit.

She also added,

There was a different group sign-in for parents. So I was allowed to be in that same group as an officer and provider. Even though some of my patients actually got slid back another twenty minutes I actually missed a whole other encounter because I need to drop my kids off at 6:30 when the CDC opened. I was still allowed to PT and then start patients and given the same amount of PT time...

She said, "We're short on appointments. The technicians still get PT time. But providers nope, but were held to the same physical standard as them [the technicians]. My favorite I love it, it's such a double standard."

Participant 9 
This Hispanic officer became a single parent after his former wife could no longer care for the children. He stated that his ex-wife had financial problems. He said “...she has four kids. So she was separated from her husband, which it can really cause some hardship. So she told me I could take my daughters, (she has four), my two daughters, if I could." He further added,

So before I even came over here I already knew that was happening, that they were coming to live with me in at my current base So this whole time I wasn't with them, but I knew coming to live at my current location that they was coming to live with me...one was starting junior high school and the other high school.

Until becoming a single parent, he did not realize how challenging being a single

parent is. He said,

I think I got lucky because they were older. So the arrangement, the bus would pick them up to school and that was good but I didn't realize that my life after the military [work day] that I had to fill in what their needs are, so I can't really go home and relax.

According to this father,

When it comes to medical appointment that means I would have to drive a 45 minute drive to come to a medical appointment here and drive back. That was one of the huge challenges, the medical appointments. One example; any time I had to go to school that means I have to take time from work and that kind of interfered because I was in charge of two programs, that was very challenging.

In terms of Family Care Plan, he noted,

The only thing, I'm concerned with, I got somebody that lives right next door if anything was to happen to me they would take guardianship, until the mother flies in to take them back to see their family. That's the only thing, my only concern, anything else I don't have to use them at all.

He said that his supervisor allowed him to take his daughters to medical appointments. When asked about anyone who might have helped him, he said, 
No. I kept it separate. The only thing is I did a lot of afterhours which interfered with family time, and so I had to stay during mental health emergencies at the emergency room. I would stay until six or seven o'clock at night.

According to him,

Sometimes I didn't get home until eleven o'clock at night so it did really interfered with me spending time with them or if they had to do something, I wasn't there or available. They kind of got used to the idea that it's not a dad that gets home at a certain time. I get home, when I get home; they got used to that. It turned out that that's another challenge. We can't really make plans because I don't know what time I'm coming home, [uncertainty has produced] especially huge challenges.

Participant 9 mentioned,

When I came on base like [to use] the library, to the computer, or maybe some activity like go to the gym, they went to bowling. Then the shots, the medical shots, they needed shots for school, they needed a physical for sports all that was different times going back and forth that I would have to juggle.

He also said he lived off base. He said, "They told me to live on this side of town was not really a safe environment. So I went over to the west side towards the mountains, a gated community for them. I wouldn't have done it if I was alone. He added:

"... because of them, it kind of changed the trajectory of where I was going to live more for them and their safety and environment away from this side."

When asked whether he felt supported as a single parent in the Air Force, he said "No." According to him:

[There] were times that my daughters got sick and right away they said [take] leave... It was always there, I just didn't want to use it. But when I did use it, it was no problem. I should have used it more. But I like to separate the two.

He noted, "I think I've been lucky because of the age of them being more independent." He articulated the difference between having younger and older children:

[When I] have to come in at five in the morning, I can't imagine those, I would think it would be extremely challenging for those single parent with those 
[younger] age brackets. With mine since they were older and more independent more autonomy that helped me out.

When asked whether Air Force could do better supporting single parents, he said,

Unfortunately I've heard a lot of cases that they're not supportive. Unfortunately they even force leave for medical appointment. Many supervisors will force their subordinates to utilize vacation time to take care of routine medical appointments for family members. I heard that, and I just couldn't imagine that.

He added:

For the times that we spend after hours, we're twenty four hours if it's legitimate medical I can't see why not to support each other. But I just heard a lot of cases that I can't believe how supervisors are not being supportive because they might have a personality conflict so I can use that against you. They always say you have a Family Care Plan, that's your problem. I don't think it should be that way because family is a part of the military.

In resolving this issue, he noted:

I'm not sure because it going to come down to the supervisors' relationship. No matter what we have in place, if you and I are not getting along I might not get to exercise the opportunity anyway if it's going to be a conflict.

According to this father:

The ones I've seen its always been a personality conflict then I can throw at you the Family Care Plan so then it comes down to what kind of relationship you have to get the support and to go the extra mile that most supervisors would not do. I heard once that the government doesn't issue children.

He further mentioned:

I think I touched on everything, I think it's very important for an individual to realize if can't take care of my home, how can I support the mission, if I'm worried about what's happening at home? What kind of stresses that we face in addition to that sometime the mission drive on.

He also emphasized that he finds everything in balance. He said that the important factor in managing work and family is that he was not required to be deployed during his separation with his ex-wife. 


\section{Participant 10}

This officer, a middle-aged White participant, is the only widower in the sample. He became a single parent because his wife passed after being diagnosed with cancer. $\mathrm{He}$ has a 12 year old daughter. In many ways his story is different than the descriptions given so far. He noted that he was so incredibly sad that he had a hard time functioning at first. "I could not be there for my daughter, I was blinded by grief." "It all seemed so overwhelming." "I didn't think about my career, my daughter, just me... it seems so selfish now."

This participant is a pilot, which often means non-traditional work hours. "I had to maintain my flying hours to keep up my skill level, but I wasn't sure how to make that happen with [my daughter]." "It was difficult at first because of the shock of losing [my

wife] but soon the day to day reality set in." "Buying groceries, cleaning the house, [attending my daughter's] school activities." He noted that he had a lot of help from his work center as well as family members. "The people from work were great, very supportive." "Everyone seemed to be there just when I needed them." He continued with "my brother flew in right away; I didn't expect him to do that." He also stated, "My mother-in-law was a God send, she had so much strength, after all, it was her daughter that died. She was really there for me and [my daughter]."

He noted that he never had an issue with childcare because "the wives in my unit stepped in and took over." "They brought meals, cleaned my house, and even took care of [his daughter]." In the following months, the help slowed down for this participant. "I didn't realize how much work my wife did on a daily basis." He noted that he was tired at 
first, trying to get into a routine that was good for him and his daughter. The grief was overwhelming and he was trying "to keep it together for [his daughter]."

This father stated that the "Family Care Plan was a necessary evil." He maintains a Family Care Plan but only because "I'm an officer and I have to maintain good order and conduct for my subordinates. I cannot expect my troops to do the right thing if I don't." He noted that the Family Care Plan was useful in establishing long term care for his daughter, but the short term care was not really useful. "I used different friends depending on the situation." "If I had to come in early, my neighbor helped; if I stayed late, my daughter's friend's mom helped....it really depended on my needs." "I don't think putting one person on the short term list is realistic."

Participant 10 utilized the Youth Center the most out of all the military programs. "[My daughter] loves the Youth Center, she has friends there and they offer so many activities, it really has been a God send." He briefly utilized the Military One Source service to obtain a counselor to speak to his daughter about the loss of her mother. He was hesitant to speak of this because pilots adhere to a higher standard than most military personnel. Any time pilots obtain any type of mental health service they can be removed from their flying status until it is determined they are safe to fly. "I was afraid to get help but Military One Source offers a service that is not reportable to the command, this made me feel better about going." He went on to say, "this service is great because one does not have to feel like everyone will know their business."

He has always felt supported as a single parent. "My work has always been great. There were times that other pilots would trade flying missions so I could make my family situation work." There have been a few times that he had to ask for help from his 
extended family. His mother-in-law came to stay with his daughter when he was tasked to deploy to [a combat zone]. He stated

The deployment was hard in and of itself; leaving [my daughter] so soon after her mother passed was hard. My mother-in-law was truly amazing; after all, she had just lost her daughter. I think it was good for her too.

Participant 10 went on to state that he has become more accustomed to being a single parent. He is unsure what the future holds for him and his daughter when it comes to his flying career. He is hopeful that she will understand, but if not he will re-evaluate his career flying for the Air Force.

\section{Participant 11}

This young, White, enlisted man became a single parent after entering the military. He had a girlfriend, also active duty in the military who became pregnant during their time together. She was "not ready to be a mother, so I stepped up." There were significant changes for him. He moved from the dorm to an apartment off base and had to make allowances in his day to day life because he was now a full time father.

"My girlfriend did not want to be a parent. She wanted to focus on her military career and go to school. It was not part of her plan to have a child." He went on to note, "She had planned on giving up [my daughter] for adoption but I couldn't do it. I wanted to raise her." According to him, "She still sees [my daughter] but I care for her full time." The father revealed, "It was amicable but maybe later it will be more difficult...with her being a girl and all, not sure I can measure up to a mom.”

Participant 11 stated "I was scared to death to be a parent." He noted that he loved to hang out with friends and "party." "After all, I live in Vegas; it was my dream to have as much fun as possible without getting into trouble." He noted, "I cannot have 
the life I thought I wanted." He went on to state, "I'm really happy I made the choice I did, I can't imagine a life without [my daughter]."

Work proved somewhat of a challenge for this participant. He was noted to have an active social life before becoming a father. He did have an advantage knowing beforehand that he was going to be a single father. He started looking into childcare first. He took advantage of the two weeks of paternity time granted by the Air Force. The Air Force grants two weeks of paternity time off compared with six weeks of maternity leave. The mother is also offered the opportunity to be granted a discharge because of her pregnancy; however the father is not offered the same opportunity. "I chose on base daycare because it was right across the street from work." He further noted,

I chose to live off base because the [on base] housing wait list was six months. I had just about everything ready when she came home from the hospital. At first my girlfriend wanted to give [my daughter] up for adoption because she thought I couldn't handle it...but I showed her, I got her room ready, base daycare, and my work schedule worked out well before she was born. The hardest part was putting myself second [and my daughter first].

He also noted, "I don't think it would have mattered either way whether I was in the military or not at that point." He went on to note that he later became more appreciative of the childcare financial advantage. Childcare on base operates on a sliding fee scale. He qualified for the lowest payment.

"My co-workers thought I was crazy for taking this on, probably because I was so into myself and partying." He noted that, "My supervisor was very lenient with flex time but that became less needed as I got a schedule going for my little girl." On the contrary, "My extended family did not really help out, I didn't expect them to. They never were there for me in the past; I didn't expect them to be there for me now." He further 
commented, "My co-workers helped out somewhat...once I had a briefing to do but the daycare called and I had to pick up [my daughter]. They (his co-workers) stepped up that time and did the briefing." There were other times when he did not feel as supported,

I know being a single parent is hard, but sometimes my co-workers make fun of me....saying "we're going out tonight, oh, right, you can't go" and then they laugh. I wish they could understand my situation, but I don't think anyone can who hasn't been there.

Participant 11 knows there are going to be some difficulties in the future. For example he noted that he has an assignment pending to go to an overseas location. $\mathrm{He}$ feels lucky that he gets to bring his daughter with him.

I could have been selected for an assignment to [a location that does not allow children]. I'm not sure what I would have done with [my daughter]. I really don't have a long term caregiver; hopefully her mom could help me out.

Participant 11 went on to convey that he has not yet deployed and has not thought through the long term childcare plan. "I guess I'll figure it out when it happens."

This father has mostly felt supported as a single parent and is proud that he has done "pretty good over the last 3 years." The participant believes the Air Force should better "educate single parents on what is available and to ensure all supervisors know the resources.”

\section{Participant 12}

A mother of two, this young, White, enlisted woman became a single parent through divorce. She joined the Air Force with two children and a husband. Her husband was not in the military. She was unemployed in the civilian community and wanted health care benefits and a stable paycheck. She and her husband went to the 
recruiter and she was accepted but her husband was not because of a medical condition that made him ineligible.

"About a year into being on active duty, my husband started having an affair...I just couldn't live with someone who cheated." She was afraid that she could lose her children because she was active duty "with the possibility of deployments and all." This situation resulted in a court battle. She did not want to lose her children or job. She retained custody of the children while the court was making a decision. She believes she was granted custody because of her "stability in the military and his lack of job." After the hearing, her ex-husband moved away. He occasionally sees the children for some school breaks but she feels she is "truly on my own." He has remarried (to the woman with whom he was having the affair) and lives in another state.

The first problem she encountered was childcare. Even during the custody battle, he cared for the children. "He was a stay at home dad, so we didn't worry about daycare." This participant's children were school age and she turned to the Youth Center for before and after school care. "I love the Youth Center; they are a safe place and my kids love it." She felt that they were in a safe environment doing "wholesome" activities. She also was appreciative of the sliding fee scale offered by the Youth Center.

After the court battle for custody, I really was tight on money. The first year was tough, just kept praying the car wouldn't break down or my mom's health would hold out. I couldn't afford a plane ticket home or even worse [I didn't know] who would take care of my kids. At least I didn't have to worry if something broke in the house.

She was already living in on-base housing,

Thank God I was already living on base. That made it easier on me to get my kids to the Youth Center. It was very convenient. All the kids' friends lived in the 
neighborhood. I think this made it an easier time [for them] to get used to dad not living there...I think they adjusted well.

The Family Care Plan is not useful to her.

I don't understand the family care plan, it seems like unnecessary paperwork. I'm going to call whoever is available (when I am deployed) not just the people I listed on the form. That is not real life; the Air Force should be more flexible... of course I put the form together, like they want me to... it just isn't what I'm going to use if I get a phone call at o-dark-thirty... whoever I can find and trust, is who is going to watch my kids.

She feels very supported at her work. She was already stationed at this base before becoming a single parent. She feels as if she has proven herself to her colleagues that she is a worker. "The people at work already knew I was a good worker, that didn't change just because I was now a single parent. I may have been more tired, but work still got done." Participant 12 noted that she has been fortunate to have a great supervisor. "He is flexible when I come to him with a parent issue." She feels he is able to understand her and "where I am coming from." She stated, "This is the most important part of making being a single parent work: your supervisor." She went on to note that she believes if her supervisor were not flexible and understanding, she would have to reevaluate whether she could stay in the Air Force.

\section{Participant 13}

This young, Black female joined the Air Force as a single parent. Her daughter was 5 years old. She wanted to provide a better life for her daughter. She indicated that she wanted a steady paycheck and health care benefits. "I want my daughter to be proud of me. I thought joining the Air Force would give me the opportunity to provide [for my daughter financially] and to make her proud of her mom." Her extended family was very 
supportive and pushed her toward the military, not because it was the "military" but because it offered security that she could not find in the civilian community.

I don't think being a single parent is harder in the military...I get a regular paycheck, I have a career, yeah, so you don't have that when you take whatever job comes along. I have to still make time for my daughter and make sure all my work stuff is completed, that is still the same [as being a civilian single parent]. I hardly ever ask for anything from my supervisor; he treats me the same, I guess. I never really noticed any favoritism, but I don't expect it either.

Participant 13's co-workers "would be there for me, if I needed them. I really try to do everything on my own and only ask if I really need something. I don't want people think I'm taking advantage of being a single parent."

Participant 13's childcare and housing requirements were met based on financial need and availability.

My daughter goes to the daycare on base. This works best for me because it is close to work and it doesn't cost as much as downtown. I live off base because that is where I could find an apartment once I got to [this base]. The waiting list to get on base was way too long and I needed to get settled fast. I [would have] liked to move on base but it seems like too much work at this point plus I don't want to change elementary schools... it is important that my daughter has very little interruption in her life.

As far as deployment is concerned, this participant stated, "I will deploy soon and I want her to be comfortable. My mother is coming out to help." She added that staying in the apartment maintains a steady environment for her daughter. She stated, "If it wasn't for my mom, I'm not sure what I would do as far as deploying." She became somewhat tearful during this part of the interview. She was tearful because she was extremely grateful to her mother for always being there for her. "My mom is so proud of what I'm doing, I don't want to let her down, but I don't know how I would do it without her." 
This mother said that for her, “The Family Care Plan doesn't really help me...you have to have civilians on the paper and I don't know anyone that I really trust." She further noted, "My mother will come out if I need her. I use her whenever I have to go TDY or when I had to do Airmen Leadership School.” She has noted that she has asked her neighbors to be on the short term caregiver list. "They have all refused. I don't blame them. Why would they want to be responsible for a child they don't even know?'

When speaking of her work situation, "My work is pretty flexible, if you mean they don't give me a hard time if I'm late sometimes or my daughter gets sick. No one ever was mean or anything. I guess they are understanding." She noted that she is appreciative of her supervisor and her co-workers, not just because they do not give her a "hard time" but because "I know they would be there for me if I needed them."

\section{Discussion of Themes}

The final analysis of determining themes is the heart of the results of this study. The master table of the themes discovered is shown in Table 7 and then discussed thereafter. The table illustrates each super-ordinate theme and the associated emergent themes found. 
Table 7

Master Table of Themes

1. Transition to Single Parent in the Air Force

Pregnant young, without partner

Divorced/widowed

Gave up custody then regained it

Relationship issues

2. Better Life

Military as a family

Material security

Appraisal support

3. Parental Responsibilities

Childcare

Education of children

Sole care of child

4. Work Responsibilities

TDY (temporary duty at another location)

Work schedules

Exercises

Deployment

5. Supports provided by work organization

Air Force family programs

Understanding supervisor

Support from peers

On/off base

6. Informal Social Supports

Family

Friends

Church

7. Work-family conflict

Child with special needs

Family Care Plan 


\section{Transition to single parent in the Air Force}

The first super-ordinate theme was introduced during the previous chapter when a description of the analytic process illustrated how the theme emerged. All participants voiced their commitment to raise their children alone despite the bureaucracy. The participants became single parents through divorce, death or were never married to their partner. The following is a discussion of the findings as they pertain to each emergent theme in support of the super-ordinate theme.

Pregnant young, without partner. Six of the participants discussed becoming pregnant at an early age with no support from their partners. These young people either tried to establish an adult life for a short while in the civilian community or immediately joined the Air Force. This population enlisted in the Air Force without having any experience as military members or without much experience living as a single parent. Participant 1 stated:

Well, we were both young, and we were trying to work it out for the first year, and then, guys just mature late, late so he was still immature. [I] left Houston and moved to Killeen Texas, and then my Aunt and Uncle, were in the military so they are the ones who gave me the idea to get in and finish high school and get a degree and then have a career for me.

Participant 13 also had a difficult time establishing a co-parenting arrangement with her young boyfriend. "I got pregnant with my then boyfriend. It never really worked out for us, we were way too young. I tried to make it on my own but it was really difficult. I decided to join the Air Force so I could better take care of my son." 
Divorced/widowed. Six of the participants were single parents because of divorce. All but two were on active duty at the time of the divorce. One was serving in the reserves (later coming onto active duty) and the other divorced and then joined. One participant was widowed. This population may have already known the military bureaucracy but they were not experienced single parents.

Participant 5 who experienced a divorce due in part to the stress of military life, stated:

[We]...kind of raised our kids and did the reserves and had the civilian job and went to school and then came back on active duty, and the first three years of my active duty we had a deployment...I think the stress of that deploying and the multiple TDY's, you know him having to do the single parenting, the stress of me having to do the single parenting when he had been deployed or TDY'd, just caused our marriage to dissolve.

Participant 10 stated:

My wife passed away five years ago from breast cancer...I was not prepared at all to be a single parent. My work and family helped with the transition, but I didn't want to give up my career and I still had to be a dad.

Gave up custody and then regained. Five participants gave up custody of their children due to the prohibition of enlistment of single parents with dependents under the age of 18 at the time of enlistment. All of them regained custody of their children after they were established in the military.

Participant 12 recounted her experience: "My kids were like 4 and 7, I think. I signed over custody of my kids to my mom while I went to basic and tech school. I regained custody when I arrived here."

Participant 3 noted:

[I first thought that] I would have to either get with my daughter's father to see if he would get custody of her while I was in training and then I would be able to get 
my daughter back...[Instead] ... what I did was give my mom temporary custody because we weren't married and he wasn't living in the same state I was.

Relationship issues. All participants reported some level of relationship issues with their partners.

Participant 1 stated: "Well, we were both young, and we were trying to work it out for the first year, and then, guys just mature late, late so he was still immature."

Participant 5 related that she and her husband went to the recruiter and she was accepted but her husband was not, because of a medical condition that made him ineligible.

About a year into being on active duty, my husband started having an affair. I just couldn't live with someone who cheated. I was afraid that I could lose my children because I was active duty with the possibility of deployments and all.

She was granted custody and her ex-husband moved away.

\section{Better life}

The participants that joined young, without a partner, and gave up custody (later regained) all wanted a better life for themselves and their children, and believed that they could have financial stability and support in the Air Force.

Military as a family. This emergent theme was noted in the interviews. The Air Force makes a concerted effort to establish this culture. The Air Force understands that its members are living far from home and family. Establishing this culture, helps the members feel like they are a part of something and that they will be taken care of by the family.

Participant 2 stated: 
I was really scared and freaked out when I was pregnant. How am I going to do this military thing alone and such? But since I've been in [the Air Force] people [Air Force personnel] have been there [for me].

Participant 3 also was clear about her belief in the supportive nature of her service, "My military family always comes through for me, whether with watching my child or just being there for me."

Material security. Participants noted that having or keeping financial security was important in their decision to join or remain in the Air Force. Financial security does not always manifest itself in the paycheck alone; the military offers free housing and healthcare.

Participant 12 stated the following: "I kept getting laid off or let go because of the economy. I needed health benefits and a steady paycheck. The Air Force offered all that."

Participant 13 reported: "I tried to make it on my own but it was really difficult [financially]. I decided to join the Air Force so I could better take care of my daughter."

Appraisal support. Appraisal support was noted earlier as support that is provided indirectly by the organization by providing a way of life that cannot be compared to any other organization, such as taking pride in serving in an organization that is so unique.

Participant 13 also noted along with financial support the following: "I want my daughter to be proud of me. I thought joining the Air Force would give me the opportunity to provide (for my daughter financially) and to make her proud of her mom."

Participant 1 recounted her family's positive appraisal of being in the armed services: 
...my aunt and uncle, were in the military so they are the ones who gave me the idea to get in and finish high school and get a degree and then have a career for me and then give [my daughter] a chance to do it too.

This theme resonates with all the participants striving to make their time in the military and being a single parent work for them and their children. Most stated that it was at times difficult but they were content in their choice.

\section{Parental responsibilities}

Air Force single parents face many of the same issues as their civilian counterparts. Each of the below emergent sub-themes could just as well be discussed in any single parent study. The emergent themes discussed here have a military foreground, since there are bureaucratic factors that both assist military parents and that restrict their parenting activities.

Childcare. Childcare in the military has been discussed at length in previous chapters. A short synopsis will be given about the system of support for the care of minor children. There are two types of official military sanctioned childcare: (a) child development centers and (b) family childcare. Air Force parents may also utilize civilian childcare which includes formalized childcare centers as well as informal babysitters.

Military childcare centers operate on a "duty day" schedule, meaning typical business hours. They are not a $24 / 7$ operation. The centers charge on a sliding scale fee, utilizing the member's rank to determine fees. Family childcare is a military sanctioned and inspected home childcare program. Military base housing residents may open their own small business offering childcare. This business is overseen by the base's childcare center. These small business owners can decide on their own hours and fees. This system was developed to help military members who do not work "typical" duty hours. 
Each of the participants utilized childcare in some form. Examples of interviewees' experiences include the reflections of Participant 2 on the difficulty of finding childcare with an irregular work schedule:

Just trying to find someone to watch her, it was just really difficult. When I worked in the clinic it was only eight hours. That wasn't too bad, Monday through Friday, so daycare was open Monday thru Friday and I could keep her there until 4:30. So that was good. But now I work in the ER twelve hour shifts, so I have to find somebody to watch her. Pick her up at four; watch her the rest of the night until I get off. So one week we work five days at a time, next week we work two. So it goes back and forth, so I have to find somebody to watch her every day when I work so that's really hard and daycare closes at six. So I think that's the biggest part trying to find somebody to watch her.

And Participant 7 talked about the costs of not being able to access onsite care:

Childcare sucked and it is expensive. I couldn't get right into the base child care so I used an off base facility. It was more expensive and further away. That was a challenge because I have to be at work at seven. Sometimes we have PT, then I would have to be there by six. This ran over at the end of the day, because she could only be at daycare for so many hours. Now that I'm on base daycare, it goes much smoother.

Whether childcare was found on or off base each of the participants noted the same frustrations with obtaining affordable childcare that fit their work schedule.

Education of children. Many of the participants had school age children who also utilized some sort of out-of-school care arrangement, which could be difficult to find. The parents stated that coming home from work and having to help with homework was a challenge, as noted by Participant 9:

I think I got lucky because they were older. So the arrangement, the bus would pick them up to school and that was good but I didn't realize that my life after [work] that I had to fill in what their needs are, so I can't really go home and relax.

Participant 3 talked about her twins' new situation: "I was excited because of the fact that they had just started full time kindergarten at school." She also mentioned that 
her daughter's school was far from where she worked, however, and that it was

sometimes challenging to coordinate her daily activities with picking up her daughter.

She stated, "So it would take me literally 20 minutes to go there and get her and then come back, so it was a challenge."

Sole care of child. In this study, Air Force single parents are solely responsible for their child. There may be other unmarried parents but they did not meet the criteria I set out for this study, since they had assistance from partners or other family members who lived with them. To meet the criteria, participants had to have full custody at least nine months of the year, no other adult living with them and to have a least one minor child in the household. The parents noted the stressful aspect of being the sole caregiver. Participant 2 said:

I left for OTS when he was three. He called me one day, I remember the most traumatic thing was, he calls and I'm a month into it, I'm miserable, it's horrible and he's like "I want you to come home Mommy"? (simulated crying) I'm like "I want to come home"(simulated crying). But we got through it, I got through OTS.

And

Participant 4 described the change that came into his life after divorce:

I used to stay late for scheduled things, that was a new one to get used to because I remember for six years of my Air Force career was do whatever needs to be done because there's somebody at home to take care of the kids.

\section{Work responsibilities}

There are two big differences between single parents in general and Air Force parents: all of the Air Force single parents are employed with health insurance and housing and they go to war. The following emergent themes were found during the analysis of statements about work responsibilities: TDY, work schedules, exercises, and 
deployment. All participants were affected to some degree by each of the subthemes. It is in the arena of work responsibilities where bureaucracy is most pronounced in this study.

TDY (temporary duty at another location). All military members are subjected to TDY. TDYs can be as short as one day or as long as 364 days. These days of off-base duty are only for training purposes, not to be confused with deploying to a combat zone. Deployments will be discussed later in this section. All participants have been TDY sometime during their career. This raises an issue for the single parent, as it directly impacts the care of their children. Participants with younger children had the option of sending their children to stay with a family member. Participants with school age children had to make arrangements for childcare at their home. The following two quotes capture what these parents are doing to keep their children's lives stable despite the challenges of TDYs. TDYs could be scheduled as far out as six months or could be short notice of a day or two.

\section{Participant 2:}

I've just been fortunate that I have this great family support system, so they've not always been in town but I've always been able to just send him. And so he's stayed with different people, and mostly they've fought over who gets to keep him as opposed to [who] doesn't get him.

Participant 13 noted: "My mother will come out if I need her. I use her whenever I have to go TDY or when I had to do Airmen Leadership School.”

Work schedules. Work schedules can at times be unpredictable in the Air Force. Although many occupations offer stable schedules, some do not. Air Force personnel can only be in one of four statuses: (a) duty; (b) leave; (c) pass; or (d) hospital. Duty status 
indicates that you are available to work. Leave status indicates that you are on vacation and unavailable to work. Pass status is never longer than three calendar days and is essentially "free" time off. You are neither on duty nor taking official vacation time. Hospital status indicates that you are being treated in an inpatient unit. Military members are on duty $24 / 7 / 365$, unless they fall into one of the other three categories.

The participants in this study discussed a multitude of different work schedules. Some were very predictable and some were not. Examples of how participants struggled with these schedules are noted below.

Participant 10 is a pilot, which often means non-traditional work hours:

I had to maintain my flying hours to keep up my skill level, but I wasn't sure how to make that happen with [my daughter]. It was difficult at first because of the shock of losing [my wife] but soon the day to day reality set in.

Participant 4 remarked about the difficulty he experienced managing an irregular work schedule with his three children:

The thing that helped me the most was my flight chief in the ER just making that move getting me out of shift work, getting on to a Monday through Friday [standard shift] so that I could be there for the kids in the evening. That was a big help.

Exercises. Exercises are a big piece of serving in the Air Force. Exercises are utilized to maintain our combat skills. Exercises can be different from base to base; however the basic premise is the same, training in your combat skills. Exercises are usually forecasted a year at a time but they can be called with only an hour's notice. Exercises typically mean twelve hour shifts or longer and can run into weekends. Participants noted that these exercises often impacted their parental responsibilities. 
Participant 3 revealed that she had to find flexibility in her child care arrangements, including supervising her daughter while she was on the job:

Our work hours are 7:00 to 4:00, and when we have different shifts, if we have exercises, that's when I use my FCC [family child care] provider or I'll arrange for somebody to come pick her up, or I'll bring her into work with me.

Participant 4 discussed the way in which her child care provider supported her during times that she engaged in exercises: "Even the exercises weren't bad because my very first day care provider was just phenomenal...it was easy she just worked with me on everything so I got lucky in that aspect."

Deployment. Deployments in the Air Force can be difficult for all personnel but can add more stress to single parents. Every Air Force member is subject to deployments. This often means six months or more away from your family, usually in a combat situation. Of note is the bracketing during this part of the analysis. As an insider social worker speaking to military members returning from deployment, it is especially difficult to be acclimated to a non-combat environment. Their sleep and eating patterns are disrupted and they are put back into a work or family situation that has been moving along at a natural rate. They often feel overwhelmed, left out, and lonely during this transition period. Single parents that are making this transition do not have another adult to help the children transition or to help the single parent, when they are again solely responsible for their children.

Participant 2 cited a period of lengthy deployment as a time that was particularly troublesome for her as a single parent. She said, "I guess the only thing where there has been trouble is when I've been deployed for the longer periods of time." During these periods, she said her son began to show anger and anxiety issues. 
The stress of change of primary caregiver was a particularly challenging aspect of deployment. Participant 6 said that her son stayed with her mother and said that it was hard for him to come back home from staying with Mom.

Family support was crucial for some. Participant 7 noted,

...I had a couple of deployments come up and then fall through. Then I got notified, like eight days, after I thought I was in the clear they were like you need to be there by the eighteenth... so I called my Mom and my Mom said 'of course.' She came out in like a week.

A positive outcome of deployment was discussed by Participant 5:

The deployment [support] was fantastic. Red Cross offers all kinds of great programs for the kids. They have a lot of scholarship programs. So when I deployed, [I found out about] things that I wasn't aware of as a single parent before.

\section{Supports provided by work organization}

Supports discussed by participants included having an understanding supervisor and receiving support from their peers. Each is discussed below with examples pulled from the transcripts. This theme was expressed extensively throughout the interviews. It was only overshadowed by Family Care Plans (discussed later in this chapter). Having peer, and more importantly, supervisor support made all the difference in their work as well as their family lives.

Understanding supervisor. All participants noted their current supervisor or past supervisor as having a direct impact on their ability to be successful in their role as a parent and as a worker. The following quotes emphasize the ways in which the attitudes and behaviors of supervisors made a difference in how the participants viewed work and their ability to care for their children. 
Participant 1 said she felt that her supervisors and co-workers were not very considerate of her situation as a single parent. She said, "It's bad because one of the supervisors is a single parent himself, but he doesn't have to do the same shifts we do, so he doesn't really have to worry about it." She continued,

So I think he kind of forgets how single parents are and I'm the only single parent in the entire work[ group]...he does eight hours and leaves at four, so I don't think he really understands or remembers how it is, so I don't really get a leeway at all.

In contrast, Participant 3 cited her supervisor as being helpful, particularly by allowing flexibility in her schedule. She explained that her supervisors usually understand. She said, "I let my supervisors know what's going on most of the time, any issues that come up, so I haven't really had too many problems with that."

On the other hand Participant 9 talked about rigid supervisors:,

Unfortunately I've heard a lot of cases that they're not supportive. Unfortunately they even force [using] leave for medical appointment. Many supervisors will force their subordinates to utilize vacation time to take care of routine medical appointments for family members. I heard that, and I just couldn't imagine that.

Support from peers. The participants also noted that support from their peers was invaluable and made the difference in determining a good work environment and a poor work environment.

Participant 2 said, “...I’ve been extraordinarily lucky I think with having people [supporting me], co-workers, bosses and sponsors."

Participant 1 said that her co-workers were the most accommodating of all those in her workplace. She said, "Very [helpful], they volunteered to help." 
On/off base. All participants were impacted by their decisions to live on base or

off base and to utilize on base or off base services. These services included housing and

childcare. Participant 1 noted fear of living in a community that she deemed unsafe,

[The] main reason [I chose to live on base in this town is safety], and it's just me and her, I'd be too scared to live off base. I wouldn't be able to handle it. I want her to be able to go outside and me not worry. So on base I know, well nothings ever secure, but it's a little better than off base. So I wanted that peace of mind especially in [this town]. [This town] isn't a family place to be.

Participant 4 noted the following surrounding the cost of living and ease of

children being close to her work,

Money was a big issue, rent in [this town] is huge, gas prices have started to climb so driving to and from base was expensive. Plus my kids were [in] elementary [school] at the time. [It was great] having them being in an elementary school that was twenty-five minutes away from work. I like to be close by in case something happens.

Participant 11 stated that childcare was expensive off base,

Childcare sucked [off base] and it is expensive. I couldn't get right into the base child care so I used an off base facility. It was more expensive and further away. That was a challenge because I have to be at work at seven. Sometimes we have PT (physical training), and then I would have to be there by six. This ran over at the end of the day, because she could only be at daycare for so many hours. Now that I'm on base daycare, it goes much smoother.

\section{Informal social supports}

Informal Social Supports in this study were identified as extended family, friends/neighbors and fellow church members. These social supports were acknowledged by participants as helpful in meeting the demands of serving on active duty as a single parent. 
Extended family. Most of the participants indicated that their extended family was crucial in helping them during critical times, such as short notice TDYs or wellplanned deployments. A few of the quotes:

Participant 1 said that her immediate family was very helpful with taking care of her child. She stated, "Yes, a lot. When I was deployed they watched her for the entire six months." She continued to explain that she is very lucky with regard to her parents and siblings being so helpful.

Participant 10's mother-in-law came to stay with his daughter when he was tasked to deploy to Afghanistan, since he was newly widowed. He stated

...the deployment was hard in and of itself; leaving [my daughter] so soon after her mother passed was hard... My mother-in-law was truly amazing; after all, she had just lost her daughter. I think it was good for her too [to focus on my daughter's care].

Friends/neighbors. Every attempt was made to clarify the difference between support received from co-workers and from friends within the interview. These were at times one and the same. The participants noted that many times they relied on friends and neighbors to help. In one case, a virtual stranger in the apartment complex came to the aid of the single parent. Participant 1 was forced to work one weekend when no other employees were available and had to leave her daughter with someone she barely knew. She said, "I couldn't switch with anybody and it was really, really hard, and I had to find some random person that I talked to a couple times."

Participant 3 stated "So basically, family and friends either from home or where I've been deployed (have helped)." 
Church. Two participants noted fellow church members were supportive to them. Participant 3 said that coworkers, service providers, and friends made at her church had been helpful in caring for her daughter. She said,

It's been mostly my military family or my FCC providers or my friends that I've made in church or my hairdresser that I've had for the six plus years since I've been here. So basically, family and friends either from home or where I've been deployed [have helped].

Participant 7 also utilized off base programs through a local church. Participant 7 said, it was "like a spiritual healing program" and child care was associated with it.

\section{Work-family conflict}

This theme is extensive because of the many factors discussed in the course of the interviews, including both responsibilities and supports. The layer of the bureaucracy is crucial to this theme. The military has already been defined earlier as a bureaucracy that was capable of social supports and the ability to change with its environment. There are two emergent subthemes themes discussed: (a) child with special needs and (b) Family Care Plan.

Child with special needs. Only one participant revealed that she cared for a child with special needs. Although, this was not a running theme with all participants, it was especially worth noting, since the parenting demands were extremely taxing. This participant divorced after entering the military. The relationship with her husband resulted in an abusive situation. After her initial training, she was sent to a remote base that lacked services for her child. The leadership at this initial base was noted to be excellent and flexible. The Air Force moved her to another location that could accommodate her child's special needs. At her present base, she was receiving all the 
needed services for her child however the leadership was not understanding or flexible.

This is captured with her words below:

I wish there was some understanding for my life. I wish there was flexibility. I wish I could say, "Hey I understand you want me to see eighteen, twenty-two patients a day. Well let's have some flexibility of how we get that accomplished in average over a week. Could I work longer today to have extra time here or some flexibility in patient scheduling?" To not feel like if I ever am doing something not right.

Family Care Plan. Although, not noted in the above themes, it is the physical representation of the bureaucracy with which these parents have to contend. Ensuring the Family Care Plan is carried out is at the basis of all decisions made by the participants. Formal arrangements designating who cares for the child when the child is sick and the member must report for work, and who cares for the child when the member deploys, are all tied together in the Family Care Plan.

Family Care Plans are utilized by single parents to ensure their children are cared for during the parent's absence. This absence can be as short as one hour or as long as one year. This plan was outlined in detail in preceding chapters; however the following is a short summary. The Family Care Plan has two sections, one for long term care and one for short term care of dependents. The long term care provider can be anyone the single parents designate as appropriate for caring for their children while away from their home station. The short term care provider has to be a local person that is not on active or reserve duty. The impact of the Family Care Plan was generally negative on the participants. They tended to view the documentation as hard to produce or to give accurate information. 
Participant 1 said that the Family Care Plan is a nearly useless element of bureaucracy. In response to a question regarding the effectiveness of the Family Care Plan, Participant 1 stated,

I don't think it does anything. You can have people, on there, and the next minute they PCS (have a permanent change of station) or they deploy. Civilians, they can just up and move, so they can get fired. I mean, it doesn't, I don't think it does anything. It's just a piece of paper that you have to have names on it.

Participant 2 mentioned that it is difficult to find local people to take care of her

child. She explained,

The problem's always been that they want all these local people and most of my plan has always been, to send him to live with family members that are not local. Typically there's not been local people that I would want to [have him stay with].

Participant 4 said this requirement was a hindrance. He stated, "[The Family Care Plan] hinders me a lot." Participant 4 recounted:

Tracking down signatures is difficult because they want an actual ink signature. You can't have a faxed copy. Asking people, "Can you do this?" and you have to explain to them what it is and what they're signing, because no one is going to willingly sign anything.

In contrast, Participant 7 was the only single parent that endorsed the Family Care

Plan.

It was good, because I had this in my mind anyway. But it really forced your hand at what's your support system, what's the plan you PCS'd or if you deploy, or get pulled out for a week long TDY or all those things.

He added, "So I valued it, like I said, for me, [it provided] structure and stability, so that made me create some sort of structure around the uncertainty of TDY's, deployments, even exercises depending on what was going on." 


\section{Chapter 6: Discussion}

The Air Force is similar to other civilian bureaucracies in how they communicate their expectations. The expectation from the Air Force to its members is to balance the family and work responsibilities. If there is ever a conflict between work and family, the Air Force then expects the member to choose the Air Force and its mission. The military

lifestyle intersects in all areas of the service member's life. One would be hard-pressed to find another employer that would demand this level of dedication (Bowen \& Orthner, 1986; Hoshmand \& Hoshmand, 2007). The Air Force has been proactive in developing policies and supports to help mitigate the conflict between the mission and the family.

\section{Major Study Findings}

Air Force single parents in this study have many things in common but what stands out is tenacity. These single parents are living in an "almost" perfect bureaucracy, which has provided some essential supports. This bureaucracy has had to change over the years to maintain its members, which now include many single parents.

The first two themes of this exploratory study reveal single parents serving in the Air Force come from varied and complicated backgrounds. Six became single parents through divorce, one through death and the remaining participants experienced parenthood without a partner from the beginning. All participants showed a tenacity to achieve work goals and to successfully raise their children in this well-defined bureaucracy. Despite giving up custody to join the Air Force or losing a spouse to cancer, this population persevered, while successfully navigating work and family responsibilities. The participants noted they wanted a better life or to maintain the life 
they were already living in the Air Force. All believed they could find or keep this better life.

The remaining themes: (a) parental responsibilities, (b) work responsibilities, (c) supports provided by the work organization, (d) informal social supports, and (e) workfamily conflict were also identified. These themes reveal how parental and work responsibilities are experienced and how work-life conflict affects the daily lives of single parents, and is lessened through supports.

Parental responsibilities weighed heavily on the participants, who revealed that they had to struggle to find suitable and affordable childcare, to arrange for and participate in the education of their children, and to bear the burden of being the sole parent.

Work responsibilities were noted to be particularly difficult by single parents serving in the Air Force. TDYs, work schedules, exercises, and deployments often complicated the life of the Air Force single parent. These parents had to negotiate in a system that was not always "user friendly" or family-friendly in order to get their needs met, while making sure that their children were cared for.

Supports provided by the work organization were discussed at length by the participants. The Air Force family programs were used by most participants because of reasonable costs and convenient location. The importance of having an understanding supervisor was noted by all participants in making the transition to and maintenance of single parenthood. Support from peers was also reported by most participants as being instrumental in maintaining a career in the Air Force. The experiences of on-base and offbase services were diverse among participants, as the use of each was decided based on 
economic practicability, safety, and convenience. Participants' decisions were heavily influenced by their personal views on how safe they felt and their financial stability.

External informal social supports were discussed by participants. They indicated a continued need to rely on resources outside the Air Force, such as extended family, friends and neighbors, and church. These social supports were utilized in various ways. Some provided the instrumental support of childcare coverage for deployments or short term work-related duties; others provided the emotional support of friendship. These supports were noted earlier in the dissertation as being important to single parents.

Finally, work-life conflict was illustrated by the case of one participant caring for a child with special needs, and by the experiences of every participant with the Family Care Plan. Although only one participant had a child with special needs, it revealed another layer to being a single parent in the Air Force. This participant required accommodations so that she could deal with special education and therapy for her child, in addition to the unusual challenges of caring for a child without a partner. The Family Care Plan appears to be at the center of work-life policy as well as a high priority practice issue for those working with single parents. All participants noted at least some displeasure, to outright irritation, with current planning processes embodied in the Family Care Plan.

\section{Contributions to Work-life Literature}

Stressors experienced on the job or in the family are often interrelated. The role overload in both the workplace and the family is one of the stressors for families (Allen \& Armstrong, 2006; Hall, 2007). Job-related stress and work-family conflict can have a 
negative effect on a worker's well-being and health, including the over-stressed single parent (Hammer, Cullen, Neal, Shafiro, \& Sinclair, 2005; Quick, Horn, \& Quick, 1987).

Participants indicated work-life conflict to be part of their experience as single parents in the Air Force, exemplified by difficulties with the Family Care Plan as well as the difficulties reported by the one participant with a child with special needs. These participants noted feeling the Family Care Plan was not beneficial (exception of one participant). The participants were either not putting the correct information on the form or would have more than one caregiver. The participant with the child with special needs found that she was having a difficult time staying on active duty. She was not finding flexibility or help within her work center. As noted in an article by Brennan, Rsoenzweig, Ogilvie, Wuest and Shindo, (2007) flexibility in the work center is important to parents with children with disabilities.

In a thirteen year old article describing stress among single parents serving in the Air Force, Heath and Orthner (1999) concluded that when members received or perceived support from their environment their stress level decreased. Each participant in the current study noted that receiving support, whether formal or informal was important to them being successful in the Air Force. Helpful base programs, understanding supervisors, and supportive friends were instrumental in decreasing the stress levels.

According to Hammer et al.,(2007), Thomson and Prottas (1995), and Kossek and Lambert (2005), having family friendly supervisors can enhance emotional support, which may be more important than policies and procedures designed to help single parents, and may result in higher levels of positive work-life spillover. 
The Family Care Plan was designed to help single parents by making sure they have thought through a pre-arranged plan with designated child care arrangements: both short and long term. This document, according to the vast majority of participants, is not helpful. The basis for the document is to assist parents to plan for the care of their children, but instead adds another burden to the single parent. The long term portion of the plan seems to be working for these single parents; it is the short term portion that causes the most negative comments. These single parents are mandated to find a short term, non-military caregiver within 30 days of arriving at a new duty station. This does not allow for the single parent to acclimate to the new assignment or to meet non-military caretakers.

In this dynamic environment, identifying opportunities to improve the support services provided to servicemen and women is a timely and worthwhile enterprise because of their capacity to contribute both to quality of life issues as well as the primary mission of the armed forces to remain combat ready. In a recently published article (Blanchard, 2012) I invite the military to reexamine its policies and practice affecting single parents. Although the article was written before the analysis of this study, it argues that the lack of research or knowledge about population demands immediate attention (Blanchard, 2012).

\section{Policy}

Policy dictates how the military controls parent status at entry. The United States Department of Defense (DoD) generally prohibits the enlistment of any individual who has sole responsibility for dependents under the age of 18 at the time of the enlistment. 
The various military services have the ability to waive this requirement and many of them have even stricter requirements than the standard DoD policy.

As noted in this study, several of the participants faced this policy head first. They gave up custody of their children only to regain custody after their initial training was complete. The purpose of the policy is to ensure the military member will not be called away from training to take care of a minor child. Changing this policy would allow the family to remain legally intact by giving power of attorney to family members in lieu of legal custody, when the military single parent is unavailable to provide care for the child.

The second policy change that could potentially affect single parents would be modification of policy that governs job assignments and their relation to work-family responsibilities. Here the fundamental norm of "equity" of tasks for all in the same job group is the rule. Policy does not limit or vary work assignments with regard to parental status. The demands that the military places equally on all employees make it a difficult environment in which to be a single parent. There are no exceptions made in the assignment of orders, duty stations, deployments or time off for individuals who have become a single parent due to divorce or death of their spouse (U.S. Code, Title 10, Armed Forces 2007. United States). Social support theory would predict that individuals with strong social support would better cope with these demands (Young, 1999). The military takes this into account at the point of assignment by putting safeguards in place to assure that the service member has taken care of family obligations and will be fully available to all assignments. Of note is the Family Care Plan. It is an arduous requirement for single parents because identifying short term caregivers is difficult in a 
30 day time span. In these cases the single parent is required to have a local individual who is not a member of the military agree in writing that he or she will accept the responsibility of those children with no notice in the event that the parent who is in the military is deployed or otherwise called to duty. An individual who fails to comply with these regulations could receive an immediate discharge from service (U.S. Code, Title 10, Armed Forces 2007. United States).

\section{Family Care Plan}

This policy was discussed at length during the interviews as well as in the results section, and is at the heart of this study, which adds to our understanding of the impact of the Family Care Plan and how this document could be transformed to help single parents. For example, the regulation dictating the requirements of this document could be improved by offering some leeway in the number of days a service member has to complete the short term care portion. Instead of designation of short term care provider within the 30 days now required, 120 days may be a more reasonable time limit. An extended time limit to find a short-term provider will give the member a chance to establish himself or herself in the community. Air Force service members typically do not deploy before 180 days after arrival on station.

\section{Policy Supports}

Policy can also establish supports for single parents. In recognizing and responding to the needs of the service members and their families, Albano (1994) has stated that there have been landmark shifts in military family policy over the past two centuries. These shifts have been made from informal implicit obligations to help meet 
the needs of military families to formal supports that have been institutionalized through the DoD in the form of directives, public laws, and policy statements.

An example of formal supports established by policy is the Airman and Family Readiness Centers. These centers provide services to help alleviate the work-life conflict. The administration of the Family Care Plan could easily be placed within this center. The center could offer assistance in preparing the plan and support because of the need of the plan. A sponsorship program could be created to assign single parents already residing at the installation to newly arriving single parents. (Air Force Instruction 36-3009, 2008).

This program could possibly be the best place to host support to single parents. The structure is already there to push out services to this population, and could provide single parent groups, parenting education, and overall support.

As Albano (1994) noted that "The more the military institution adapts to family needs, the more it will preserve itself as an institution. As family members become increasingly integrated into the military community, there is an increased commitment to the organization" (p.13).

\section{Practice}

Air Force leaders are aware of the stresses that being employed by the military places on the family structure. For example, many of the classes to offered to families assist married couples to deal with the stress caused by deployment. However there are no classes dealing with handling stress caused by being a single parent in an emotionally demanding job. This class could be designed by the same personnel that have designed classes for our spouses left behind when the military member deploys. These classes could be easily tailored to meet the needs of full time active duty single parents. 
The military is also aware of the stresses caused by long term deployments on the family unit. In order to minimize the amount of stress on the family unit and the member, programs and initiatives have been created to help provide the necessary support which results in minimizing the negative effects of long term deployments. While the military's main focus is in responding to situations requiring military force they understand that by providing for the dependents left at home they can create an atmosphere where the service men and women can focus on the responsibilities of their jobs with the knowledge that their family left behind at home is supported by the branch of the military that they serve. Single parents who have completed the Family Care Plan also know that their children are taken care of; however, the individual watching their children is most likely off base and not close to the services located on base. While the children have access to these services, by not being close to those services, it is less likely for them to be utilized. The dependents have access to base services and a power of attorney will provide access to the caregivers. Creating a "to go" packet for the substitute caregivers with all the information they need, could ease the minds of these caretakers that they will have the resources they need during the parents' deployment.

"Childcare is crucial due to an increase in the number of single parents and dual military career couples, along with their odd working hours, rotating shifts, deployment, and frequent moves" (Blanchard, 2012, p. 92). As the solo parent, the scheduled hours of service can be a hindrance. Medical appointments, childcare hours, and school hours impact the ability of the single parent to work and to parent effectively. Extended or flexible hours in child care may help single parents meet both obligations. 
Another program designed to help parents as well as children are military youth programs. They were developed to reach pre-teens and teens. These programs provide this population with structured activities. There is also a wide variety of programs that are designed for school-age children (Jowers, 1994). A training element incorporated into an existing program to train these caregivers could give added assurance to single parents that they and their children are understood. Again, the structure is in place to add this critical service. Military social workers can be instrumental in taking on the responsibility of education of childcare workers regarding the intricacies of raising children without a partner while serving in the military.

Another area of practice that needs to be explored is advocating for one's self. Participant 4 noted that she would utilize her chain of command to ensure she had her needs met. Social workers could educate single parents about advocating for themselves to achieve a work-life balance.

Practice could also be improved through the promotion of flexibility on the part of military supervisors. When an individual serves in the military there is a limited amount of flexibility with regard to family emergencies and the needs of the military come before the needs of the family. Educating supervisors to be more family friendly (Antoniou et al., 2009; Kossek \& Hammer, 2008) would help alleviate the single parents' stress level. In Kossek and Hammer's study (2008), grocery store employees that had less family friendly supervisors were more likely to have worse job attitudes and less likely to remain in the company. Military social workers can assist these members by offering parenting classes for single parents and initiating a sponsorship program that introduces single parents relocating to single parents already established in the military community. 


\section{Limitations}

A major limitation of this study involves the researcher's status as an active duty military social worker. Although there are benefits of this position to the research (i.e., understanding the culture, knowing rank structure and deployment patterns), the limitations should also be noted. The researcher maintains the rank of Lieutenant Colonel. This position does not always allow the participant to freely answer questions during the interview. Every effort was made to ensure the comfort level of the participant. These efforts included the consent form and referral sources that were made available after the interview. The consent form offered confidentiality with identifying demographics removed from the final analysis. The referral sources were given to ensure that the participant was given an opportunity to seek help or information after the interview.

A second major limitation was that the high level of work family-demands of the participants made only a single interview possible. Only conducting a single interview limits the study because the participant may not feel comfortable during the interview and not reveal relevant information. A second interview would have produced more candid responses, as the participant would have been more comfortable in the interview situation. The second interview would have allowed for more follow up questions to be asked. As discussed earlier, the participant may not feel comfortable at the single interview because of the power differential, noted by the researcher's rank and status within the organization, and may have opened up more at a second meeting.

The sampling methods are also a limitation. Participants were selected by convenience and snowballing methods. The convenience sampling may have eliminated 
potential participants because they had not seen the announcement for the study or may have forgotten to call to inquire about the study. The snowball technique also eliminated those individuals that did not know someone participating in the study. Participants were only selected from a single Air Force base.

A disadvantage of in-depth interviews is the possibility of researcher-induced bias. I was a single parent for many years in the Air Force. This bias may have manifested itself in the development of the questions as well as the interpretation of the results. This was mitigated by utilizing the literature to direct my questions and the use of a co-analyst.

The small sample of the study may also be viewed as a limitation but adhering to the qualitative tradition, the in-depth understanding of the realities of a few was of interest and not the broad experiences of many. As this is an exploratory research study, a small sample is ideal to start to understand this population that has not been studied in over 20 years, and examine contemporary and emerging issues.

One final limitation is the lack of inclusion in this study of racial and social justice considerations. This was not a focus of this study but it should be noted that this issue is of utmost importance to the social work profession. This researcher was blinded to the implications of this issue for this study, because of her social status and race. The military does not tolerate social injustice even though it may exist. When race or social injustice is recognized it is dealt with in a swift and decisive manner. Future research should include considerations of the intersection of race, class, and single parent status. 


\section{Future Research and Conclusion}

The literature review of prior studies revealed little in the way of research surrounding single parents in the military. The majority of the research on work and family issues done throughout the years has focused on two-parent family units rather than single parent households. When single parent households were examined the researchers more typically chose single parents employed in the civilian job market.

Understanding how being a single parent in the Air Force may impact moving up in rank or attaining a desired job would be of value for future research. Although, not clearly noted during the interviews, I was keenly aware of my limitations as a single parent to obtain a desirable job. Attending professional military education did prove stressful for at least one participant because of the long hours and study that is required. The question would be "How does being a single parent impact the ability to obtain rank or a desirable job in the military?"

Studying the differences between two parent military families and one parent military families would shed light on the different stressors as well as coping mechanisms each possesses. The impact of the Family Care Plan alone indicates a significant stressor that the one parent family must endure that their two parent counterparts do not.

The differences in the experiences of single parents depending on the age of their children would also be beneficial. In this study, it was noted that the age of the children had a different effect on the family and work dynamics. Participant 9 stated, "I think I got lucky because [my children] older. They could get on the bus by themselves." A more indepth understanding would help shed light on unpacking this phenomenon and pin point the focus of interventions designed to help these parents. 
As concluded by Blanchard (2012),

[The] demands and norms are enforced by both social and legal sanctions. In contrast to their counterparts in civilian life, single military parents are offered an important asset: reasonable job security with fringe benefits (medical, housing, and childcare subsidies; Bowen, et al., 1993). Although these benefits exist, the military should examine its policies to insure that they also meet the needs of this increasing proportion of the military population. In essence, Bowen (1987) has stated that a working knowledge of this segment of the military culture, and sensitivity to the diversity of their needs within it, provides a value-added contribution both to effective leadership by military decision makers and delivery of services by military and civilian employees (p. 91). 


\section{References}

Adams, G. A., Jex, S. M., \& Cunningham, C. J. L. (2005). Work-family conflict among military personnel. In T. W. Britt, A. B. Adler, \& C. A. Castro (Eds.), Military life: The psychology of serving in peace and combat, the military family, (pp. 169192). Westport, CT: Praeger Publishers.

Agar, M. H. (1980). The professional stranger: An informed introduction to ethnography. In J.W. Creswell (Ed.), Qualitative inquiry and research design (pp. 147-176). Thousand Oaks, CA: Sage.

Air Force Instruction 36-3009. (2008). Airman and family readiness centers. 18 January 2008.

Air Force Personnel Center. (2012). Unpublished data from password secured website.

Albano, S. (1994). Military recognition of family concerns: Revolutionary war to 1993. Armed Forces and Society, 20(2), 283-302.

Antoniou, G., Cooper, L., Chrousos, P., Speilberger, D., \& Eysenck, W. (2009). Handbook of managerial behavior and occupational health. New York, NY: Edward Elgar.

Armstrong, B. (2007). Financial relief for single parents: A proven plan for achieving the seemingly impossible. Illinois, IL: Moody Publishers.

Ary, D., Jacobs, L., Razavieh, A., \& Sorensen, C. (2009). Introduction to research in education. Belmont, CA: Cengage Learning.

Bailyn, L. (1993). Breaking the mold: Women, men, and time in the new corporate world. New York, NY: Free Press.

Bakker, A., Demerouti, E., \& Burke, R. (2009). Workaholism and relationship quality: A 
spillover-crossover perspective. Journal of Occupational Health Psychology, 14(1), 23-33.

Balsure, K., \& Arnold-Mann, J. (1992). Return and reunion: A psychoeducational program aboard U. S. Navy ships. Family Relations, 41, (2), 178-185.

Bandura, A. (1977). Social learning theory. Englewood Cliffs, NJ: Prentice Hall.

Barnes, J. A. (1954). Class and committees in a Norwegian Island parish. Human Relations, 7 (1), 39-58.

Barnett, R., \& Hyde, J. (2001). Women, men, work, and family: An expansionist theory. American Psychologist, 56 (10), 781-796.

Barnett, R. C., Marshall, N. L., \& Singer, J. D. (1992). Job experiences over time, multiple roles, and women's mental health: A longitudinal study. Journal of Personality and Social Psychology, 62, 634-644.

Barrera, M., Li, S. A., \& Chassin, L. (1993). Ethnic group differences in vulnerability to parental alcoholism and life stress: A study of Hispanic and non-Hispanic Caucasian adolescents. American Journal of Community Psychology, 21(1), 1535.

Basch, C.E. (1987). Focus group interviews: An underutilized research technique for improving theory and practice in health education. Health Education Quarterly 14, 411-448.

Bernard, H. (2006). Research methods in anthropology: Qualitative and quantitative approaches. Thousand Oaks, CA: Sage Publications.

Bianchi, S. M., Casper, L. M., \& King, R.B. (Eds.). (2005). Work, family, health and well-being. Mahwah, NJ: Lawrence Erlbaum. 
Blanchard, S. E. (2012). Are the needs of single parents in the Air Force being met? Advances in Social Work, 13 (1), 83-97.

Boles, J. S. (2001). An investigation into the interrelationships of work-family conflict and work satisfaction. Journal of Managerial Issues, 13 (3), 376-390.

Bornstein, S. \& Weber, J. (2008). Addressing Family Responsibilities Discrimination. Work-family Information for State Legislators, Vol. 16.

Boss, P. (1987). Family stress. New York, NY: Plenum.

Bowen, L. (1985). Families in blue: Insights from Air Force families. Social Casework, $66(8), 459-466$.

Bowen, L. (1987). Single fathers in the Air Force. Social Casework, 68(6), 339-344.

Bowen, L., \& Orthner, D.K. (1986). Single parents in the U.S. Air Force. Family Relations, 35(1), 45-52.

Bowen, G. L., Orthner, D. K., \& Zimmerman, L. I. (1993). Family adaptation of single parents in the United States Army: An empirical analysis of stressors and adaptive resources. Family Relations, 42(3), 293-304.

Brennan, E. M., Rosenzweig, J. M., Ogilvie, A. M., Wuest, L., \& Shindo, A. A. (2007). Employed parents of children with mental health disorders: Achieving workfamily fit, flexibility, and role quality. Families in Society. 88(3), 115-123.

Britt, T. W. (2006). Military life: The psychology of serving in peace and combat: The military family. Westport, CT: Praeger Security International.

Buddin, R., Ron, B. P., \& Zimmer, W. (2001). Impact aid and the education of military children. Santa Monica, CA: Rand. 
Buddin, R., Gresenz, C. R., Hosek, S. D., Elliott, M., \& Hawes-Dawson, J. (1999). An evaluation of housing options for military families. Santa Monica, CA: Rand.

Burke, R. J. \& Bradshaw, P. (1981). Occupational and life stress and the family. Small Group Behavior, 12, 329-375.

Burr, W. R. (1973). Theory construction and the sociology of the family. New York, NY: John Wiley.

Carspecken, P. F., \& Apple, M. (1992). Critical qualitative research: Theory, methodology, and practice. In M. L. LeCompte, W. L. Millroy, \& J. Preissle (Eds.), The handbook of qualitative research in education (pp. 507-553). San Diego, CA: Academic Press.

Chow, E. N., \& Berheide, C. W. (1988). The interdependence of family and work: A framework for family life education, policy and practice. Family Relations, 37 (1), 23-28.

Cohen, S., \& Willis, T. (1995). Stress, social support and buffering hypothesis. Psychological Bulletin, 98, 310-315.

Cohen, S., \& McKay, G. (1984). Social support, stress, and the buffering hypothesis: A theoretical analysis. In A. Baum, J. E. Singer, \& S. E. Taylor (Eds.), Handbook of psychology and health (Vol. 4; pp. 253-367). Hillsdale, NJ: Erlbaum.

Coser, L. A. (1974). Greedy institutions: Patterns of undivided commitment. New York, NY: Free Press.

Creswell, J.W. (2007). Qualitative inquiry \& research design: Choosing among five approaches. Thousand Oaks, CA: Sage. 
Daley, J. G. (1999). Social work practice in the military. Binghamton, NY: Hayworth Press.

Drummet, A. R. (2003). Military families under stress: Implications for family life education. Family Relations 52 (3), 279-287.

Eastman, E., Archer, R. P., \& Ball, J. D. (1990). Psychosocial and life stress characteristics of Navy families: Family Environment Scale and Life Experiences Scale findings. Military Psychology, 2(2), 113-127.

Edmunds, H. (1999). The focus group research handbook. Thousand Oaks, CA: Sage.

Edwards, J. R., \& Rothbard, N. P. (2000). Mechanisms linking work and family: Clarifying the relationship between work and family constructs. Academy of Management Review, 25 (1), 178-199.

Faber, A. (2008). Ambiguous absence, ambiguous presence: A qualitative study of military reserve families in wartime. Journal of Family Psychology 22, (8), 222230.

Felstehausen, G., Glosson, L.R., \& Couch, A.S. (1986). A study to determine the relationship between the workplace and the home: Final report. Lubbock: Texas Tech University, College of Home Economics.

Figley, C. (1993). Coping with stressors on the home front. Journal of Social Issues, 49 (4), 113-116.

Finkel, L. B. 2003. Geographic mobility, family, and maternal variables as related to the psychosocial adjustment of military children. Military Medicine, 168 (12), 10191024.

Fitzgerald, M. (2004). Militarism: A way of life. The Humanist, 64(6), 26- 27. 
Gates, R. M. (2008). Military child education coalition conference. U. S. Department of Defense Speeches, July 25, 2008.

Garber, D. L., \& McNelis, P. J. (1995). Military social work. In R. L. Edwards (Ed.), Encyclopedia of social work (19th ed., Vol. 2; pp. 1726-1736). Washington, DC: NASW Press.

Goldberg, W. A., Greenberger, E., Hamill, S., \& O’Neil, R. (1992). Role demands in the lives of employed single mothers with preschoolers. Journal of Family Issues, 13 (3), 312-333.

Goode, W.J. (1960). A theory of role strain. American Sociological Review, 25, (4), 483-496.

Grall, T. (2008). Custodial mothers and fathers and their child support: 2005. Current Population Reports, P60-237, Washington, DC: U. S. Census Bureau.

Grbich, C. (2007). Qualitative data analysis. Thousand Oaks, CA: Sage.

Greenhaus, J., \& Singh, R. (2007). Mentoring and the work-family interface. In B. Ragins \& K. Kram (Eds.), Handbook of mentoring at work (pp. 519-544). Thousand Oaks, CA: Sage.

Greenhaus, J. H., \& Powell, G. N. (2006). When work and family are allies: A theory of work-family enrichment. Academy of Management Review, 31 (1), 72-92.

Grzywacz, J., \& Marks, N. (2000). Reconceptualizing the work-family interface: An ecological perspective on the correlates of positive and negative spillover between work and family. Journal of Occupational Health Psychology, 5 (2), 111-126.

Hammelman, T. L. (1995). The Persian Gulf conflict: The impact of stressors as perceived by army reservists. Health and Social Work, 20 (2), 140-145. 
Hammer, L., Kossek, E., Yragui, N., Bodner, T., \& Ginger, C. (2009). Development and validation of a multidimensional measure of family supportive supervisor behaviors. Journal of Management, 35, 837-856.

Hammer, L., Kossek, E., Zimmermann, K., \& Daniels, R. (2007). Classifying the construct of family supportive supervisory behaviors. Research in Occupational Stress and Well Being, 6, 171-211.

Hammer, L. B., Cullen, J. C., Marchand, G. C., \& Dezsofi, J. A. (2005). Reducing the negative impact of work-family conflict on military personnel: Individual coping strategies and multilevel interventions In T. W. Britt, A. B. Adler, \& C. A. Castro (Eds.), Military life: The psychology of serving in peace and combat, the military family (pp. 220-242). Westport, CT: Praeger Publishers.

Hanson, G., Hammer, L. B., \& Colton, C. (2006). Development and validation of a multidimensional scale of work-family positive spillover. Journal of Occupational Health Psychology, 11 (3), 249-265.

Hill, R. (1949). Families under stress: Adjustment to the crises of war, separation and reunion. New York, NY: Harper.

Hiratsuka, J. (1989). Easing the trauma for released hostages. NASW News, January 1989, 5.

Hiratsuka, J. (1991). Social workers lessen Gulf War's trauma. NASW News, March, 1991, 3-4.

Hiratsuka, J. (1993). Somalia force aided to face painful scene. NASW News, February, 1993, 1-12.

Horn, W. F. \& Bush, A. (1997). Fathers and welfare reform. Public Interest, 129, 38-39. 
House, J.S. (1981). Work stress and social support. Reading, MA: Addison-Wesley.

Howard, A. (1992). Work and family crossroads. In S. Zedeck (Ed.), Work, families, and organizations (pp. 70-137). San Francisco, CA: Jossey-Bass.

Jensen, P. S., Lewis, R. L., \& Xenakis, S. N. (1986). The military family in review: Context, risk, and prevention. Journal of the American Academy of Child Psychiatry 25 (2), 225-234.

Kanter, R. M. (1977). Work and family in the United States: A critical review and agenda for research and policy. New York, NY: Russell Sage.

Kelley, M. L. (2006). Single military parents in the new millennium In T. W. Britt, A. B. Adler, \& C. A. Castro (Eds.). Military life: The psychology of serving in peace and combat, the military family. (pp. 93-114). Westport, CT: Praeger.

Kelley, M. L., Herzog-Simmer, P. A., \& Harris, M. A. (1994). Effects of militaryinduced separation on the parenting stress and family functioning of deploying mothers. Military Psychology, 6(2), 125-138.

Kossek, E., \& Lambert, S. (2005). Introduction: Work-family scholarship. In E. E. Kossek, \& S. Lambert (Eds.), Work and life integration: Organizational, cultural, and psychological perspectives, (pp. 3-18). Mahwah, NJ: Lawrence Erlbaum Associates Press.

Kossek, E., \& Hammer, L. (2008). Supervisor work life training. East Lansing : University of Michigan State University Press.

Lengua, L.J., Roosa, M. W., Schupak-Neuberg, E., Michaeles, M. L., Berg, C. N., \& Weschler, L. F. (1992). Using focus groups to guide the development of a 
parenting program for difficult-to-research, high-risk families. Family Relations 41, 163-168.

Lewis, S., Rapoport, R., \& Gambles, R. (2003). Reflections on the integration of paid work and the rest of life. Journal of Managerial Psychology, 18(8), 824-841.

Lincoln, Y., \& Guba, E. (1985). Naturalistic inquiry. Beverly Hills, CA: Sage.

Lindlof, T. R. \& Taylor, B.C. (2002) Qualitative communication research methods (2nd ed.), Thousand Oaks, CA:Sage.

Long, D. (2009). Learned helplessness: The 21st century affliction of single parents. Milton Keynes, England: Author House

Mackey, A., \& Gass, S. (2005). Second language research: methodology and design. Mahwah, NJ: Routledge.

Malhotra, N. (1996). Marketing research: An applied orientation. Saddle River, NJ: Prentice Hall.

McCubbin, H. I. (1979). Integrating coping behavior in family stress theory. Journal of Marriage and the Family, 41 (2), 237-244.

McCubbin, H. I., Joy, C. B., Cauble, A. E., Comeau, J. K., Patterson, J. M., \& Needle, R. H. (1980). Family stress and coping: A decade review. Journal of Marriage and the Family, 42 (4), 855-871.

Mintzberg, H. (1983). Structure in fives: Designing effective organizations. Saddle River, NJ: Prentice Hall.

Morse, J., \& Field, P. (1995). Qualitative research methods for health professionals. London, England: Sage Publications.

Moustakas, C. (1994). Phenomenological research methods. Thousand Oaks, CA: Sage. 
Partis, M. (2003). Hope in homeless people: A phenomenological study. Primary Health Care Research and Development, 4, 9-19.

Pierce, P. F. (1998). Retention of Air Force women serving during Desert Shield and Desert Storm. Military Psychology, 10 (3), 195-213.

Pincus, S. H. (2001). The emotional cycle of deployment: A military family perspective. U.S. Army Medical Department Journal, 4 (1), 15-23.

Polkinghorne, D. E. (1989). Phenomenological research methods. In J. S. Creswell (Ed.), Qualitative inquiry and research design (p. 117-145). Thousand Oaks, CA: Sage.

Price, J. L., \& Kim, S. (1993). The relationship between demographic variables and intent to stay in the military: Medical personnel in a U.S. Air Force hospital. Armed Forces \& Society, 20 (1), 125-144.

Pryor, M., Harlow, D. \& Howes, L. (1982). The dissatisfaction profile: The key obstacle to motivation. Industrial Management, 24 (4), 8-10.

Reimen, D. J. (1986). The essential structure of a caring interaction: Doing phenomenology. In P. L. Marshall \& C. J. Oiler (Eds.), Nursing research: A qualitative perspective (pp. 85-108). Norwalk, NJ: Appleton-Century-Crofts.

Rothrauff, T. (2004). All that you can be: Negotiating work and family demands in the military. Journal of Teaching in Marriage and Family, 4 (1), 1-25.

Segal, M. W. (1986). The military and the family as greedy institutions. Armed Forces and Society, 3 (1), 9-38. 
Shinn, M., Wong, N. W., Simko, P. A., \& Ortiz-Torres, B. (1989). Promoting the wellbeing of working parents: Coping, social support, and flexible job schedules. American Journal of Community Psychology, 17, (1), 31-55.

Shirom, A. (2003) Job related burnout: A review. In J. C. Quick, \& L. E. Tetrick, (Eds.), Occupational Health Psychology, (pp. 245-264). Washington, DC: American Psychological Association.

Simons, R. L., Beaman, J., Conger, R. D., \& Chao, W. (1993). Stress, support, and antisocial behavior traits as determinants of emotional well-being and parenting practices among single mothers. Journal of Marriage \& the Family, 55 (2), 385398.

Smith, J.A., Flower, P., \& Larkin, M. (2009). Interpretative phenomenological analysis: Theory, method and research. London, England: Sage.

Sobh, R., \& Perry, C. (2005). Research design and data analysis in realism research. European Journal of Marketing, 40 (11/12), 1194-1209.

Stacie, J. (2010). Single parents at work - Research and perspectives from professionals. Retrieved from: http://www.singleparentadvocate.org/singleparents/workplace

Stake, R. E. (2005). Qualitative case studies. In N. K. Denzin \&Y. S. Lincoln (Eds.), The Sage handbook of qualitative research (3rd ed., pp. 443-446). Thousand Oaks, CA: Sage.

Stern, J. (2006). Teaching religious education: Researchers in the classroom. London, England: Continuum International Publishing Group.

Swanberg, J. (2006). Making it work. Journal of Psychosocial Oncology, 24, 1-18. 
Taylor, F. W. (1947). Scientific management. New York, NY: Harper \& Row.

Taylor, N. E., Wall, S. A., Liebow, H., Sabatino, C. A., Timberlake, E. M. \& Farber, M. Z. (2005). Mother and soldier: Raising a child with a disability in a low-income military family. Exceptional Children, 72(1), 83-99.

Terre Blanche, M., Durrheim, K., \& Painter, D. (Eds.). (2006). Research in practice: Applied methods for the social sciences (2nd ed.). Cape Town, South Africa: UCT Press.

Thomas, J. (1993). Doing critical ethnography. Newbury Park, CA: Sage.

Thomson, C., \& Prottas, D. (1995). Relationships among organizational family support, job autonomy, perceived control, and employee well being. Journal of Occupational Health Psychology, 11(1), 100-118.

U.S. Census Bureau (2012), America's Families and Living Arrangements, Current Population Reports, p. 5.

Van Steenberger, E. F., Ellemers, N., \& Mooijaart, A. (2007). How work and family can facilitate each other: Distinct types of work-family facilitation and outcomes for women and men. Journal of Occupational Health Psychology, 12(3), 279-300.

Voydanoff, P. (2004). The effects of work and community resources and demands on family integration. Journal of Family and Economic Issues, 25(1), 7-23.

Walker, A. J. (1985). Reconceptualizing family stress. Journal of Marriage and the Family, 47(4), 827-837.

Weber, M. (1978). Economy and society (4th ed.). Berkeley: University of California Press. 
Weeks, S. B., \& Meconis, C. A. (1999). The armed forces of the USA in the Asia-Pacific region. London, England: I.B. Tauris and Co. Ltd.

Whitworth, S. (1984). American military families: Basic demographics. Springfield, VA: Military Family Resource Center.

Williams, P., Barclay, L., \& Schmeid, V. (2004). Defining social support in context: A necessary step in improving research, intervention and practice. Qualitative Health Research, 14 (7), 942-960.

Wingo, J. D. (2002). Growing up as a global nomad. Minerva: Quarterly Report on Women and the Military, 20(3-4), 30-31.

Yin, R.K. (2003). Case study research: Design and method (3rd Ed.). Thousand Oaks, CA: Sage.

Young, L. \& Kleiner, B. H. (1992). Work and family: Issues for the 1990s. Women in Management Review, 7 (5), 24-28.

Young, M. (1999). Work-family backlash: Begging the question, what's fair? Annals of the American Academy of Political and Social Science, 562 (1), 38-40.

Zikmund, W. C. (2000). Business research methods (6th ed.). Fort Worth, TX: Dryden Press. 


\section{Appendix A}

\section{Demographic Form}

\section{Questions for screening potential participants:}

1. How many children are living with you at the current time?

Ages:

2. How many children live with you at least nine months of the year?

3. Is there another adult who lives with you?

4. If yes, does this person help you take care of your children?

5. How long have you been a single parent?

6. Rank:

7. Time in military:

8. Gender:

9. How would you describe your race/ethnicity?

10. Year of birth 


\section{Appendix B}

\section{PROTOCOL FOR INTERVIEWS}

I. Pre-Interview Activities.

A. The participant will be greeted and welcomed, and child care will be provided, if requested.

B. The participant will be offered water.

C. The participant will be given a pencil- and asked to complete the Demographic and Supplemental Questions Form and given two copies of the informed consent.

\section{Interview Start-up Activities}

A. Script for the Interviewer

Thank you for agreeing to participate in this interview. The purpose of the interview to obtain information for a dissertation that is required for a graduate degree in Social Work and Social Research at Portland State University. The purpose of this research is to understand the experiences of single parents serving in the Air Force in relation to work and family. I would like for you to share your experiences as a single parent serving in the Air Force.

I will be asking you to share your personal experiences and I would appreciate your candid responses and impressions. None of your personal information will be attached to any of the reports of results.

Your participation in this interview in this project is strictly voluntary. The interview will take approximately 45 minutes to complete. I will be tape- 
recording this meeting and the tapes will be transcribed into a manuscript. At any time, you can decide not to answer a question.

At this time, I am going to give you the $\$ 20$ gift card to the Base Exchange that was mentioned in the screening phone call. If you do not wish to keep it for your personal use, please feel free to donate it to your favorite charity. You will be asked to sign a receipt. I thank you very much for deciding to give me some of your time for this interview.

B. Informed Consent Forms

I will now distribute forms which are to record your consent to participate in this project. I will be giving you two forms. I will keep one in a locked file cabinet for my records. The other is for you to take home. After we read the forms together, I would be happy to answer any questions that you may have. [Read the form with the participant]

Are there any questions?

C. Start-up Activities

1. May I tape this interview?

2. Test the tape recorder

\section{Interview Script}

At this time, I would like to begin the interview. We have 45 minutes to address a set of questions concerning being a single parent in the Air Force and how it affects your work and family. I am now recording this session.

Let's begin.

\section{Could you describe the circumstances that led you to become a single parent?}


Probe: When did you start being a single parent?

Probe: What were the circumstances? Divorce, death, etc?

2. After becoming a single parent, what work or family challenges or issues did you experience that you had not encountered before you were a single parent?

Probe: Were some family (work) challenges easier or harder for you?

Probe: Which were easier or harder?

Probe: How did you resolve these challenges?

Probe: How did the Family Care Plan help or hinder you?

Probe: Please describe your most recent PCS as a single parent.

\section{Of the issues noted in the previous question, how did you resolve these}

\section{challenges?}

Probe: Who or what helped you?

Probe: Who helped with child care?

Probe: Did your supervisor allow for any "flex" time?

Probe: Did your co-workers give you the support that you needed?

Probe: Did your extended family help?

Probe: Did any formal military programs help you?

Probe: What is your housing situation?

Probe: Why did you choose your particular housing situation?

\section{Describe a time that you felt supportive as a single parent in the Air Force.}

Describe a time that you felt unsupportive as a single parent in the Air Force.

Probe: In what ways do you feel comfortable or uncomfortable?

Probe: What military programs have you used for support? 
Probe: What things would have to change in order for you to feel comfortable with serving in the Air Force?

Probe: What could the Air Force do better to support single parents?

\section{Is there anything you would like to add to our discussion that I may have missed? III. Closing Activities}

I would like to thank you again for sharing your experiences and ideas with me. I hope this research will be a starting point for understanding the experiences of single parents serving in the Air Force. I am providing a resource card in the event you would like to contact any support services after this interview.

If you would like to have a copy of my report from the interview, please write your name and address on this card. A copy will be mailed as soon as the project is completed. Also, I am looking for a few interviewees to participate in member checking. Member checking is where the participant reads my interpretation of the results and lets me know if I captured the meaning of what was being stated during the interview. If you would like to participate in member checking please indicate that on the card. I am also recruiting other single parents to participate in this study, if you know of anyone that would be interested please have them contact me. 


\section{Appendix C}

\section{Supplemental Questions}

Understanding the Experiences of Air Force Single Parents: A Phenomenological Study

The following questions will be utilized in conjunction with the interview questions.

1. What is your gender? Male Female

2. What is your ethnic background?

3. What year were you born?

4. How many children do you have?

Ages:

5. How long have you been a single parent?

6. What is your rank?

7. How long have you served on active duty?

8. How many duty hours do you work in a typical week?

Do your duty hours remain constant or do they vary greatly?

9. Have you deployed during your time as a single parent? Yes No

If so, when was your last deployment?

How long were you deployed?

10. Have you PCSd as a single parent? Yes

No

If so, how many times?

How long since your last PCS?

11. Do you live on base? Yes No 
12. Please indicate any of the agencies that you have used because of your status as a single parent. Please indicate how helpful each program was to you.

1-- being not helpful and 5-- being very helpful.

Airmen and Family Readiness Center $\quad$ Yes No

If so, what program?

Military Personnel Flight

Yes No

If so, what program?

Child Development Center

Yes No

If so, what program?

Family Daycare

Yes No

If so, what program?

Youth Programs

Yes No

If so, what program?

$\begin{array}{ll}\text { Command/First Sergeant } & \text { Yes No }\end{array}$

If so, what program?
Medical Group
Yes No

If so, what program?

Tricare

Yes No

If so, what program?

Outdoor Recreation

Yes No

If so, what program?

Other 


\section{Appendix D}

\section{Informed Consent}

\section{Understanding the Experiences of Air Force Single Parents}

\section{Purpose}

You are invited to participate in a research study conducted by Samantha Blanchard, from Portland State University, a doctoral student in the School of Social Work. The purpose of the study is to understand the experiences of Air Force single parents as they pertain to their work and family balance and the supports they need. The research is being conducted in partial fulfillment of the requirements for a doctoral degree, and is under the supervision of Eileen Brennan, Ph.D. You were selected because of your status as an active duty single parent who has held that status for at least two years.

\section{Description of Participation}

If you decide to participate in the study, I will interview you for approximately 45 minutes. I will interview you at a convenient location you select and will audiotape the interview with your permission. The interview will cover topics such as support received or not received as a single parent, your experiences in handling the stressors as a single parent, and how you learned to navigate the system after becoming a single parent.

\section{Compensation}

If you agree to participate in this project, you will receive a \$20 gift card to the Base Exchange in compensation for your time.

\section{Confidentiality}

Any information that is obtained in connection with this study and that can be linked to you or identify you will be kept confidential. Special precautions will be taken to protect your privacy. Only I, a transcriber, and a consultant will have access to the information you provide. The Air Force will not have access to the information you provide. Your name and any identifying information will be kept separately from the tape and transcripts of the interview. The information you provide will identified with a code. All documents will be kept in a locked file cabinet. Computerized data will be kept in a password-protected computer file. In reports, I will not mention names. Information will presented as summaries of findings across all participants. I may use direct quotes of comments you have made, but I will not connect your words with your identity.

The focus of the study is upon understanding your experiences as a single parent serving in the Air Force. This is not focused on criticizing or finding fault with services, programs, or people. Any information that is critical of a specific program will be 
summarized in the form of challenges to be addressed in the discussion and conclusion or the report.

There are some important exceptions to confidentiality: I am required by law to report information on child abuse and neglect and immediate danger to self or others that is obtained during interviews to appropriate local and state agencies. Also, since these interviews are being conducted with military personnel, I will report any threats to the Air Force mission.

\section{Rights regarding decision to participate}

Your participation is voluntary. You do not have to take part in this study, and it will not affect your relationship with the Air Force or Portland State University. If you agree to participate, you have the right to refuse to answer any question. You may change your mind and withdraw from the study at any time without affecting your relationship with the Air Force or Portland State University. If you change your mind, any records of the attempted interview will be destroyed.

\section{Risks and benefits of participation}

Because some of the information asked might bring up difficult topics, there is a risk that you may feel some discomfort or uneasiness when answering some questions. You may decline to answer any questions, withdraw from the project, or discuss your concerns with the researcher at any point during the study.

The benefits to participation include:

- Contributing to the understanding of single parents serving in the Air Force

- Contributing to possible positive changes concerning single parents serving in the Air Force

\section{Concerns about participation}

If you have any concerns or problems regarding your participation in this study or your rights as a research subject, please contact the Human Subjects Research Review Committee, Office of Research and Sponsored Projects 600 Unitus Building, Portland State University, (503) 725-4288/1-877-480-4400 (toll free). If you have questions about the study itself please contact Samantha Blanchard (702)653-2773 or Eileen Brennan, $\mathrm{PhD}$ at (503) 725-5003. 
Voluntary Consent

By signing below, you certify that you have read this information, or that it has been read to you, and that you understand its content. Any questions you may have had were answered. A copy of this consent form will be given to you to keep. Your signature below means that you freely agree to participate in the Understanding the Experiences of Air Force Single Parents Study. Please understand that you may withdraw your consent at any time without penalty, and that by signing, you are not waiving any legal claims, rights or remedies. The researcher will provide you with a copy of this form for your own records.

Print Full

Name:

Signature:

Date: 